.028 


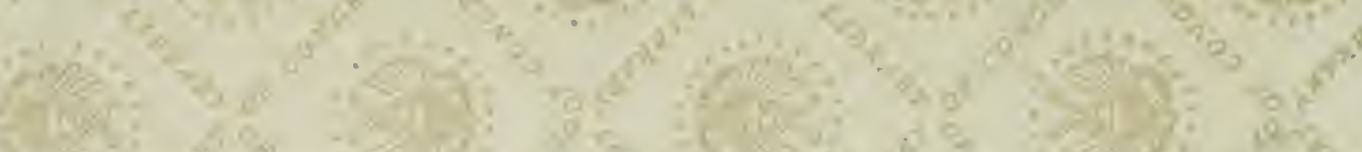
C.

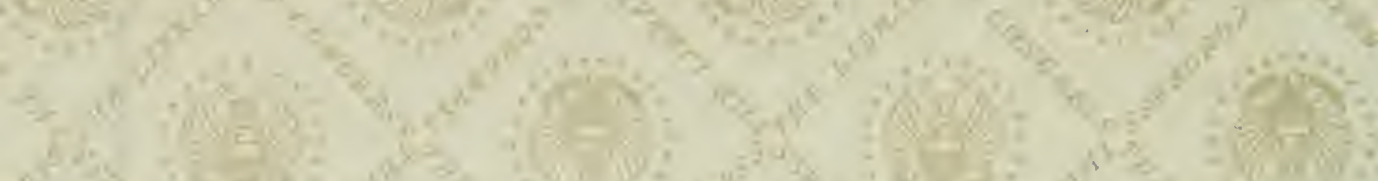
(1) (2) को

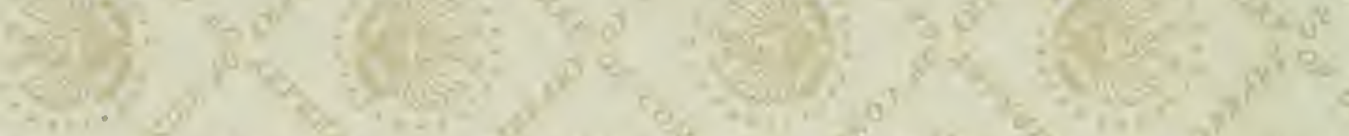

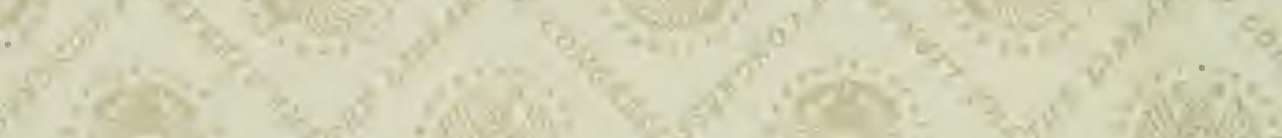

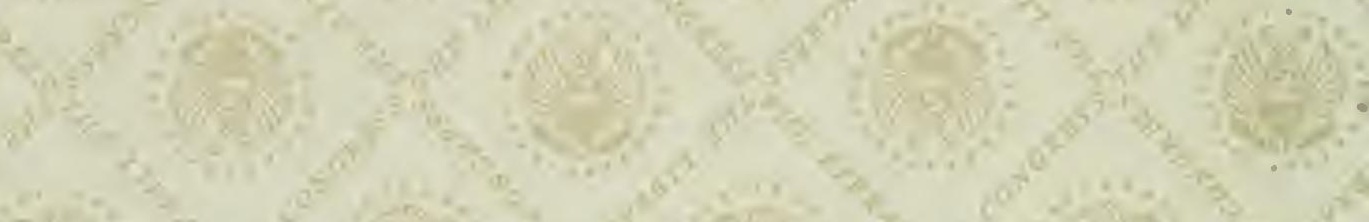

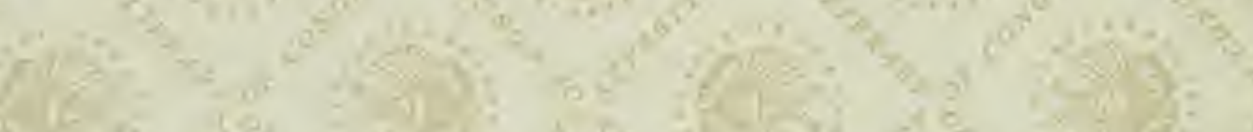

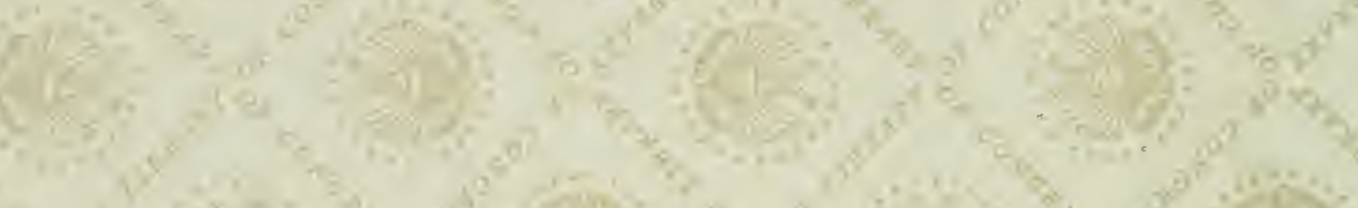

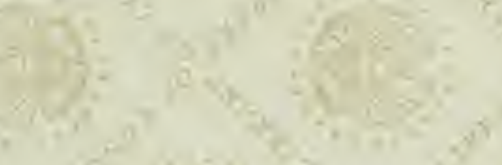


${ }_{1} 0 \gamma, \quad \infty^{\infty} \quad y$.

$40 . i 270$

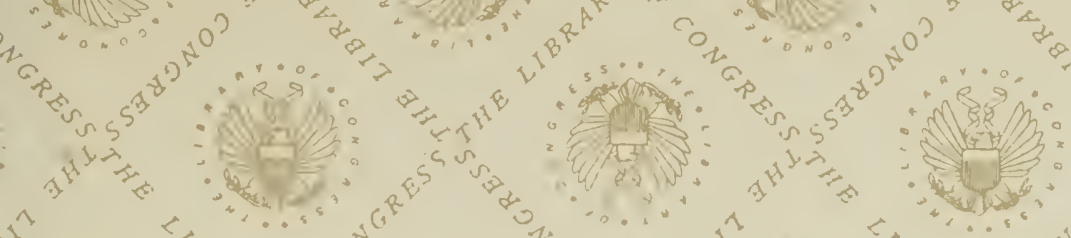

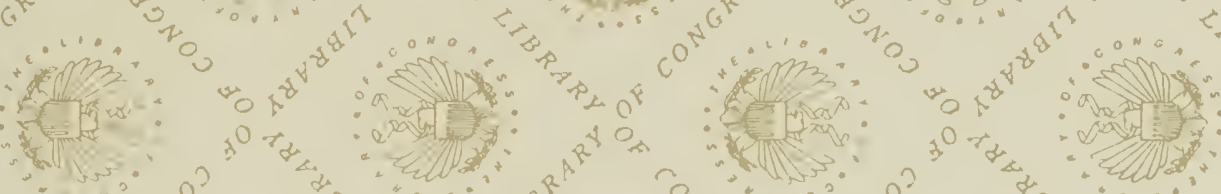
$\mathrm{C}_{2}$

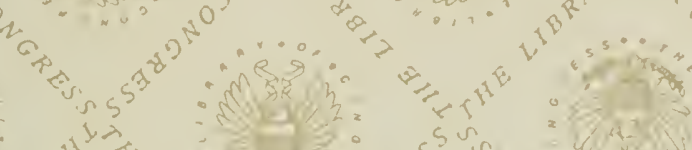

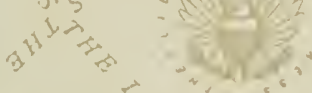
$\lambda$
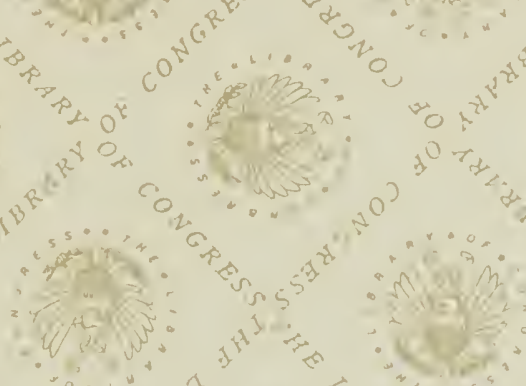

(t)

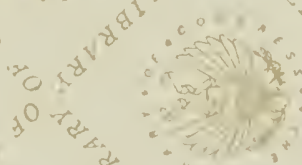

and

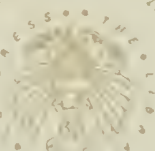

a 15
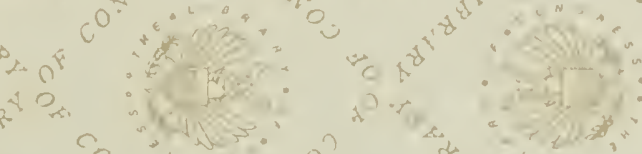

궁

$40^{x^{3}}$

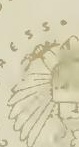







\title{
RESISTANCE OF THE ROOTS OF SOME FRUIT SPECIES TO LOW TEMPERATURE
}

\section{A THESIS}

PRESENTED TO

THE FACULTY OF THE GRADUATE SCHOOL OF CORNELL UNIVERSITY FOR THE DEGREE OF DOCTOR OF PHILOSOPHY

\author{
BY \\ D. B. CARRICK
}

I1 

CONTENTS

PAGE

Review of the literature $\ldots \ldots \ldots \ldots \ldots \ldots \ldots \ldots \ldots \ldots \ldots \ldots$

Method used in freezing the roots.................... 616

Results of the experiments.....................618

Resistance of apple roots to low temperature..........66 618

Resistance of pear roots to low temperature.............6 624

Resistance of Elberta peach roots to low temperature. . . . . . . 627

Comparative resistance of Mazzard and Mahaleb cherry roots to

low temperature........................ 629

Resistance of Myrobalan plum roots to low temperature...... 632

Resistance of the roots of six grape varieties to low temperature. . 633

Resistance of blackberry, dewberry, and red raspberry roots to low temperature.......................... 637

Resistance of gooseberry and currant roots to low temperature. . 63؛ Sap concentration of American and French apple seedlings and Wilder currant as measured by the freezing-point depression.........642 Effect of rapid temperature fall on the freezing of apple roots..... 64 s Effect of rate of thawing on the freezing of roots. . . . . . . . . Injury to apple roots when frozen in soil, in water, and in paraffin... 646 Influence of the scion on the hardiness of one-year roots of the stock. $64 \mathrm{C}$ Effect of sugar solutions, water, and drying out, on the resistance of apple roots to freezing. . . . . . . . . . . . . . . 653 Summary....................................6656 Literature cited............................660 

RESISTANCE OF THE ROOTS OF SOME FRUIT SPECIES TO LOW TEMPERATURE 



\section{PESISTANCE OF THE ROOTS OF SOME FRUIT SPECIES TO LOW TEMPERATURE ${ }^{1}$}

\section{B. CARRICK}

There are several types of winter injury to fruit plants which are of more or less frequent occurrence in New York State. Among these may be mentioned injury to small twigs, especially those of peach trees and of tender apple varieties such as Tompkins King; injury to the winter buds and sometimes to the blossoms; sun-scald, and the rather closely related forms of crotch injury and crown rot; and injury to the roots. Perhaps the killing of the roots by low temperature should be associated with the less serious types of winter injury in this State, due in part to the fact that it occurs in restricted areas. Yet in the Champlain Valley and in the upper Hudson River section, the freezing of the roots is one of the important problems in fruit production. This is also the case in parts of New England, in Canada, and in a number of the Western States.

The work reported in this paper was begun in the fall of 1915 and extended thru the spring of 1917. An attempt has been made to determine approximately under standard conditions the range of variation and the relative hardiness of some of the more commonly grown fruit stocks, including a few varieties of the small fruits. Some data were also obtained regarding the influence of certain factors on the freezing to death of plant tissue.

Careful field studies and the testing of possible fruit stocks capable of withstanding severe cold are significant aspects of the question that have not been attacked. It is hoped, however, that some of the results presented here may be suggestive in the working out of these other phases of the problem of root injury by low temperature.

\section{REVIEW OF THE LITERATURE}

Craig (1900) observed extensive winter injury to the roots of apple, plum, and cherry in Iowa. The one- and two-year-old apple trees in the

\footnotetext{
1 Also presented to the Faculty of the Graduate School of Cornell University, in August, 1917, as a major thesis in partial fulfillment of the requirements for the degree of doctor of philosophy.

Author's ACKNOWLedgments. The author wishes to acknowledge his indebtedness to Professor W. H. Chandler for the direction of this work and for helpful criticisms given during its progress.
} 
nursery were almost completely destroyed. In the orchard, apple trees from three to fifteen years old, situated on a north slope on light soils and unprotected by snow or vegetation, suffered very severely. It was noted, however, that hardy varieties rooted from the scion often withstood the same cold that killed trees which were wholly on seedling roots. The varieties least injured were: first, Siberian crab apple; second, native crab apples and the Hibernal type of Russian apples; and third, varieties of western origin such as Northwestern.

The most resistant plum stock seemed to be Prunus Besseyi. No injury in any case was found in this species. Prunus americana was the next in resistance, being only slightly injured. Marianna roots were seriously damaged, while Peach and Myrobalan roots were entirely killed.

The hardiest cherry root observed was the Morello stock, which, except where exposed, escaped with slight injury. Trees in the nursery on Mazzard stock were practically a total loss, while those on the Mahaleb stock suffered less.

From the foregoing observations Craig concluded that the absence of snow or other protective covering during an unusually severe winter accounted for the very considerable root injury. To prevent a recurrence he advocated the use of desirable cover crops, the employment of the hardiest stocks available, and the deep planting of young trees, especially on the loess soils of the State.

Emerson (1903) conducted an interesting experiment to determine the influence of mulching and soil moisture on the freezing of roots. $\mathrm{He}$ filled seven boxes, 2 feet square and 18 inches deep, with a loam soil, and planted twenty-five apple seedlings in each box.

In the box protected by a 4-inch straw mulch, there was a soil moisture content of 16 per cent. By this treatment no roots were found dead and but seven were injured. In the box covered occasionally with snow and containing 15.8 per cent of moisture, seven roots were dead and eight were injured. In the unprotected boxes the injury seemed to vary inversely with the increased water content of the soil. With 10.4 per cent of moisture the roots of twenty trees were dead and five were uninjured; with 25.6 per cent of moisture, eight roots were dead, four were injured, and thirteen were uninjured. Not a root was injured in a box stored in a cool, dry place, altho its soil contained only 10 per cent of moisture. 
Emerson (1906) found some striking, differences in the protection of certain cover crops against deep freezing. In one case in which the snow was held, the ground froze to a depth of six inches where corn was planted, twelve inches with a heavy cover of oats, fifteen inches under a medium heavy crop of millet, and twenty-four inches where the soil was bare. These facts suggest the use of cover crops which will catch and hold the snow in regions where root injury is prevalent.

Macoun (1908) mentions the killing of roots as one of the ten forms of winter injury occurring in Canada. He recommends the use of cover crops as a means of increasing the soil moisture and holding the snow. His observations on the effect of soil moisture were similar to the experience of Emerson. He states also that the grafting of apples on the garden crab-apple trees has somewhat reduced the root injuries due to freezing.

By means of careful artificial freezings, Chandler (1913) obtained a considerable amount of interesting data on the relative hardiness of various fruit stocks. He found that the range of killing temperature of apple, peach, pear, and plum roots was from $-3^{\circ} \mathrm{C}$. in summer to $-12^{\circ}$ in late winter with rather rapid freezing. He compared the killing temperature of apple roots actively growing in the greenhouse with that of dormant unes in cold storage, in basement storage, and outside in frozen soil, respectively. The three dormant treatments showed little difference in resistance, but the active tissues killed at three centigrade degrees higher than did the dormant roots. Similar comparisons of peach and Marianna plum roots showed somewhat less variation between the conditions of growth and dormancy.

Chandler observed also a diminished hardiness in the roots farthest from the crown, apparently varying with their soil depth. He demonstrated further that in most cases the roots coming from the scions of Ben Davis apple trees were hardier than similar roots from French apple seedlings. An extended laboratory determination of the comparative resistance of Marianna and Myrobalan plum roots and Mahaleb and Mazzard cherry stocks strongly confirmed Craig's observations under orchard conditions.

Mix (1916), while studying sun-scald in the northern part of the Champlain Valley, New York, observed a great amount of winter injury in the roots of apple trees from one to twenty years old. The injured condition 
seemed most serious where fall plowing was practiced and where the trees were on light soils and in windy situations. The Ben Davis trees were especially susceptible, from 50 to 75 per cent of these being left in a dying condition. Northern Spy and Wealthy trees also were injured, but in a degree much less than the Ben Davis. Mix observed also some cases in which, as he states, "the hardiness of the stock seems to have been influenced by the scion."

\section{METHOD USED IN FREEZING THE ROOTS}

The apparatus used in this study for freezing the roots consisted of: an inner chamber of galvanized iron 9 inches long, $1 \frac{1}{2}$ inches wide, and 30 inches deep; an outer chamber of the same material, 6 inches long, 12 inches wide, and of the same depth as the inner chamber; and around the outer chamber, 5 inches of insulation held in place by a casing of wood. The roots to be frozen were placed in the inner compartment, and were surrounded by the freezing mixture of ice and common salt in the second chamber. At no time was the actual tissue temperature determined, but the temperature of the air around the tissues was measured by means of three electrical resistance thermometers and a balance indicator. The latter instrument consisted of the circuit of a Wheatstone bridge mounted in a suitable case with a galvanometer and means for balancing the bridge by moving a contact along a slide wire. ${ }^{2}$ The three electrical resistance bulbs, each with leads 5 feet long, were used until the variation in temperature in the lower part of the freezing chamber was determined. These bulbs were standardized by the makers and were carefully checked against one another in the laboratory here. The bulbs were securely attached to a piece of hardware cloth 6 inches square. The various roots to be tested were fastened to this wire by means of rubber bands. The bulbs always stood perpendicular to the bottom of the chamber, and the roots were always arranged on the cloth parallel to the bulbs.

Careful tests showed that, while the temperature was uniform at given levels within certain limits, it varied slightly at different levels. Because of this fact, a complete record as to the injury in the lower and in the upper ends of the roots was kept. To further standardize this variation, all of the pieces of material used were cut 4 inches in length. When the

\footnotetext{
2This is a standard apparatu obtrinablo from the Leeds, Northrup Company, of Rhiladelphia,
} 
hardware cloth and the bulbs were in position, the roots extended to within one inch of the bottom of the chamber in a regular row.

The difference in temperature on either side of a bulb - that is, horizontally - within a compass of five inches was found to be negligible. However, a number of tests of the temperature in either extreme end of the freezing chamber showed that a maximum difference of one centigrade degree might exist. Accordingly, no roots were tested at these points.

In order to subject all the material to as nearly uniform conditions of freezing as were possible, the killing temperature of a number of different roots was determined at the same time rather than an attempt being made to freeze at once many roots of a single sort. Owing to the variety of roots used, however, it was neither practicable nor desirable to test all of these at any one time. As they naturally divided themselves into groups of more or less tenderness, material of similar resistance was usually frozen together.

While the temperature was being gradually lowered, the inner compartment was kept tightly closed. In no case were any of the roots removed before the minimum degree was reached.

Since several workers have found a distinct influence in the amount of injury resulting from the rapidity of cooling, care was taken to allow a standard rate of fall for all freezings, except as noted to the contrary. This uniform lowering of temperature began at $1.5^{\circ} \mathrm{C}$, and reached $0^{\circ}$ in fifteen minutes. The fall from this point to the desired degree was at the rate of one degree every twenty-two and one-half minutes. The minimum temperature was always maintained for fifteen minutes. Ordinarily the roots were removed from the chamber and allowed to thaw rapidly.

Russell (1914) and others have noted that the death of a plant from freezing is rarely immediate but may be delayed for several days. Because of this possibility the treated roots were set aside and examined at different intervals. During this time they were kept moist by placing them on a hardware eloth which projected above the surface of the water in an agate pan. The roots and the pan were covered with a bell jar.

An inspection of the roots for injury was usually made within from one to three days after exposure. In most cases when injury occurred, it was apparent by the end of this period. At first microtome sections were prepared and the character of the injury was determined with a low- 
power microscope. This was soon found to be unnecessary, since the color changes of the frozen cells, except in the gooseberry and the currant, were rather striking. The affected tissues of the apple became of some shade of brown and appeared water-soaked; in Mazzard cherry, Myrobalan plum, and red raspberry roots, the injured cells were somewhat yellowish; while in the blackberry and the dewberry they often appeared almost black. The early appearance of Rhizopus species and probably other saprophytic fungi on the dead part was also characteristic of injury. In not an instance did the fungus or the discoloration appear in the unfrozen roots left similarly located for comparison.

The roots of all species tested from October 24 to November 18 were collected from the nursery row. All the leaves were present on the plants used in the first determinations and some had not fallen in the latter freezings. . The remainder of the material was kept in common storage and removed as needed. With this material the temperature varied somewhat, due to outside changes, but it seldom went below $0^{\circ} \mathrm{C}$. and did not-rise above $5^{\circ}$ until April 1 . The plants were stored in normally moist sawdust, and there was little opportunity for them to dry out later as they were placed on the hardware cloth attached to the resistance bulb while in storage and were then immediately frozen.

\section{RESULTS OF THE EXPERIMENTS}

\section{RESISTANCE OF APPLE ROOTS TO LOW TEMPERATURE}

For all the tests conducted, the diameter of each end and of the center of the root, and the date of freezing, are recorded as possible factors that might influence the kind or the amount of injury. The results of the tests with apple roots are shown in table 1.

Four kinds of seedlings were used: one-year American stocks, grown in this country but from French seed; one-year French seedlings imported from France; two-year French roots which had grown for one year in the nursery here; and one-year stored French seedlings which had been held at approximately $0^{\circ} \mathrm{C}$. in cold storage for one year.

One noticeable feature in the apple freezings was the differences in the individual resistance of roots similarly treated and frozen apparently under the same conditions. Unless the temperature is above or below the average freezing point, all gradations of injury may occur. 
Resistance of Roots of Fruit Species to Low Temperature 619

TABle 1. Effect of Low Temperature on Roots of Apple Seedlings

\begin{tabular}{|c|c|c|c|c|c|c|c|c|}
\hline \multirow{2}{*}{$\begin{array}{l}\text { Temper- } \\
\text { ature } \\
\text { (centi- } \\
\text { grade) }\end{array}$} & \multirow{2}{*}{$\begin{array}{l}\text { Date of } \\
\text { freezing }\end{array}$} & \multirow{2}{*}{ Variety } & \multirow{2}{*}{$\begin{array}{l}\text { Diam- } \\
\text { eter } \\
\text { of roots } \\
\text { (milli- } \\
\text { meters) }\end{array}$} & \multirow{2}{*}{$\begin{array}{l}\text { Num- } \\
\text { ber of } \\
\text { roots }\end{array}$} & \multirow{2}{*}{$\begin{array}{l}\text { Num= } \\
\text { ber of } \\
\text { roots } \\
\text { unin= } \\
\text { jured }\end{array}$} & \multicolumn{3}{|c|}{$\begin{array}{l}\text { Per cent of cells killed } \\
\text { in injured roots }\end{array}$} \\
\hline & & & & & & $\begin{array}{l}\text { Cam- } \\
\text { bium }\end{array}$ & Phloëm & Cortex \\
\hline \multirow[t]{2}{*}{$-7^{\circ}$} & \multirow[t]{6}{*}{$\begin{array}{c}\text { October } 24 \\
\text { to } \\
\text { November } 18\end{array}$} & American & $\begin{array}{l}7 \times 6 \\
5 \times 4 \\
4 \times 3\end{array}$ & $\begin{array}{l}2 \\
4 \\
7\end{array}$ & $\begin{array}{r}2 \\
3 \\
\\
\ldots \ldots \ldots\end{array}$ & $\begin{array}{l}50 \\
40\end{array}$ & $\begin{array}{l}50 \\
40\end{array}$ & $\begin{array}{l}50 \\
40\end{array}$ \\
\hline & & $\begin{array}{l}\text { 2-year } \\
\text { French }\end{array}$ & $\begin{array}{l}7 \times 5 \\
5 \times 4 \\
4 \times 3\end{array}$ & $\begin{array}{r}10 \\
8 \\
6\end{array}$ & $\begin{array}{r}10 \\
5 \\
1\end{array}$ & $\begin{array}{l}40 \\
60\end{array}$ & $\begin{array}{l}40 \\
50\end{array}$ & $\begin{array}{l}40 \\
50\end{array}$ \\
\hline \multirow[t]{2}{*}{$-8^{\circ}$} & & American & $\begin{array}{l}5 \times 4 \\
4 \times 3 \\
3 \times 3\end{array}$ & $\begin{array}{l}1 \\
8 \\
1\end{array}$ & $\begin{array}{r}1 \\
2 \\
\cdots\end{array}$ & $\begin{array}{l}40 \\
40\end{array}$ & $\begin{array}{l}30 \\
20 \\
50\end{array}$ & $\begin{array}{l}20 \\
50\end{array}$ \\
\hline & & $\begin{array}{l}\text { 2-year } \\
\text { French }\end{array}$ & $\begin{array}{l}7 \times 5 \\
5 \times 4 \\
4 \times 3\end{array}$ & $\begin{array}{r}3 \\
2 \\
13\end{array}$ & $\begin{array}{l}3 \\
2 \\
2\end{array}$ & $\ldots$ & $\begin{array}{l}\cdots \cdots \\
\cdots \\
60\end{array}$ & \\
\hline \multirow[t]{2}{*}{$-9^{\circ}$} & & American & $\begin{array}{l}7 \times 5 \\
6 \times 5 \\
5 \times 4\end{array}$ & $\begin{array}{l}3 \\
2 \\
4\end{array}$ & 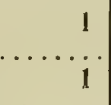 & $\begin{array}{l}35 \\
25 \\
90\end{array}$ & $\begin{array}{l}35 \\
25 \\
90\end{array}$ & $\begin{array}{l}35 \\
50 \\
90\end{array}$ \\
\hline & & $\begin{array}{l}\text { 2-year } \\
\text { French }\end{array}$ & $\begin{array}{l}7 \times 5 \\
5 \times 4 \\
4 \times 3\end{array}$ & $\begin{array}{l}2 \\
6 \\
5\end{array}$ & $\begin{array}{l}2 \\
\vdots\end{array}$ & $\begin{array}{r}75 \\
\cdots \\
\cdots\end{array}$ & $\begin{array}{r}75 \\
\ldots \ldots \\
\cdots\end{array}$ & \\
\hline \multirow[t]{2}{*}{$-9^{\circ}$} & \multirow[t]{4}{*}{$\begin{array}{c}\text { December } \\
\text { to } \\
\text { January }\end{array}$} & American & $\begin{array}{l}9 \times 7 \\
6 \times 6 \\
5 \times 4\end{array}$ & $\begin{array}{l}5 \\
4 \\
4\end{array}$ & $\begin{array}{l}2 \\
1\end{array}$ & $\begin{array}{l}80 \\
50 \\
75\end{array}$ & $\begin{array}{l}35 \\
45 \\
60\end{array}$ & $\begin{array}{l}35 \\
45 \\
60\end{array}$ \\
\hline & & $\begin{array}{l}\text { 2-year } \\
\text { French }\end{array}$ & $\begin{array}{l}7 \times 5 \\
5 \times 3 \\
4 \times 2\end{array}$ & $\begin{array}{l}6 \\
6 \\
6\end{array}$ & $\begin{array}{l}4 \\
2 \\
3\end{array}$ & $\begin{array}{r}5 \\
35 \\
80\end{array}$ & $\begin{array}{r}5 \\
20 \\
65\end{array}$ & $\begin{array}{l}10 \\
20 \\
65\end{array}$ \\
\hline$-10^{\circ}$ & & $\begin{array}{l}\text { 2-year } \\
\text { French }\end{array}$ & $\begin{array}{l}7 \times 5 \\
5 \times 3 \\
4 \times 3\end{array}$ & $\begin{array}{r}5 \\
14 \\
11\end{array}$ & $\begin{array}{l}3 \\
1\end{array}$ & $\begin{array}{l}45 \\
50 \\
60\end{array}$ & $\begin{array}{l}15 \\
50 \\
60\end{array}$ & $\begin{array}{l}15 \\
50 \\
60\end{array}$ \\
\hline$-12^{\circ}$ & & $\begin{array}{l}\text { 2-year } \\
\text { French }\end{array}$ & $\begin{array}{l}8 \times 6 \\
4 \times 3\end{array}$ & $\begin{array}{l}2 \\
3\end{array}$ & & $\begin{array}{r}5 \\
100\end{array}$ & $\begin{array}{r}5 \\
100\end{array}$ & $\begin{array}{r}5 \\
100\end{array}$ \\
\hline \multirow[t]{2}{*}{$-9^{\circ}$} & \multirow[t]{2}{*}{$\begin{array}{l}\text { February } \\
\text { to March }\end{array}$} & American & $\begin{array}{l}7 \times 6 \\
5 \times 4\end{array}$ & $\begin{array}{l}9 \\
9\end{array}$ & $\begin{array}{l}6 \\
4\end{array}$ & $\begin{array}{l}20 \\
60\end{array}$ & $\begin{array}{l}10 \\
60\end{array}$ & $\begin{array}{l}10 \\
60\end{array}$ \\
\hline & & $\begin{array}{l}\text { 2-year } \\
\text { French }\end{array}$ & $\begin{array}{l}8 \times 5 \\
3 \times 2\end{array}$ & $\begin{array}{l}3 \\
3\end{array}$ & $\begin{array}{r}3 \\
\ldots \ldots\end{array}$ & 50 & 50 & 50 \\
\hline
\end{tabular}


TABLE 1 (continued)

\begin{tabular}{|c|c|c|c|c|c|c|c|c|}
\hline \multirow{2}{*}{$\begin{array}{l}\text { Temper- } \\
\text { ature } \\
\text { (centi- } \\
\text { grade) }\end{array}$} & \multirow{2}{*}{$\begin{array}{l}\text { Date of } \\
\text { freezing }\end{array}$} & \multirow{2}{*}{ Variety } & \multirow{2}{*}{$\begin{array}{l}\text { Diam- } \\
\text { eter } \\
\text { of roots } \\
\text { (milli- } \\
\text { meters) }\end{array}$} & \multirow{2}{*}{$\begin{array}{l}\text { Num- } \\
\text { ber of } \\
\text { roots }\end{array}$} & \multirow{2}{*}{$\begin{array}{l}\text { Num= } \\
\text { ber of } \\
\text { roots } \\
\text { unin= } \\
\text { jured }\end{array}$} & \multicolumn{3}{|c|}{$\begin{array}{l}\text { Per cent of cells killed } \\
\text { in injured roots }\end{array}$} \\
\hline & & & & & & $\begin{array}{l}\text { Cam- } \\
\text { bium }\end{array}$ & Phloëm & Cortex \\
\hline \multirow[t]{2}{*}{$-10^{\circ}$} & \multirow[t]{13}{*}{$\begin{array}{c}\text { Fcbruary } \\
\text { to } \\
\text { March } \\
\text { (continued) }\end{array}$} & American & $\begin{array}{l}7 \times 6 \\
5 \times 4 \\
3 \times 2\end{array}$ & $\begin{array}{r}12 \\
8 \\
10\end{array}$ & $\begin{array}{l}\quad 10 \\
\ldots \ldots \\
\ldots \ldots\end{array}$ & $\begin{array}{l}65 \\
50 \\
55\end{array}$ & $\begin{array}{l}10 \\
50 \\
55\end{array}$ & $\begin{array}{l}45 \\
50\end{array}$ \\
\hline & & $\begin{array}{l}\text { 2-year } \\
\text { French }\end{array}$ & $\begin{array}{l}7 \times 5 \\
3 \times 2\end{array}$ & $\begin{array}{l}3 \\
8\end{array}$ & $\begin{array}{l}3 \\
1\end{array}$ & 65 & 65 & $\ddot{65}$ \\
\hline \multirow[t]{3}{*}{$-11^{\circ}$} & & American & $\begin{array}{l}7 \times 6 \\
5 \times 4 \\
3 \times 2\end{array}$ & $\begin{array}{r}12 \\
6 \\
30\end{array}$ & $\begin{array}{r}4 \\
2 \\
20\end{array}$ & $\begin{array}{l}60 \\
55 \\
40\end{array}$ & $\begin{array}{l}30 \\
55 \\
40\end{array}$ & $\begin{array}{l}25 \\
55 \\
40\end{array}$ \\
\hline & & $\begin{array}{l}\text { 2-year } \\
\text { French }\end{array}$ & $\begin{array}{l}6 \times 5 \\
3 \times 2\end{array}$ & $\begin{array}{r}5 \\
20\end{array}$ & $\begin{array}{r}5 \\
11\end{array}$ & $\dddot{45}$ & 45 & 45 \\
\hline & & $\begin{array}{l}\text { 1-year } \\
\text { French }\end{array}$ & $\begin{array}{l}8 \times 5 \\
3 \times 2\end{array}$ & $\begin{array}{l}5 \\
8\end{array}$ & 2 & 40 & 10 & 30 \\
\hline \multirow[t]{4}{*}{$-12^{\circ}$} & & American & $\begin{array}{l}7 \times 6 \\
5 \times 5 \\
4 \times 3 \\
3 \times 2\end{array}$ & $\begin{array}{r}9 \\
11 \\
8 \\
22\end{array}$ & \begin{tabular}{c}
\multicolumn{1}{c}{1} \\
$\ldots \ldots \ldots$ \\
$\ldots \ldots \ldots$ \\
$\ldots \ldots \ldots$
\end{tabular} & $\begin{array}{l}80 \\
85 \\
75 \\
80\end{array}$ & $\begin{array}{l}70 \\
85 \\
75 \\
80\end{array}$ & $\begin{array}{l}70 \\
85 \\
75 \\
80\end{array}$ \\
\hline & & $\begin{array}{l}\text { 2-year } \\
\text { French }\end{array}$ & $\begin{array}{l}6 \times 5 \\
3 \times 2\end{array}$ & $\begin{array}{r}5 \\
33\end{array}$ & & $\begin{array}{l}75 \\
85\end{array}$ & $\begin{array}{l}75 \\
85\end{array}$ & $\begin{array}{l}75 \\
85\end{array}$ \\
\hline & & $\begin{array}{l}\text { 1-year } \\
\text { French }\end{array}$ & $\begin{array}{l}8 \times 6 \\
3 \times 2\end{array}$ & $\begin{array}{r}4 \\
19\end{array}$ & $\begin{array}{l}4 \\
5\end{array}$ & & 15 & $\ddot{15}$ \\
\hline & & $\begin{array}{l}\text { 1-year } \\
\text { French, } \\
\text { stored }\end{array}$ & $\begin{array}{l}8 \times 5 \\
3 \times 2\end{array}$ & $\begin{array}{r}4 \\
22\end{array}$ & $\ddot{7}$ & $\begin{array}{r}100 \\
55\end{array}$ & $\begin{array}{r}100 \\
55\end{array}$ & $\begin{array}{l}80 \\
55\end{array}$ \\
\hline$-12.5^{\circ}$ & & $\begin{array}{l}\text { 1-year } \\
\text { French }\end{array}$ & $8 \times 6$ & 4 & 1 & 50 & 50 & 50 \\
\hline \multirow[t]{2}{*}{$-13^{\circ}$} & & American & $\begin{array}{l}7 \times 6 \\
3 \times 2\end{array}$ & $\begin{array}{r}8 \\
16\end{array}$ & ${ }^{\prime}$ & $\begin{array}{l}90 \\
75\end{array}$ & $\begin{array}{l}90 \\
75\end{array}$ & $\begin{array}{l}90 \\
75\end{array}$ \\
\hline & & $\begin{array}{l}\text { 1-year } \\
\text { French, } \\
\text { stored }\end{array}$ & $3 \times 2$ & 9 & & 85 & $\$ 5$ & 85 \\
\hline$-14.5^{\circ}$ & & American & $\begin{array}{l}7 \times 6 \\
3 \times 2\end{array}$ & $\begin{array}{l}15 \\
27\end{array}$ & $\begin{array}{l}\ldots \ldots \cdots \\
\cdots \cdots \cdots\end{array}$ & $\begin{array}{l}80 \\
90\end{array}$ & $\begin{array}{l}80 \\
90\end{array}$ & $\begin{array}{l}80 \\
90\end{array}$ \\
\hline
\end{tabular}


TABLE 1 (continued)

\begin{tabular}{|c|c|c|c|c|c|c|c|c|}
\hline \multirow{2}{*}{$\begin{array}{l}\text { Temper- } \\
\text { ature } \\
\text { (centi- } \\
\text { grade) }\end{array}$} & \multirow{2}{*}{$\begin{array}{l}\text { Date of } \\
\text { freezing }\end{array}$} & \multirow{2}{*}{ Variety } & \multirow{2}{*}{$\begin{array}{c}\text { Diam- } \\
\text { eter } \\
\text { of roots } \\
\text { (milli- } \\
\text { meters) }\end{array}$} & \multirow{2}{*}{$\begin{array}{l}\text { Num- } \\
\text { ber of } \\
\text { roots }\end{array}$} & \multirow{2}{*}{$\begin{array}{l}\text { Num= } \\
\text { ber of } \\
\text { roots } \\
\text { unin= } \\
\text { jured }\end{array}$} & \multicolumn{3}{|c|}{$\begin{array}{l}\text { Per cent of cells killed } \\
\text { in injured roots }\end{array}$} \\
\hline & & & & & & $\begin{array}{l}\text { Cam- } \\
\text { bium }\end{array}$ & Phloëm & Cortex \\
\hline $\begin{array}{l}-14.5^{\circ} \\
(\text { conc. })\end{array}$ & $\begin{array}{c}\text { February } \\
\text { to } \\
\text { March } \\
\text { (concluded) }\end{array}$ & $\begin{array}{l}\text { 1-year } \\
\text { French }\end{array}$ & $\begin{array}{l}8 \times 7 \\
3 \times 2\end{array}$ & $\begin{array}{l}2 \\
6\end{array}$ & $\begin{array}{c}1 \\
\cdots\end{array}$ & $\begin{array}{l}100 \\
100\end{array}$ & $\begin{array}{l}100 \\
100\end{array}$ & $\begin{array}{r}75 \\
100\end{array}$ \\
\hline \multirow[t]{3}{*}{$-9^{\circ}$} & \multirow{12}{*}{$\begin{array}{c}\text { March } 29 \\
\text { to } \\
\text { April } 15\end{array}$} & $\begin{array}{l}\text { 1-year } \\
\text { French }\end{array}$ & $\begin{array}{l}8 \times 6 \\
6 \times 4\end{array}$ & $\begin{array}{l}2 \\
3\end{array}$ & $\begin{array}{l}1 \\
3\end{array}$ & $\ldots \cdots$ & $\begin{array}{r}60 \\
\ldots \ldots \\
\end{array}$ & $\cdots \cdots$ \\
\hline & & American & $\begin{array}{l}8 \times 6 \\
6 \times 4\end{array}$ & $\begin{array}{l}8 \\
4\end{array}$ & $\begin{array}{l}8 \\
2\end{array}$ & $\ddot{25}$ & $\ldots \ldots \cdots$ & $\cdots \cdots$ \\
\hline & & $\begin{array}{l}\text { 1-year } \\
\text { French, } \\
\text { stored }\end{array}$ & $8 \times 6$ & 3 & .. & 100 & 100 & 100 \\
\hline \multirow[t]{3}{*}{$-10^{\circ}$} & & $\begin{array}{l}\text { 1-year } \\
\text { French }\end{array}$ & $\begin{array}{l}8 \times 6 \\
6 \times 4 \\
5 \times 3\end{array}$ & $\begin{array}{l}4 \\
4 \\
4\end{array}$ & $\begin{array}{c}3 \\
3\end{array}$ & $\begin{array}{r}100 \\
60\end{array}$ & $\begin{array}{l}\dddot{4} 5 \\
60\end{array}$ & $\begin{array}{r}\because 45 \\
60\end{array}$ \\
\hline & & American & $8 \times 6$ & 5 & 5 & $\ldots$ & $\ldots \ldots \ldots$ & $\ldots$. \\
\hline & & $\begin{array}{l}\text { 1-year } \\
\text { French, } \\
\text { stored }\end{array}$ & $8 \times 6$ & 5 & 1 & 100 & 100 & 100 \\
\hline \multirow[t]{3}{*}{$-11^{\circ}$} & & $\begin{array}{l}\text { 1-year } \\
\text { French }\end{array}$ & $\begin{array}{l}8 \times 6 \\
3 \times 2\end{array}$ & $\begin{array}{l}2 \\
6\end{array}$ & $\begin{array}{r}2 \\
\cdots \cdots \\
\end{array}$ & $\dddot{100}$ & $\ddot{100}$ & $\ddot{100}$ \\
\hline & & American & $\begin{array}{l}8 \times 6 \\
6 \times 5\end{array}$ & $\begin{array}{l}5 \\
4\end{array}$ & 1 & $\begin{array}{r}75 \\
100\end{array}$ & ${ }_{100}$ & 100 \\
\hline & & $\begin{array}{c}\text { 1-year } \\
\text { French, } \\
\text { stored }\end{array}$ & $8 \times 6$ & 2 & & 100 & 100 & 100 \\
\hline \multirow[t]{3}{*}{$-12^{\circ}$} & & $\begin{array}{l}\text { 1-year } \\
\text { French }\end{array}$ & $\begin{array}{l}8 \times 6 \\
3 \times 2\end{array}$ & $\begin{array}{r}3 \\
12\end{array}$ & $\begin{array}{r}2 \\
\cdots \cdots\end{array}$ & $\begin{array}{l}100 \\
100\end{array}$ & $\begin{array}{l}100 \\
100\end{array}$ & $\begin{array}{r}50 \\
100\end{array}$ \\
\hline & & American & $7 \times 5$ & 8 & & 100 & 100 & 100 \\
\hline & & $\begin{array}{c}\text { 1-year } \\
\text { French, } \\
\text { stored }\end{array}$ & $8 \times 6$ & 3 & $\ldots \ldots$ & 100 & 100 & 100 \\
\hline
\end{tabular}




\section{B. CARrick}

TABLE 1 (concluded)

\begin{tabular}{|c|c|c|c|c|c|c|c|c|}
\hline \multirow{2}{*}{$\begin{array}{l}\text { Temper- } \\
\text { ature } \\
\text { (centi- } \\
\text { grade) }\end{array}$} & \multirow{2}{*}{$\begin{array}{l}\text { Date of } \\
\text { freezing }\end{array}$} & \multirow{2}{*}{ Variety } & \multirow{2}{*}{$\begin{array}{l}\text { Diam- } \\
\text { eter } \\
\text { of roots } \\
\text { (milli- } \\
\text { meters) }\end{array}$} & \multirow{2}{*}{$\begin{array}{l}\text { Num- } \\
\text { ber of } \\
\text { roots }\end{array}$} & \multirow{2}{*}{$\begin{array}{l}\text { Num= } \\
\text { ber of } \\
\text { roots } \\
\text { unin= } \\
\text { jured }\end{array}$} & \multicolumn{3}{|c|}{$\begin{array}{l}\text { Per cent of cells killed } \\
\text { in injured roots }\end{array}$} \\
\hline & & & & & & $\begin{array}{l}\text { Cam- } \\
\text { bium }\end{array}$ & Phloëm & Cortcx \\
\hline \multirow[t]{3}{*}{$-7^{\circ}$} & \multirow[t]{10}{*}{$\begin{array}{c}\text { April } 16 \\
\text { to } \\
\text { May } 8\end{array}$} & $\begin{array}{l}\text { 1-year } \\
\text { French }\end{array}$ & $\begin{array}{l}8 \times 6 \\
3 \times 2\end{array}$ & $\frac{2}{5}$ & $\begin{array}{r}2 \\
\ldots \ldots\end{array}$ & 50 & 50 & 50 \\
\hline & & American & $\begin{array}{l}8 \times 6 \\
6 \times 4\end{array}$ & $\begin{array}{l}7 \\
4\end{array}$ & $\begin{array}{r}1 \\
\cdots\end{array}$ & $\begin{array}{r}100 \\
\ldots \ldots\end{array}$ & $\begin{array}{r}100 \\
\ldots \ldots\end{array}$ & $\begin{array}{r}90 \\
\ldots \ldots \\
\end{array}$ \\
\hline & & $\begin{array}{c}\text { 1-year } \\
\text { French, } \\
\text { stored }\end{array}$ & $\begin{array}{l}7 \times 5 \\
3 \times 2\end{array}$ & $\begin{array}{l}2 \\
4\end{array}$ & $\begin{array}{l}2 \\
4\end{array}$ & & & \\
\hline \multirow[t]{3}{*}{$-8^{\circ}$} & & $\begin{array}{c}\text { 1-year } \\
\text { French, } \\
\text { stored }\end{array}$ & $\begin{array}{l}7 \times 6 \\
3 \times 2\end{array}$ & $\begin{array}{r}4 \\
13\end{array}$ & $\begin{array}{l}4 \\
4\end{array}$ & 80 & 25 & 25 \\
\hline & & American & $\begin{array}{l}8 \times 6 \\
6 \times 4\end{array}$ & $\begin{array}{l}4 \\
5\end{array}$ & $\begin{array}{l}1 \\
\ldots \ldots\end{array}$ & $\begin{array}{l}80 \\
90\end{array}$ & $\begin{array}{l}25 \\
80\end{array}$ & $\begin{array}{l}25 \\
80\end{array}$ \\
\hline & & $\begin{array}{l}\text { 1-year } \\
\text { French, } \\
\text { stored }\end{array}$ & $\begin{array}{l}8 \times 6 \\
6 \times 5\end{array}$ & $\begin{array}{l}2 \\
2\end{array}$ & & $\begin{array}{l}10 \\
90\end{array}$ & 90 & 90 \\
\hline \multirow[t]{3}{*}{$-9^{\circ}$} & & $\begin{array}{l}\text { 1-year } \\
\text { French }\end{array}$ & $\begin{array}{l}8 \times 6 \\
3 \times 2\end{array}$ & $\frac{2}{7}$ & $\begin{array}{l}2 \\
7\end{array}$ & & & \\
\hline & & American & $8 \times 6$ & 6 & 3 & 25 & & $\ldots \ldots$ \\
\hline & & $\begin{array}{c}\text { 1-year } \\
\text { French, } \\
\text { stored }\end{array}$ & $\begin{array}{l}7 \times 4 \\
3 \times 2\end{array}$ & $\frac{2}{4}$ & 2 & 100 & 100 & 100 \\
\hline$-10^{\circ}$ & & American & $\begin{array}{l}8 \times 6 \\
6 \times 5\end{array}$ & $\begin{array}{l}6 \\
6\end{array}$ & & $\begin{array}{r}70 \\
100\end{array}$ & $\begin{array}{r}60 \\
100\end{array}$ & $\begin{array}{r}60 \\
100\end{array}$ \\
\hline
\end{tabular}

It is a common opinion among some nurserymen that the Frenchgrown apple stocks are hardier than the home-grown seedlings. The results obtained from the freezing of hundreds of roots of each stock indicate that these differences in resistance are negligible. Both stocks are found to show considerable injury from $-11^{\circ}$ to $-11.5^{\circ} \mathrm{C}$., and at $-12^{\circ}$ few of either sort survived. The two-year French roots were grown 
under unfavorable conditions in the nursery, and apparently because of this were more easily killed than the one-year stock. The one-year seedlings held in cold storage for one year showed about the same hardiness as the two-year roots.

The observations of Chandler (1913) led him to conclude that the hardiness of the root tissues varies with the season. This is to be expected and the results obtained readily support this theory. The material frozen in October and November shows a marked tenderness compared with roots tested in February and March. The period of maximum resistance seems to end somewhat before the last of March, tho the date would, of course, vary with the conditions affecting after-ripening and possibly also with the variety. From the first of April until these observations ceased, an increasing amount of injury was noted. This range of hardiness indicates a difference in resistance of between three and four centigrade degrees. These seasonal differences obtain, not only in the apple seedlings, but in all the roots reported in this paper.

The influence of the size of the root in withstanding cold seems reasonably well established by the data in table 1 as well as by those in the succeeding tables. The resistance is in direct proportion to the diameter of the root. In practically all cases in which the whole forked roots of the French seedling were employed, the small roots killed first. Similarly, the smaller roots of the American stocks having the same soil depth suffered more quickly and severely than the larger roots.

The results in the apple tests seem to point rather clearly to the relative resistance of the different tissues in these roots. It is seen, in practically all instances in which injury occurs, that the cambium is the first tissue to be killed. This is followed closely by the phloëm, while the cortex seems somewhat hardier than either of the other tissues. Only a few cases are recorded in which the cortex alone was severely injured, tho frequently the three tissues were equally affected. Unless the temperature is especially low for apple roots, or they are especially tender as in the fall and the spring, the cambium, the phloëm, and the cortex are browned without further injury. Occasionally under extreme conditions the xylem and the pith may be killed, in which case they both seem to show about equal resistance. An exposure at $-20^{\circ} \mathrm{C}$. would ordinarily kill all the cells in the roots of any apple seedlings tested in these experiments, even when they were in a dormant condition. 
A number of observations were made on material four inches long, in which two inches of the plant represented the stem above the soil level and two inches represented the root below the surface of the ground. From the results of these freezings some indications were given as to just where the tenderness of the root tissues ended and the well-known hardiness of the stem tissues began. Where injury occurred to the specimen, the region of browning much oftener than otherwise extended from the lower end of the root upward, decreasing abruptly at the crown. This is somewhere near the point of differentiation of root and stem structures. It was indicated from these data that this difference in resistance may have been brought about by a change in cellular structure.

While Chandler (1913) seemed to find that roots deeper down in the soil were tenderel than those near the surface, an examination of his data shows that the deeper roots were also considerably the smaller in diameter. Many observations of roots of equal transverse section and growing at different soil levels were recorded from time to time. From the results of these observations, it was suggested that the size of the root was, perhaps, a greater factor in its resistance than the soil depth at which it grew.

From the foregoing eonsiderations it is rather difficult to assign a fixed temperature at which an apple-seedling root may be partially or completely injured by freezing. Examination of all of the material tested showed that, while severe injury is found at exposures ranging from $-7^{\circ}$ to $-13^{\circ} \mathrm{C}$, one French root survived a temperature of $-14.5^{\circ}$. However, the majority of the dormant roots were seriously injured in the three outer tissues by a temperature of $-12^{\circ} \mathrm{C}$.

\section{RESISTANCE OF PEAR ROOTS TO LOW TEMPERATURE}

In the work with pear roots the comparative tenderness of two-year French stock (Pyrus communis) and one-year Kieffer stock was determined. The two-year roots were given the same field treatment the second year as was given to the two-year French apples previously mentioned. A few one-year French stocks were also available in 1916.

In almost all eases, as shown by the data recorded in table 2, the oneyear Kieffer roots proved more resistant than either of the French stocks. At an exposure of $-10^{\circ} \mathrm{C}$. in the January-March period, the Kieffer roots show a less number and percentage affected than do the two-year French 
roots. The temperature of $-11^{\circ}$ during dormancy was too low for the survival of either species. In the April tests at $-8^{\circ}$ the Kieffer stock again demonstrates its superiority. When exposed to $-9^{\circ}$ in April the Kieffer shows only a small amount of injury in the phloëm while the two-year French roots were killed thruout.

Table 2. Effect of Low Temperature on Roots of Pear Seedings

\begin{tabular}{|c|c|c|c|c|c|c|c|c|}
\hline \multirow{2}{*}{$\begin{array}{l}\text { Temper- } \\
\text { ature } \\
\text { (centi- } \\
\text { grade) }\end{array}$} & \multirow{2}{*}{$\begin{array}{l}\text { Date of } \\
\text { freezing }\end{array}$} & \multirow{2}{*}{ Variety } & \multirow{2}{*}{$\begin{array}{l}\text { Diam- } \\
\text { eter } \\
\text { of roots } \\
\text { (milli- } \\
\text { meters) }\end{array}$} & \multirow{2}{*}{$\begin{array}{l}\text { Num- } \\
\text { ber of } \\
\text { roots }\end{array}$} & \multirow{2}{*}{$\begin{array}{l}\text { Num- } \\
\text { ber of } \\
\text { roots } \\
\text { unin= } \\
\text { jured }\end{array}$} & \multicolumn{3}{|c|}{$\begin{array}{l}\text { Per cent of cells killed } \\
\text { in injured roots }\end{array}$} \\
\hline & & & & & & $\begin{array}{l}\text { Cam- } \\
\text { bium }\end{array}$ & Phloëm & Cortex \\
\hline$-7^{\circ}$ & \multirow{4}{*}{$\begin{array}{c}\text { October } 24 \\
\text { to } \\
\text { December } 15\end{array}$} & \multirow[t]{4}{*}{$\begin{array}{l}\text { 2-year } \\
\text { French }\end{array}$} & $\begin{array}{l}7 \times 6 \\
4 \times 3\end{array}$ & $\begin{array}{l}8 \\
5\end{array}$ & $\begin{array}{r}6 \\
6 .\end{array}$ & $\begin{array}{r}20 \\
100\end{array}$ & 100 & 100 \\
\hline$-S^{\circ}$ & & & $\begin{array}{l}8 \times 6 \\
5 \times 3\end{array}$ & $\begin{array}{r}10 \\
5\end{array}$ & 2 & $\begin{array}{r}75 \\
100\end{array}$ & $\begin{array}{r}75 \\
100\end{array}$ & $\begin{array}{r}75 \\
100\end{array}$ \\
\hline$-9^{\circ}$ & & & $\begin{array}{l}7 \times 5 \\
5 \times 3\end{array}$ & $\begin{array}{l}3 \\
6\end{array}$ & $\begin{array}{c}1 \\
\cdots\end{array}$ & $\begin{array}{r}50 \\
100\end{array}$ & $\begin{array}{r}50 \\
100\end{array}$ & $\begin{array}{r}50 \\
100\end{array}$ \\
\hline$-10^{\circ}$ & & & $\begin{array}{l}9 \times 8 \\
4 \times 3\end{array}$ & $\begin{array}{l}3 \\
6\end{array}$ & & $\begin{array}{r}60 \\
100\end{array}$ & $\begin{array}{r}60 \\
100\end{array}$ & $\begin{array}{r}60 \\
100\end{array}$ \\
\hline$-9^{\circ}$ & \multirow{7}{*}{$\begin{array}{c}\text { January } \\
\text { to } \\
\text { March }\end{array}$} & \multirow[t]{2}{*}{$\begin{array}{l}\text { 2-year } \\
\text { French }\end{array}$} & $\begin{array}{l}8 \times 6 \\
5 \times 3\end{array}$ & $\begin{array}{l}5 \\
8\end{array}$ & 4 & $\begin{array}{l}100 \\
100\end{array}$ & $\begin{array}{l}100 \\
100\end{array}$ & $\begin{array}{l}100 \\
100\end{array}$ \\
\hline$-10^{\circ}$ & & & $\begin{array}{l}9 \times 7 \\
5 \times 4\end{array}$ & $\begin{array}{r}4 \\
13\end{array}$ & $\begin{array}{r}1 \\
\ldots \ldots\end{array}$ & $\begin{array}{l}100 \\
100\end{array}$ & $\begin{array}{l}100 \\
100\end{array}$ & $\begin{array}{l}100 \\
100\end{array}$ \\
\hline & & $\begin{array}{l}\text { 1-year } \\
\text { Kieffer }\end{array}$ & $6 \times 6$ & 6 & 3 & 60 & 40 & 40 \\
\hline \multirow[t]{2}{*}{$-11^{\circ}$} & & $\begin{array}{l}\text { 2-year } \\
\text { French }\end{array}$ & $\begin{array}{l}9 \times 7 \\
6 \times 4\end{array}$ & $\frac{5}{7}$ & $\begin{array}{r}1 \\
\ldots \ldots\end{array}$ & $\begin{array}{l}80 \\
85\end{array}$ & $\begin{array}{l}85 \\
80\end{array}$ & $\begin{array}{l}85 \\
80\end{array}$ \\
\hline & & $\begin{array}{l}\text { 1-year } \\
\text { Kieffer }\end{array}$ & $7 \times 6$ & 7 & & 100 & 100 & 100 \\
\hline \multirow[t]{2}{*}{$-12^{\circ}$} & & $\begin{array}{l}\text { 2-year } \\
\text { French }\end{array}$ & $7 \times 6$ & 4 & & 100 & 100 & 100 \\
\hline & & $\begin{array}{l}\text { 1-year } \\
\text { Kieffer }\end{array}$ & $\begin{array}{l}8 \times 7 \\
7 \times 6\end{array}$ & $\begin{array}{l}2 \\
2\end{array}$ & & $\begin{array}{r}100 \\
10\end{array}$ & $\begin{array}{r}100 \\
45\end{array}$ & $\begin{array}{r}100 \\
45\end{array}$ \\
\hline$-7^{\circ}$ & $\begin{array}{c}\text { April } \\
1 \text { to } 21\end{array}$ & $\begin{array}{l}\text { 2-year } \\
\text { French }\end{array}$ & $\begin{array}{l}8 \times 6 \\
4 \times 3\end{array}$ & $\begin{array}{l}2 \\
4\end{array}$ & $\begin{array}{l}2 \\
3\end{array}$ & 50 & 50 & $\ddot{50}$ \\
\hline
\end{tabular}


TABLE 2 (concluded)

\begin{tabular}{|c|c|c|c|c|c|c|c|c|}
\hline \multirow{2}{*}{$\begin{array}{l}\text { Temper- } \\
\text { ature } \\
\text { (centi- } \\
\text { grade) }\end{array}$} & \multirow{2}{*}{$\begin{array}{l}\text { Date of } \\
\text { freezing }\end{array}$} & \multirow{2}{*}{ Variety } & \multirow{2}{*}{$\begin{array}{l}\text { Diam- } \\
\text { eter } \\
\text { of roots } \\
\text { (milli- } \\
\text { meters) }\end{array}$} & \multirow{2}{*}{$\begin{array}{l}\text { Num- } \\
\text { ber of } \\
\text { roots }\end{array}$} & \multirow{2}{*}{$\begin{array}{l}\text { Num= } \\
\text { ber of } \\
\text { roots } \\
\text { unin= } \\
\text { jured }\end{array}$} & \multicolumn{3}{|c|}{$\begin{array}{l}\text { Per cent of cells killed } \\
\text { in injured roots }\end{array}$} \\
\hline & & & & & & $\begin{array}{l}\text { Cam- } \\
\text { bium }\end{array}$ & Phloëm & Cortex \\
\hline$\left(\begin{array}{l}-7^{\circ} \\
(\text { conc. })\end{array}\right.$ & \multirow{10}{*}{$\begin{array}{c}\text { April } \\
1 \text { to } 21 \\
\text { (concluded) }\end{array}$} & $\underset{\text { Kieffer }}{\text { 1-year }}$ & $\begin{array}{l}6 \times 6 \\
6 \times 3\end{array}$ & $\begin{array}{l}3 \\
3\end{array}$ & $\begin{array}{r}3 \\
\ldots . . .\end{array}$ & $\cdots \ddot{25}$ & $\ldots \ldots$ & 100 \\
\hline \multirow[t]{3}{*}{$-8^{\circ}$} & & $\begin{array}{l}\text { 2-year } \\
\text { French }\end{array}$ & $8 \times 5$ & 3 & $\ldots$ & 100 & 100 & 100 \\
\hline & & $\begin{array}{l}\text { 1-year } \\
\text { Kieffer }\end{array}$ & $6 \times 6$ & 9 & 7 & 100 & 100 & 100 \\
\hline & & $\begin{array}{l}\text { 1-year } \\
\text { French }\end{array}$ & $\begin{array}{l}6 \times 6 \\
5 \times 4 \\
4 \times 3\end{array}$ & $\begin{array}{r}2 \\
12 \\
8\end{array}$ & $\begin{array}{r}2 \\
\cdots \\
4\end{array}$ & $\begin{array}{l}60 \\
70\end{array}$ & $\begin{array}{l}60 \\
70\end{array}$ & $\begin{array}{l}60 \\
70\end{array}$ \\
\hline \multirow[t]{3}{*}{$-9^{\circ}$} & & $\begin{array}{l}\text { 2-year } \\
\text { French }\end{array}$ & $7 \times 5$ & 3 & & 100 & 100 & 100 \\
\hline & & $\begin{array}{l}\text { 1-year } \\
\text { Kieffer }\end{array}$ & $7 \times 5$ & 3 & $\ldots \ldots$ & 0 & 15 & 0 \\
\hline & & $\begin{array}{l}\text { 1-year } \\
\text { French }\end{array}$ & $\begin{array}{l}6 \times 4 \\
3 \times 2\end{array}$ & $\begin{array}{l}9 \\
7\end{array}$ & & $\begin{array}{r}75 \\
100\end{array}$ & $\begin{array}{r}75 \\
100\end{array}$ & $\begin{array}{r}75 \\
100\end{array}$ \\
\hline \multirow[t]{3}{*}{$-10^{\circ}$} & & $\begin{array}{l}\text { 2-year } \\
\text { French }\end{array}$ & $10 \times 6$ & 3 & $\ldots \ldots$ & 100 & 100 & 100 \\
\hline & & $\begin{array}{l}\text { 1-year } \\
\text { Kieffer }\end{array}$ & $7 \times 6$ & 3 & & 100 & 100 & 100 \\
\hline & & $\begin{array}{l}\text { 1-year } \\
\text { French }\end{array}$ & $8 \times 5$ & 3 & & 100 & 100 & 100 \\
\hline
\end{tabular}

The pear roots, like those of the apple, showed individual variations an increase in hardiness with an increase in diameter, a region at the crown less tender than the root below, little influence due to depth below the soil surface, relative tenderness of the same tissues, and a gradual acquiring of hardiness thru the winter, reaching the maximum in February and March. This seasonal hardiness, however, seems rather more delayed in the pear root than in the apple. 
If the resistance of the pear and the apple seedlings is contrasted, it is found that an approximate difference of from one to two degrees generally obtains, and sometimes even a much greater difference. Thus, while in March the apple does not begin to show much injury until a temperature of $-11^{\circ}$ or $-12^{\circ} \mathrm{C}$. is reached, $-10^{\circ}$ or $-11^{\circ}$ is sufficient to kill most of the tissues, except the xylem and the pith, in both the French and the Kieffer pear stocks.

RESISTANCE OF ELBERTA PEACH ROOTS TO LOW TEMPERATURE

The name Elberta as used here refers only to the bearing surface of the tree and has no reference to the origin of the roots. The peach stocks probably were derived from several different varieties; at least, the range of variation presented in table 3 indicates such a possibility.

table 3. Effect of Low Temperature on Roots of Elberta Peach Trees

\begin{tabular}{|c|c|c|c|c|c|c|c|c|}
\hline \multirow{2}{*}{$\begin{array}{l}\text { Temper- } \\
\text { ature } \\
\text { (centi- } \\
\text { grade) }\end{array}$} & \multirow{2}{*}{$\begin{array}{l}\text { Date of } \\
\text { freezing }\end{array}$} & \multirow{2}{*}{$\begin{array}{l}\text { Diam- } \\
\text { eter } \\
\text { of roots } \\
\text { (milli- } \\
\text { meters) }\end{array}$} & \multirow{2}{*}{$\begin{array}{l}\text { Num- } \\
\text { ber of } \\
\text { roots }\end{array}$} & \multirow{2}{*}{$\begin{array}{l}\text { Num= } \\
\text { ber of } \\
\text { roots } \\
\text { unin= } \\
\text { jured }\end{array}$} & \multicolumn{4}{|c|}{$\begin{array}{l}\text { Per cent of cells killed in } \\
\text { injured roots }\end{array}$} \\
\hline & & & & & $\begin{array}{l}\text { Cam- } \\
\text { bium }\end{array}$ & Phloëm & Cortex & Pith \\
\hline$-8.5^{\circ}$ & $\begin{array}{c}\text { February } 12 \\
\text { to } \\
\text { March } 24\end{array}$ & $\begin{array}{r}12 \times 6 \\
5 \times 4\end{array}$ & $\begin{array}{l}2 \\
4\end{array}$ & 2 & & & $\dddot{15}$ & $\cdots \cdots$ \\
\hline$-10^{\circ}$ & & $\begin{array}{r}15 \times 8 \\
10 \times 6 \\
7 \times 5 \\
5 \times 4\end{array}$ & $\begin{array}{l}3 \\
6 \\
5 \\
7\end{array}$ & $\begin{array}{l}\ldots \\
2 \\
\ldots \ldots \ldots \\
\ldots \ldots \ldots\end{array}$ & $\begin{array}{r}100 \\
90 \\
100 \\
65\end{array}$ & $\begin{array}{r}100 \\
90 \\
100 \\
65\end{array}$ & $\begin{array}{r}100 \\
90 \\
100 \\
65\end{array}$ & $\begin{array}{r}100 \\
60 \\
55 \\
45\end{array}$ \\
\hline$-11^{\circ}$ & & $\begin{array}{r}15 \times 8 \\
10 \times 9 \\
7 \times 5 \\
5 \times 4\end{array}$ & $\begin{array}{l}1 \\
5 \\
4 \\
7\end{array}$ & & $\begin{array}{r}100 \\
30 \\
3 \\
35\end{array}$ & $\begin{array}{r}100 \\
30 \\
35\end{array}$ & $\begin{array}{r}100 \\
35 \\
\cdots \quad 35\end{array}$ & $\begin{array}{r}45 \\
100 \\
100\end{array}$ \\
\hline$-12^{\circ}$ & & $\begin{array}{r}12 \times 8 \\
10 \times 6 \\
7 \times 5 \\
4 \times 3\end{array}$ & $\begin{array}{l}5 \\
5 \\
3 \\
4\end{array}$ & & $\begin{array}{l}60 \\
40 \\
\cdots \\
50\end{array}$ & $\begin{array}{r}60 \\
40 \\
\ldots \\
50\end{array}$ & $\begin{array}{l}60 \\
40 \\
40 \\
50\end{array}$ & $\begin{array}{l}100 \\
100 \\
100 \\
100\end{array}$ \\
\hline$-14.5^{\circ}$ & & $\begin{array}{l}7 \times 6 \\
7 \times 5\end{array}$ & $\begin{array}{l}5 \\
5\end{array}$ & $\begin{array}{l}1 \\
1\end{array}$ & $\begin{array}{l}65 \\
25\end{array}$ & $\begin{array}{l}65 \\
25\end{array}$ & $\begin{array}{l}65 \\
35\end{array}$ & $\begin{array}{l}100 \\
100\end{array}$ \\
\hline
\end{tabular}


TABLE 3 (concluded)

\begin{tabular}{|c|c|c|c|c|c|c|c|c|}
\hline \multirow{2}{*}{$\begin{array}{c}\text { Temper- } \\
\text { ature } \\
\text { (centi- } \\
\text { grade) }\end{array}$} & \multirow{2}{*}{$\begin{array}{l}\text { Date of } \\
\text { freezing }\end{array}$} & \multirow{2}{*}{$\begin{array}{l}\text { Diam- } \\
\text { eter } \\
\text { of roots } \\
\text { (milli- } \\
\text { meters) }\end{array}$} & \multirow{2}{*}{$\begin{array}{l}\text { Num- } \\
\text { ber of } \\
\text { roots }\end{array}$} & \multirow{2}{*}{$\begin{array}{l}\text { Num= } \\
\text { ber of } \\
\text { roots } \\
\text { unin= } \\
\text { jured }\end{array}$} & \multicolumn{4}{|c|}{$\begin{array}{l}\text { Per cent of cells killed in } \\
\text { injured roots }\end{array}$} \\
\hline & & & & & $\begin{array}{l}\text { Cam- } \\
\text { bium }\end{array}$ & Phloëm & Cortex & Pith \\
\hline$-5.5^{\circ}$ & $\begin{array}{c}\text { March } 25 \\
\text { to } \\
\text { April } 25\end{array}$ & $7 \times 5$ & 7 & 3 & & 25 & 25 & $\cdots$ \\
\hline$-7^{\circ}$ & & $\begin{array}{c}11 \times 10 \\
7 \times 5\end{array}$ & $\begin{array}{l}3 \\
6\end{array}$ & $\frac{2}{2}$ & $\ddot{20}$ & $\begin{array}{r}100 \\
20\end{array}$ & $\begin{array}{r}100 \\
20\end{array}$ & \\
\hline$-8^{\circ}$ & & $\begin{array}{r}12 \times 6 \\
7 \times 5 \\
5 \times 4\end{array}$ & $\begin{array}{l}2 \\
2 \\
4\end{array}$ & $\begin{array}{l}\cdots \\
\ldots \\
\cdots\end{array}$ & 100 & $\begin{array}{r}10 \\
60 \\
100\end{array}$ & $\begin{array}{r}25 \\
60 \\
100\end{array}$ & $\cdots$ \\
\hline$-9^{\circ}$ & & $10 \times 6$ & 3 & $\ldots \ldots$ & 100 & $\ldots \ldots$ & 100 & $\ldots$ \\
\hline$-10^{\circ}$ & & $11 \times 10$ & 3 & & 100 & 100 & 100 & SO \\
\hline$-11^{\circ}$ & & $7 \times 5$ & 3 & $\ldots$ & 100 & 100 & 100 & 75 \\
\hline
\end{tabular}

During the middle of February an exposure at $-10^{\circ} \mathrm{C}$., included in the February-March period, shows an average injury of 75 per cent in all tissues except the xylem in nineteen out of twenty-one roots. The tests at $-11^{\circ}$, which were made on March 1 , indicate an average injury of less than 50 per cent. An average injury of from 55 to 60 per cent in all the cells is seen at a temperature of $-12^{\circ}$, altho at two and one-half degrees lower two roots out of ten were uninjured.

As a general rule the order of resistance of the various tissues in the peach root seems to be as follows: pith, cortex, phloëm, cambium, xylem. At $-18^{\circ} \mathrm{C}$. or below, the xylem was usually killed during the hardiest period. In most cases during February and March the pith is the tissue most easily killed, but in April the cambium is the least resistant.

It is not so easy, with the data at hand, to assign an arbitrary limit within which the peach root is injured by freezing. This is because of the great variation in the root tissues. The peach cambium certainly is as hardy as the pear cambium, tho less so than the apple. Regardless of the size of the root, most of the peach material tested showed some injury 
at $-10^{\circ} \mathrm{C}$, and, except in unusual cases, serious injury occurred at $-11^{\circ}$. This would then place the hardiness of the peach root very close to that of either pear seedling.

COMPARATIVE RESISTANCE OF MAZZARD AND MAHALEB CHERRY ROOTS TO LOW TEMPERATURE

In the cherry freezing determinations previous to January, 1916, only two-year cherry seedlings were used. Subsequent to that date, only one-year material was tested. A few roots of Prunus Besseyi were available in March.

Table 4. Effect of Low Temperature on Mazzard and Mahaleb Cherry Roots

\begin{tabular}{|c|c|c|c|c|c|c|c|c|c|c|}
\hline \multirow{2}{*}{$\begin{array}{l}\text { Temper- } \\
\text { ature } \\
\text { (centi- } \\
\text { grade) }\end{array}$} & \multirow{2}{*}{$\begin{array}{l}\text { Date of } \\
\text { freezing }\end{array}$} & \multirow{2}{*}{ Variety } & \multirow{2}{*}{$\begin{array}{l}\text { Diam- } \\
\text { eter } \\
\text { of roots } \\
\text { (milli- } \\
\text { meters) }\end{array}$} & \multirow{2}{*}{$\begin{array}{l}\text { Num- } \\
\text { ber of } \\
\text { roots }\end{array}$} & \multirow{2}{*}{$\begin{array}{l}\text { Num- } \\
\text { ber of } \\
\text { roots } \\
\text { unin- } \\
\text { jured }\end{array}$} & \multicolumn{5}{|c|}{$\begin{array}{c}\text { Per cent of cells killed in injured } \\
\text { roots }\end{array}$} \\
\hline & & & & & & $\begin{array}{l}\text { Cam- } \\
\text { bium }\end{array}$ & Phloëm & Cortex & Pith & Xylem \\
\hline \multirow[t]{2}{*}{$-7^{\circ}$} & \multirow{8}{*}{$\begin{array}{c}\text { October } 24 \\
\text { to } \\
\text { December } 11\end{array}$} & Mahaleb & $\begin{array}{l}7 \times 3 \\
5 \times 4 \\
\end{array}$ & $\begin{array}{l}5 \\
5 \\
\end{array}$ & $\begin{array}{l}5 \\
4\end{array}$ & 25 & & & & $\ldots \ldots$ \\
\hline & & Mazzard & $\begin{array}{l}8 \times 3 \\
7 \times 5\end{array}$ & $\begin{array}{l}2 \\
2\end{array}$ & & $\begin{array}{l}50 \\
50\end{array}$ & $\begin{array}{l}50 \\
50 \\
\end{array}$ & $\begin{array}{l}50 \\
50\end{array}$ & & $\overline{\cdots \cdots}$ \\
\hline \multirow[t]{2}{*}{$-8^{\circ}$} & & Mahaleb & $\begin{array}{r}10 \times 8 \\
9 \times 7 \\
5 \times 4 \\
4 \times 2\end{array}$ & $\begin{array}{l}2 \\
3 \\
5 \\
5\end{array}$ & $\begin{array}{r}2 \\
1 \\
3 \\
3\end{array}$ & $\begin{array}{l}25 \\
15 \\
50\end{array}$ & $\begin{array}{l}25 \\
250 \\
60\end{array}$ & $\begin{array}{l}25 \\
60\end{array}$ & & \\
\hline & & Mazzard & $\begin{array}{l}9 \times 5 \\
5 \times 3\end{array}$ & $\begin{array}{l}1 \\
4\end{array}$ & 1 & $\ldots$ & $\dddot{80}$ & 80 & & \\
\hline \multirow[t]{2}{*}{$-9^{\circ}$} & & Mahaleb & $\begin{array}{l}6 \times 5 \\
5 \times 3\end{array}$ & $\begin{array}{r}10 \\
2\end{array}$ & $\begin{array}{l}4 \\
1\end{array}$ & $\begin{array}{l}50 \\
50\end{array}$ & & & & $\overline{\cdots \cdots}$ \\
\hline & & Mazzard & $6 \times 5$ & $\overline{4}$ & $\ldots \ldots$ & 80 & 80 & 80 & $\ldots \ldots$ & $\ldots \ldots$ \\
\hline$-10^{\circ}$ & & Mahaleb & $\begin{array}{r}10 \times 5 \\
5 \times 2\end{array}$ & $\begin{array}{l}2 \\
2\end{array}$ & 1 & 100 & $\cdots \quad 50$ & 100 & & $\cdots \cdots$ \\
\hline$-12^{\circ}$ & & Mahaleb & $15 \times 13$ & 2 & $\ldots \ldots \ldots$ & 100 & 100 & 100 & $\ldots \ldots$ & $\ldots \ldots$ \\
\hline \multirow[t]{2}{*}{$-9^{\circ}$} & \multirow{6}{*}{$\begin{array}{c}\text { January } 1 \\
\text { to } \\
\text { March } 29\end{array}$} & Mahaleb & $7 \times 5$ & 2 & 2 & & $\ldots \ldots \ldots$ & $\ldots \ldots$ & $\ldots$ & $\ldots \ldots$ \\
\hline & & Mazzard & $\begin{array}{l}6 \times 6 \\
5 \times 4 \\
\end{array}$ & $\begin{array}{l}2 \\
3 \\
\end{array}$ & $\begin{array}{r}2 \\
\cdots \cdots \cdots \\
\end{array}$ & $\ddot{4} \dot{5}^{\circ}$ & 45 & 45 & & \\
\hline \multirow[t]{2}{*}{$-10^{\circ}$} & & Mahaleb & $6 \times 2$ & 2 & 2 & $\ldots \ldots$ & .......... & $\ldots \ldots$ & $\ldots \ldots$ & $\ldots \ldots$ \\
\hline & & Mazzard & $\begin{array}{l}7 \times 6 \\
4 \times 2 \\
\end{array}$ & $\begin{array}{l}2 \\
2 \\
\end{array}$ & $\ldots \ldots \ldots$ & 30 & 30 & $\begin{array}{r}30 \\
\ldots \ldots \\
\end{array}$ & & \\
\hline \multirow[t]{2}{*}{$-11^{\circ}$} & & Mahaleb & $\begin{array}{l}7 \times 5 \\
4 \times 2\end{array}$ & $\begin{array}{l}6 \\
2 \\
\end{array}$ & $\begin{array}{r}6 \\
6 \ldots \ldots\end{array}$ & $50^{\circ}$ & $\ddot{50}$ & 30 & & \\
\hline & & Mazzard & $\begin{array}{l}8 \times 8 \\
5 \times 4\end{array}$ & $\begin{array}{l}6 \\
4\end{array}$ & & $\begin{array}{r}85 \\
100\end{array}$ & $\begin{array}{r}85 \\
100\end{array}$ & $\begin{array}{r}85 \\
100\end{array}$ & & \\
\hline
\end{tabular}


TABLE 4 (concluded)

\begin{tabular}{|c|c|c|c|c|c|c|c|c|c|c|}
\hline \multirow{2}{*}{$\begin{array}{l}\text { Temper- } \\
\text { ature } \\
\text { (centi- } \\
\text { grade) }\end{array}$} & \multirow{2}{*}{$\begin{array}{l}\text { Date of } \\
\text { freezing }\end{array}$} & \multirow{2}{*}{ Variety } & \multirow{2}{*}{$\begin{array}{c}\text { Diam- } \\
\text { eter } \\
\text { of roots } \\
\text { (milli- } \\
\text { meters) }\end{array}$} & \multirow{2}{*}{$\begin{array}{l}\text { Num- } \\
\text { ber of } \\
\text { roots }\end{array}$} & \multirow{2}{*}{$\begin{array}{l}\text { Num- } \\
\text { ber of } \\
\text { roots } \\
\text { unin- } \\
\text { jured }\end{array}$} & \multicolumn{5}{|c|}{$\begin{array}{c}\text { Per cent of cells killed in injured } \\
\text { roots }\end{array}$} \\
\hline & & & & & & $\begin{array}{l}\text { Cam- } \\
\text { bium }\end{array}$ & Phloëm & Cortex & Pith & $\mathrm{X}$ lem \\
\hline$\left(\begin{array}{l}-11^{\circ} \\
(\text { conc. })\end{array}\right.$ & \multirow{10}{*}{$\begin{array}{c}\text { January } 1 \\
\text { to } \\
\text { March } 29 \\
\text { (concluded) }\end{array}$} & $\begin{array}{c}\text { Prunus } \\
\text { Besseyi }\end{array}$ & $\begin{array}{l}9 \times 7 \\
6 \times 3\end{array}$ & $\begin{array}{l}2 \\
4\end{array}$ & 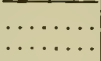 & $\begin{array}{l}100 \\
100\end{array}$ & $\begin{array}{l}100 \\
100\end{array}$ & $\begin{array}{l}100 \\
100\end{array}$ & $\cdots \cdots$ & $\ldots \ldots$ \\
\hline \multirow[t]{3}{*}{$-12^{\circ}$} & & Mahaleb & $\begin{array}{l}7 \times 6 \\
6 \times 3\end{array}$ & $\begin{array}{l}3 \\
2\end{array}$ & ..... & $\begin{array}{r}10 \\
100\end{array}$ & $\begin{array}{r}10 \\
100\end{array}$ & $\begin{array}{r}10 \\
100\end{array}$ & & $\cdots$ \\
\hline & & Mazzard & $7 \times 6$ & 4 & $\ldots$ & 100 & 100 & 100 & $\ldots$ & $\ldots$ \\
\hline & & $\begin{array}{c}\text { Prunus } \\
\text { Besseyi }\end{array}$ & $\begin{array}{l}7 \times 8 \\
7 \times 6\end{array}$ & $\frac{2}{2}$ & & $\begin{array}{r}50 \\
100\end{array}$ & $\ldots \ldots \ldots$ & $\begin{array}{l}25 \\
30\end{array}$ & ${ }^{1000}$ & $\cdots$ \\
\hline \multirow[t]{3}{*}{$-15^{\circ}$} & & Mahaleb & $\begin{array}{r}10 \times 8 \\
7 \times 6\end{array}$ & $\begin{array}{l}7 \\
2\end{array}$ & i & $\begin{array}{l}20 \\
30\end{array}$ & $\begin{array}{l}20 \\
30\end{array}$ & $\begin{array}{l}20 \\
30\end{array}$ & $\cdots \cdots$ & $\cdots \cdots$ \\
\hline & & Mazzard & $10 \times 8$ & 7 & $\ldots \ldots \ldots$ & 100 & 100 & 100 & $\ldots \ldots$ & $\ldots$ \\
\hline & & $\begin{array}{c}\text { Prunus } \\
\text { Besseyi }\end{array}$ & $7 \times 7$ & 2 & & 100 & 100 & 100 & $\ldots \ldots$ & $\cdots$ \\
\hline \multirow[t]{3}{*}{$-17^{\circ}$} & & Mahaleb & $8 \times 7$ & 2 & ........ & 75 & 75 & 75 & $\ldots \ldots$ & $\ldots \ldots$ \\
\hline & & Mazzard & $8 \times 7$ & 2 & ......... & 100 & 100 & 100 & 100 & $\ldots \ldots$ \\
\hline & & $\begin{array}{c}\text { Prunus } \\
\text { Besseyi }\end{array}$ & $9 \times 7$ & 4 & & 100 & 100 & 100 & 100 & 50 \\
\hline \multirow[t]{2}{*}{$-7^{\circ}$} & \multirow{12}{*}{$\begin{array}{l}\text { March } 30 \\
\text { to } \\
\text { April } 20\end{array}$} & Mahaleb & $9 \times 4$ & 2 & 2 & ....... & $\ldots \ldots$ & $\ldots . .$. & $\ldots \ldots$ & $\ldots \ldots$ \\
\hline & & Mazzard & $9 \times 8$ & 4 & ........ & 100 & 100 & 100 & $\ldots \ldots$ & $\ldots$. \\
\hline \multirow[t]{2}{*}{$-8^{\circ}$} & & Mahaleb & $8 \times 5$ & 4 & 4 & $\ldots \ldots$ & ..... & $\ldots \ldots$ & $\ldots \ldots$ & $\ldots \ldots$ \\
\hline & & Mazzard & $\begin{aligned} & 12 \times 11 \\
& 8 \times 6\end{aligned}$ & $\begin{array}{l}2 \\
2\end{array}$ & 1 & $\begin{array}{r}40 \\
100\end{array}$ & $\begin{array}{r}40 \\
100\end{array}$ & $\begin{array}{r}40 \\
100\end{array}$ & & \\
\hline \multirow[t]{2}{*}{$-9^{\circ}$} & & Mahaleb & $\begin{array}{l}9 \times 5 \\
8 \times 3\end{array}$ & $\frac{2}{5}$ & $\begin{array}{l}2 \\
4\end{array}$ & iis & $\because 5$ & $i 5$ & $\ldots \ldots$ & \\
\hline & & Mazzard & $\begin{array}{r}10 \times 8 \\
8 \times 5 \\
\end{array}$ & $\begin{array}{l}5 \\
5\end{array}$ & $\ldots \ldots \ldots$ & $\begin{array}{l}100 \\
100\end{array}$ & $\begin{array}{l}100 \\
100\end{array}$ & $\begin{array}{l}100 \\
100\end{array}$ & & $\ldots \ldots$ \\
\hline \multirow[t]{2}{*}{$-10^{\circ}$} & & Mahaleb & $\begin{array}{l}7 \times 6 \\
5 \times 2\end{array}$ & $\begin{array}{l}5 \\
2\end{array}$ & $\begin{array}{l}5 \\
\cdots\end{array}$ & 40 & $\ddot{4} 0^{\circ}$ & 40 & $\cdots$ & \\
\hline & & Mazzard & $\begin{array}{r}10 \times 9 \\
8 \times 8\end{array}$ & $\begin{array}{l}4 \\
4\end{array}$ & & $\begin{array}{l}100 \\
100\end{array}$ & $\begin{array}{l}100 \\
100\end{array}$ & $\begin{array}{l}100 \\
100\end{array}$ & 100 & 50 \\
\hline \multirow[t]{2}{*}{$-11^{\circ}$} & & Mahaleb & $8 \times 4$ & 2 & 2 & ....... & ....... & ...... & $\ldots \ldots$ & $\ldots \ldots$ \\
\hline & & Mazzard & $8 \times 8$ & 3 & ........ & 100 & 100 & 100 & 100 & $\ldots \ldots$ \\
\hline \multirow[t]{2}{*}{$-12^{\circ}$} & & Mahaleb & $\begin{array}{l}9 \times 6 \\
7 \times 4\end{array}$ & $\frac{2}{3}$ & & $\begin{array}{r}60 \\
5\end{array}$ & $\begin{array}{r}75 \\
\ldots \ldots\end{array}$ & $\begin{array}{l}75 \\
10\end{array}$ & $\ldots \ldots$ & \\
\hline & & Mazzard & $\begin{aligned} 12 \times 10 \\
8 \times 7 \\
7 \times 4\end{aligned}$ & $\begin{array}{l}2 \\
4 \\
3\end{array}$ & & $\begin{array}{l}100 \\
100 \\
100\end{array}$ & $\begin{array}{l}100 \\
100 \\
100\end{array}$ & $\begin{array}{l}100 \\
100 \\
100\end{array}$ & $\begin{array}{l}100 \\
100 \\
100\end{array}$ & $\begin{array}{l}1000 \\
100\end{array}$ \\
\hline
\end{tabular}


The most striking fact brought out by the data in table 4 is the uniform. tenderness of the Mazzard as compared with the Mahaleb stock. This difference can readily be seen in any comparable instance. It extends thru all stages of maturity. Thus, during November, Mazzard tissue was injured much more severely when exposed to $-8^{\circ} \mathrm{C}$. than was corresponding Mahaleb stock tested at $-9^{\circ}$. In the January-March period a similar difference is noted; the six larger Mazzard stocks given an exposure at $-11^{\circ}$ show 85 per cent browning in the three outer tissues, while three smaller Mahaleb roots were similarly affected only 10 per cent when exposed at $-12^{\circ}$. At $-15^{\circ}$ the Mahaleb tissue suffers relatively little injury, but the two roots subjected to $-17^{\circ}$ are mostly killed. In the March-April period the continued resistance of the Mahaleb tissue is striking. On April 15 it is about three or four degrees hardier than the Mazzard, which when exposed to $-10^{\circ}$ is seriously injured in the pith and the xylem. These results are in accord with the field observations of Craig (1900) and the laboratory studies of Chandler (1913).

The freezing tests with Prunus Besseyi, altho this is a plum species, are included in the cherry data since it is frequently used as a cherry stock. These results with Prunus Besseyi do not bear out the experience of most writers regarding its exceptional hardiness. During the January-March exposures, it is noted that at $-11^{\circ} \mathrm{C}$. this variety was injured somewhat more than was the Mazzard. At $-12^{\circ}$ it was rather more resistant than the Mazzard but the pith in the smaller roots was killed thruout. At $-15^{\circ}$ and $-17^{\circ}$ it suffered equally with the Mazzard or worse.

Under field conditions with severe freezing, Craig (1900) found Prunus Besseyi much hardier than all other stocks used for cherries. The writer is not prepared to say that the hardiness of this species has been overestimated. His own very limited experience, however, shows it to be inferior in resistance to Mahaleb, and slightly better than Mazzard. Since the writer is not familiar with the Prunus Besseyi stock, it is of course possible that the roots tested as recorded above were not of this species. The only evidence that they were correctly named is from the nurseryman who sold them as such.

A sinall amount of data on Prunus avium and Prunus pennsylvanicum, not included in table 4, indicate merely that these roots seem to be quite as easily killed by freezing as are Mazzard roots. Since these roots were taken directly from the partly frozen ground in April, they were rather 
moist and were probably beginning activity. A larger number of determinations under different conditions might entirely change the tendency just mentioned.

Considering the data on the four cherry stocks, their order of relative hardiness seems about as follows: Mahaleb, Prunus Besseyi, Prunus pennsylvanicum, Mazzard. If the Mahaleb cherry is compared with the apple, it is seen that the resistance of the former is markedly superior in most cases. In large Mahaleb roots during their hardiest period, little injury is found under $-14^{\circ} \mathrm{C}$., while at $-15^{\circ}$ the injury is relatively small. Prunus Besseyi did not survive a temperature of $-11^{\circ}$. Prunus pennsylvanicum succumbed at $-10^{\circ}$ or $-11^{\circ}$, altho the date of freezing may partly account for its tenderness. The Mazzard roots in no instance withstood $-11^{\circ}$, but the number of tests run at $-10^{\circ}$ was insufficient to place this as its minimum. From these results the Mazzard cherry stock does not appear hardier than Kieffer pear stock.

\section{RESISTANCE OF MYROBALAN PLUM ROOTS TO LOW TEMPERATURE}

Unfortunately, only one commonly used plum stock was available in this work, aside from the Prunus Besseyi roots included in table 4 with the cherry stocks. The number of one-year Myrobalan roots tested was too small to give very conclusive results. However, some indication at least of its comparative hardiness may be gained from table 5. The data in this table place the one-year Myrobalan root in the same group in regard to hardiness as the pear and the Mazzard cherry. The Myrobalan plum does not appear quite so hardy as the Kieffer pear and probably it would prove to be less hardy than a vigorous one-year French pear. The fact that the roots of the latter are normally somewhat larger than the average plum roots, would give still more evidence in favor of the superior hardiness of the pear. 
Table 5. Effect of Low Temperature on Mrrobalan Plum Roots

\begin{tabular}{|c|c|c|c|c|c|c|c|}
\hline \multirow{2}{*}{$\begin{array}{l}\text { Temper- } \\
\text { ature } \\
\text { (centi- } \\
\text { grade) }\end{array}$} & \multirow{2}{*}{$\begin{array}{l}\text { Date of } \\
\text { freezing }\end{array}$} & \multirow{2}{*}{$\begin{array}{l}\text { Diam- } \\
\text { eter } \\
\text { of roots } \\
\text { (milli- } \\
\text { meters) }\end{array}$} & \multirow{2}{*}{$\begin{array}{l}\text { Num- } \\
\text { ber of } \\
\text { roots }\end{array}$} & \multirow{2}{*}{$\begin{array}{l}\text { Number } \\
\text { of roots } \\
\text { uninjured }\end{array}$} & \multicolumn{3}{|c|}{$\begin{array}{l}\text { Per cent of cells killed } \\
\text { in injured roots }\end{array}$} \\
\hline & & & & & $\begin{array}{l}\text { Cam- } \\
\text { bium }\end{array}$ & Phloëm & Cortex \\
\hline$-7^{\circ}$ & $\begin{array}{c}\text { October } 24 \\
\text { to } \\
\text { December } 20\end{array}$ & $\begin{array}{l}8 \times 7 \\
5 \times 3\end{array}$ & $\frac{2}{5}$ & & $\begin{array}{l}50 \\
65\end{array}$ & $\begin{array}{l}50 \\
65\end{array}$ & $\begin{array}{l}10 \\
65\end{array}$ \\
\hline$-8^{\circ}$ & & $5 \times 4$ & 3 & $\ldots \ldots \ldots$ & 100 & 100 & 100 \\
\hline$-9^{\circ}$ & & $\begin{array}{l}7 \times 5 \\
5 \times 3\end{array}$ & $\begin{array}{l}3 \\
2\end{array}$ & $\begin{array}{r}1 \\
\ldots \ldots\end{array}$ & $\begin{array}{l}100 \\
100\end{array}$ & $\begin{array}{l}100 \\
100\end{array}$ & $\begin{array}{l}100 \\
100\end{array}$ \\
\hline$-10^{\circ}$ & & $\begin{array}{l}9 \times 5 \\
8 \times 7\end{array}$ & $\begin{array}{l}2 \\
2\end{array}$ & $\begin{array}{l}\ldots \ldots \\
\cdots \cdots\end{array}$ & $\begin{array}{l}80 \\
65\end{array}$ & $\begin{array}{l}80 \\
65\end{array}$ & $\begin{array}{l}80 \\
65\end{array}$ \\
\hline$-9^{\circ}$ & $\begin{array}{c}\text { January } 1 \\
\text { to } \\
\text { M Iarch } 29\end{array}$ & $\begin{array}{l}7 \times 6 \\
5 \times 4 \\
2 \times 1\end{array}$ & $\begin{array}{r}6 \\
11 \\
11\end{array}$ & & $\begin{array}{r}100 \\
30 \\
40\end{array}$ & $\begin{array}{r}100 \\
30 \\
40\end{array}$ & $\begin{array}{r}100 \\
35 \\
40\end{array}$ \\
\hline$-10^{\circ}$ & & $\begin{array}{l}8 \times 5 \\
5 \times 4\end{array}$ & $\begin{array}{l}2 \\
9\end{array}$ & $\begin{array}{l}\ldots \ldots \ldots \\
\ldots \ldots\end{array}$ & $\begin{array}{r}100 \\
80\end{array}$ & $\begin{array}{r}100 \\
80\end{array}$ & $\begin{array}{r}100 \\
80\end{array}$ \\
\hline$-11^{\circ}$ & & $\begin{array}{l}9 \times 7 \\
5 \times 4\end{array}$ & $\frac{2}{4}$ & & $\begin{array}{r}75 \\
100\end{array}$ & $\begin{array}{r}75 \\
100\end{array}$ & $\begin{array}{r}75 \\
100\end{array}$ \\
\hline$-8^{\circ}$ & April 1 to 8 & $\begin{array}{r}6 \times 5 \\
5 \times 4 \\
3 \times 2\end{array}$ & $\begin{array}{r}5 \\
7 \\
13\end{array}$ & $\begin{array}{l}\ldots \ldots \\
\ldots \ldots \ldots \\
\ldots \ldots\end{array}$ & $\begin{array}{l}80 \\
25 \\
80\end{array}$ & $\begin{array}{l}80 \\
25 \\
80\end{array}$ & $\begin{array}{r}80 \\
60 \\
100\end{array}$ \\
\hline
\end{tabular}

RESISTANCE OF THE ROOTS OF SIX GRAPE VARIETIES TO LOW 'TEMPERATURE

It is well known that there is a rather wide difference in hardiness in the canes of certain varieties of grapes. Such a variation, tho less important and conspicuous, is found also in grape roots. To determine these differences, six varieties were selected for testing, embracing severa? species.

- According to Hedrick (1908), the varieties used represent the following species: Concord, Vitis labrusca; Clinton, Vitis vulpina and Vitis labrusca, the variety being more characteristic of the former species; Diamond, Vitis labrusca and Vitis vinifera, the former predominating; Lindley, Vitis labrusca and Vitis vinifera; Norton, Vitis aestivalis and Vitis labrusca, 


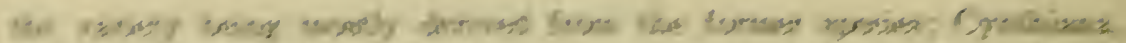

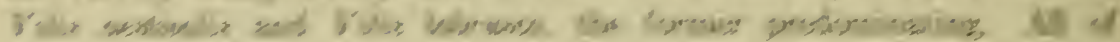

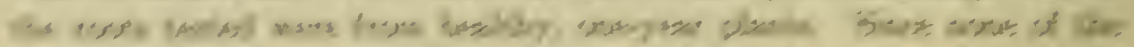

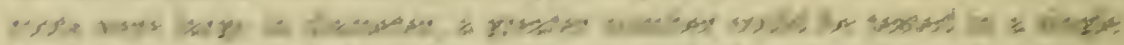

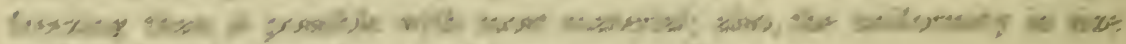

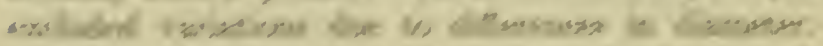

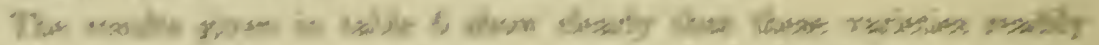

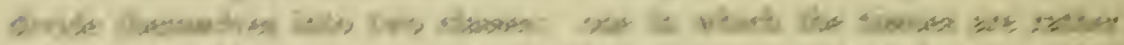

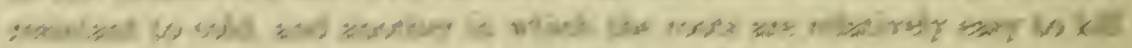

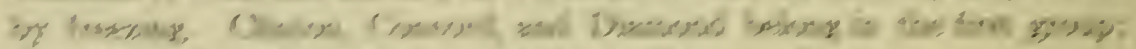

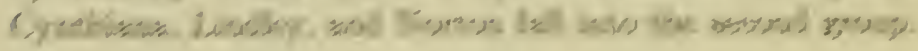

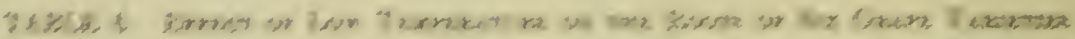

\begin{tabular}{|c|c|c|c|c|c|c|c|c|c|c|}
\hline \multirow{2}{*}{ 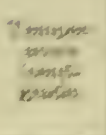 } & \multirow{2}{*}{ lisend of } & \multirow{2}{*}{ Thens? } & \multirow{2}{*}{ 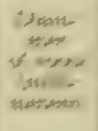 } & \multirow{2}{*}{$\lim _{x \rightarrow \infty}$} & \multirow{2}{*}{ 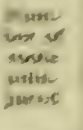 } & \multicolumn{5}{|c|}{ 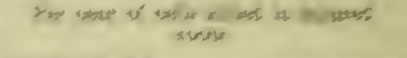 } \\
\hline & & & & & & rent- & H s. & rowers & 7 & $x$ yom \\
\hline-4 & 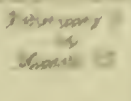 & 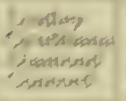 & $\begin{array}{l}x=2 \\
y=2 \\
x=2 \\
x=2\end{array}$ & $\frac{14}{6}$ & $\begin{array}{l}y \\
y \\
x\end{array}$ & & & & - & - \\
\hline$=y$ & & 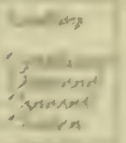 & 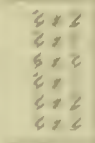 & $\begin{array}{l}4 \\
6 \\
6 \\
6 \\
6\end{array}$ & iv & to & wit & 5 & $=$ & \\
\hline$\rightarrow w^{\prime}$ & & 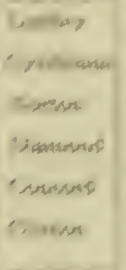 & 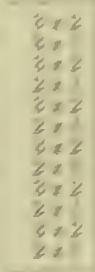 & $\begin{array}{l}\frac{1}{2} \\
2 \\
2 \\
2 \\
6 \\
4 \\
4 \\
4\end{array}$ & 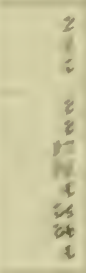 & $\begin{array}{l}\text { ys } \\
\text { is } \\
\text { wy } \\
\text { by } \\
\text { ty } \\
y \\
5 \\
5\end{array}$ & 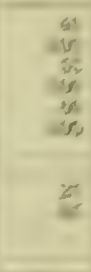 & 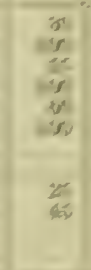 & $=$ & a \\
\hline$-1 \%$ & & 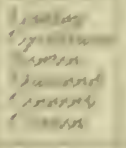 & 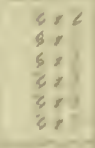 & if & 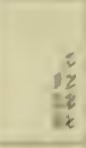 & $\begin{array}{l}6 \\
65 \\
6 \\
5\end{array}$ & $\begin{array}{l}0 \\
18 \\
6 \\
6\end{array}$ & 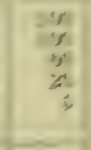 & is & 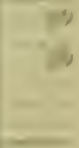 \\
\hline-4 & & 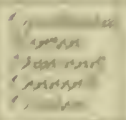 & 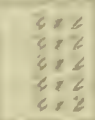 & $\frac{2}{4}$ & $\begin{array}{l}3 x \\
26 \\
2\end{array}$ & $\because s$ & wes & yis & & $=$ \\
\hline
\end{tabular}




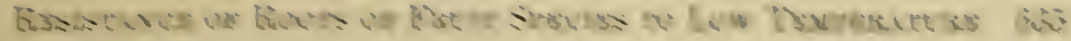
$+2$

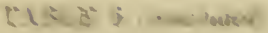

\begin{tabular}{|c|c|c|c|c|c|c|c|c|c|c|}
\hline \multirow{2}{*}{ 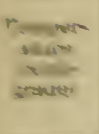 } & \multirow{2}{*}{ Dices $n$} & \multirow{2}{*}{ wivels } & \multirow{2}{*}{ 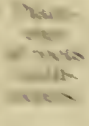 } & \multirow{2}{*}{ 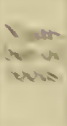 } & \multirow{2}{*}{ 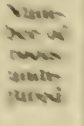 } & \multicolumn{5}{|c|}{ 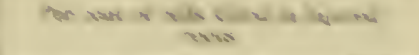 } \\
\hline & & & & & & hisen & $\operatorname{mal} x=$ & ( $3 x=x$ & rus & V reatua \\
\hline$--2+3^{*}$ & 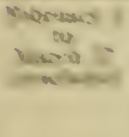 & 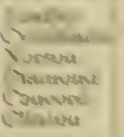 & 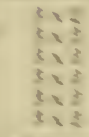 & $\therefore$ & $\frac{1}{8}$ & $\begin{array}{l}n \\
\text { un } \\
\text { in } \\
\text { in } \\
\text { wi }\end{array}$ & $\begin{array}{l}\text { int } \\
\text { in } \\
\text { un? } \\
i ? \\
n\end{array}$ & $\begin{array}{r}w \\
w \\
w \\
w \\
w\end{array}$ & at & 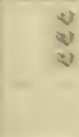 \\
\hline 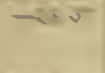 & & 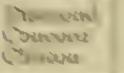 & 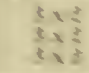 & $\frac{2}{3}$ & $\begin{array}{l}\text { iv } \\
\text { iv }\end{array}$ & 5 & $\begin{array}{l}\text { sin } \\
\text { su }\end{array}$ & $\begin{array}{l}x \\
x\end{array}$ & 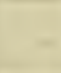 & \\
\hline$-i$ & & 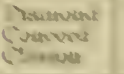 & 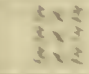 & $\frac{1}{2}$ & 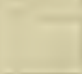 & $\begin{array}{l}y^{2} \\
14 \\
4 n\end{array}$ & $\begin{array}{l}\text { en } \\
\text { iv } \\
\text { iv }\end{array}$ & $\frac{w}{v}$ & 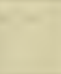 & $2 u$ \\
\hline- & 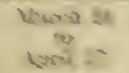 & 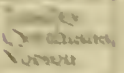 & $\begin{array}{l}5,2 \\
3 x \leq 2 \\
3 x\end{array}$ & 3 & $\frac{5}{5}$ & $2 u$ & $\begin{array}{l}2 v \\
\mid e v\end{array}$ & $\begin{array}{l}3 \\
-w\end{array}$ & & 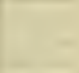 \\
\hline- & & 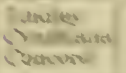 & 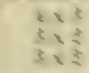 & s & $\frac{1}{3}$ & si & 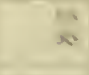 & ss & & \\
\hline-24 & & 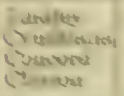 & $\begin{array}{l}3 x+2 \\
3 x \frac{2}{3} \\
x+2\end{array}$ & $\therefore$ & 3 & $\begin{array}{l}3 x \\
y \\
y\end{array}$ & $\begin{array}{l}\text { w } \\
\text { it } \\
y \\
y\end{array}$ & $\begin{array}{l}\text { n' } \\
\text { wiv } \\
\text { wu }\end{array}$ & 4 & $\checkmark$ \\
\hline-2 & & 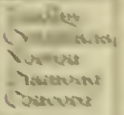 & 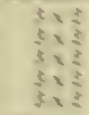 & $\frac{2}{2}$ & 8 & 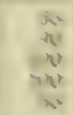 & 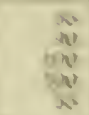 & $\begin{array}{l}n \\
n \\
n \\
n \\
n \\
n \\
n\end{array}$ & & \& \\
\hline$-i=$ & & 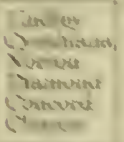 & 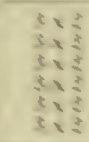 & $\frac{3 y}{31}$ & ? & 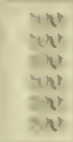 & 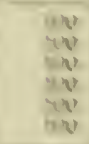 & 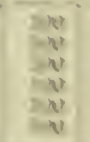 & $\begin{array}{l}\text { wr } \\
\text { nt } \\
\text { ar } \\
\text { in }\end{array}$ & $\therefore$ \\
\hline$-6=$ & & 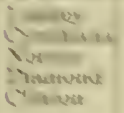 & 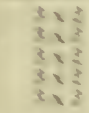 & $\frac{15}{3}$ & & $\begin{array}{l}y \\
y \\
y \\
y \\
y \\
y\end{array}$ & 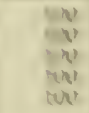 & 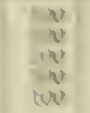 & 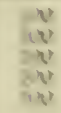 & $\begin{array}{l}3 \\
3\end{array}$ \\
\hline
\end{tabular}

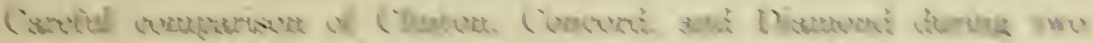

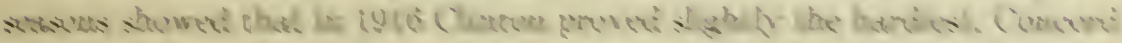

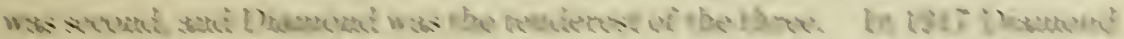

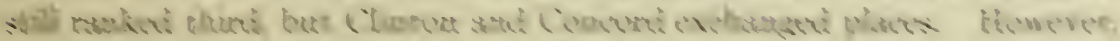

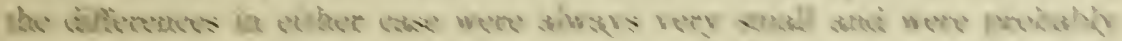

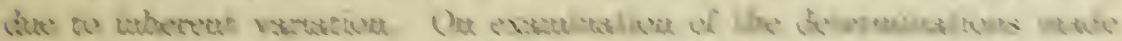

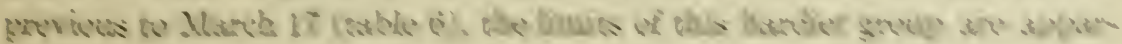


ent. Only seattering injury is recorded at $-11^{\circ},-12^{\circ}$, and $-13^{\circ} \mathrm{C}$. At an exposure of $-14.5^{\circ}$, twenty-two out of twenty-seven Concord roots were uninjured and only a trace of cambium and cortex injury was noted in the remainder. One-half of the Clinton and two-thirds of the Diamond roots were injured more than 50 per cent by the same temperature. At $-15.5^{\circ}$ an injury of 20 per cent is seen in one-third of the Concord roots and 15 per cent more in the other two varieties. At $-18^{\circ}$, however, the cambium, phloëm, and cortex tissues were completely injured in all roots, with some xylem injury in the Diamond and the Concord. By March 21 tenderness began to return, and a few days later these varieties were severely injured by temperatures several degrees higher.

A contrast of the root resistance in the varieties of the second class shows the following order of hardiness: Norton, Lindley, Cynthiana. The variations, however, are so slight that they may be entirely disregarded.

In 1917 Cynthiana was quite as resistant as Norton, as shown by the injury in both at the higher and lower temperatures. Lindley seemed to be a trifle easier to kill than either Cynthiana or Norton in 1916, but here again the differences are slight. The limits of this second group as shown in table 6 lie between $-10^{\circ}$ and $-12^{\circ} \mathrm{C}$., the roots usually undergoing considerable injury at $-11^{\circ}$. In relative hardiness this places these varieties between the Mazzard cherry and the apple.

The Clinton, Concord, and Diamond roots, even excluding the influence of size, are considerably more resistant than apple roots, and Concord and Clinton seem equal if not superior to the Mahaleb stock.

The results shown on comparing the hardiness of the respective species of grapes are somewhat as would be expected. Vitis aestivalis, represented by Norton and Cynthiana, is not adapted to severe cold, and this may account for the fact that its range is limited to the South. The tenderness of Lindley is probably due in part to the influence of Vitis vinifera, which, as is well known, will not survive the winter in the latitude of New York State without much protection. Concord and Diamond represent Vitis labrusca, the Northern Fox grape, which, while restricted in distribution, is found in Maine. Vitis vulpina, represented by Clinton - a variety with extremely resistant roots - has the greatest range of any American species of grape, it having been found in Canada north of Quebec. 
RESISTANCE OF BLACKBERRY, DEWBERRY, AND RED RASPBERRY ROOTS TO LOW TEMPERATURE

An attempt was made to test representative varieties of blackberries, dewberries, and red raspberries, in order to determine any varietal or specific differences in the hardiness of their roots. But, since many of the roots either were dead when received or blackened soon afterward, little variation among varieties is recorded. Only one-year plants were used. Since the one-year roots of the black raspberry are so small, and injury to them is difficult to detect, no data are given on this species.

Comparison of the resistance of the blackberry varieties recorded in table 7 shows the Eldorado to be apparently the least affected. The roots of the Early Harvest and the Watt show about equal tenderness.

TABLE 7. Effect of Low Temperature on the Roots of Blackberry, Dewberry, AND RED RASPBERRY

\begin{tabular}{|c|c|c|c|c|c|c|c|c|c|c|}
\hline \multirow{2}{*}{$\begin{array}{l}\text { Temper- } \\
\text { ature } \\
\text { (centi- } \\
\text { grade) }\end{array}$} & \multirow{2}{*}{$\begin{array}{l}\text { Date of } \\
\text { freezing }\end{array}$} & \multirow{2}{*}{ Variety } & \multirow{2}{*}{$\begin{array}{l}\text { Diam- } \\
\text { eter } \\
\text { of roots } \\
\text { (milli- } \\
\text { meters) }\end{array}$} & \multirow{2}{*}{$\begin{array}{l}\text { Num- } \\
\text { ber of } \\
\text { roots }\end{array}$} & \multirow{2}{*}{$\begin{array}{l}\text { Num- } \\
\text { ber of } \\
\text { roots } \\
\text { unin- } \\
\text { jured }\end{array}$} & \multicolumn{5}{|c|}{$\begin{array}{l}\text { Per cent of cells killed in injured } \\
\text { roots }\end{array}$} \\
\hline & & & & & & $\begin{array}{l}\text { Cam- } \\
\text { bium }\end{array}$ & Phloëm & Cortex & Pith & Xylem \\
\hline$-9^{\circ}$ & $\begin{array}{c}\text { March } 6 \\
\text { to } 20\end{array}$ & $\begin{array}{l}\text { Eldorado } \\
\text { Watt } \\
\text { Early } \\
\quad \text { Harvest } \\
\text { Lucretia } \\
\text { Austin }\end{array}$ & $\begin{array}{l}5 \times 4 \\
5 \times 4 \\
6 \times 5 \\
5 \times 4 \\
4 \times 3 \\
5 \times 4\end{array}$ & $\begin{array}{l}5 \\
5 \\
2 \\
3 \\
5 \\
5\end{array}$ & 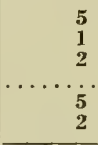 & $\begin{array}{r}\cdots \\
\cdots 0 \\
\cdots \\
45 \\
\cdots \\
85\end{array}$ & 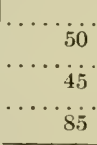 & $\begin{array}{l}\cdots \\
50 \\
\cdots \\
45 \\
\cdots_{85}\end{array}$ & $\begin{array}{l}\ldots \ldots \\
\cdots \cdots \\
\cdots \\
\cdots \\
\cdots \\
\cdots\end{array}$ & $\begin{array}{l}\ldots \ldots \\
\cdots \cdots \\
\cdots \cdots \\
\cdots \cdots \\
\cdots \cdots \\
\cdots \cdots\end{array}$ \\
\hline$-10^{\circ}$ & & $\begin{array}{l}\text { Eldorado } \\
\text { Watt } \\
\text { Early } \\
\quad \text { Harvest } \\
\text { Lucretia } \\
\text { Austin }\end{array}$ & $\begin{array}{l}3 \times 2 \\
3 \times 2 \\
3 \times 2 \\
3 \times 2 \\
3 \times 2\end{array}$ & $\begin{array}{r}10 \\
7 \\
\\
11 \\
10 \\
10\end{array}$ & $\begin{array}{r}10 \\
\ldots \ldots \\
9 \\
9 \\
9\end{array}$ & $\begin{array}{l}\cdots 6 \\
50 \\
25 \\
25\end{array}$ & $\begin{array}{r}\cdots 0 \\
\\
50 \\
25 \\
25\end{array}$ & $\begin{array}{r}60 \\
50 \\
25 \\
25\end{array}$ & $\begin{array}{r}\ldots \\
40 \\
50 \\
\ldots \ldots \\
\cdots \cdots\end{array}$ & $\begin{array}{l}\ldots \ldots \\
\cdots \\
\cdots \\
\cdots \cdots\end{array}$ \\
\hline$-11^{\circ}$ & & $\begin{array}{l}\text { Eldorado } \\
\text { Watt } \\
\text { Early } \\
\text { Harvest } \\
\text { Lucretia }\end{array}$ & $\begin{array}{l}5 \times 4 \\
5 \times 4 \\
5 \times 4 \\
5 \times 4 \\
3 \times 2\end{array}$ & $\begin{array}{l}6 \\
7 \\
\\
6 \\
5 \\
8\end{array}$ & $\begin{array}{l}4 \\
5 \\
\\
5 \\
4 \\
3\end{array}$ & $\begin{array}{r}15 \\
100 \\
\\
100 \\
50 \\
100\end{array}$ & $\begin{array}{r}15 \\
100 \\
100 \\
50 \\
100\end{array}$ & $\begin{array}{r}15 \\
100 \\
\\
100 \\
50 \\
100\end{array}$ & $\begin{array}{c}\cdots \\
50 \\
\cdots \\
\cdots \\
\cdots\end{array}$ & $\begin{array}{l}\cdots \cdots \\
\ldots \ldots \\
\cdots \cdots \\
\cdots \cdots \\
\cdots \cdots\end{array}$ \\
\hline$-12^{\circ}$ & - & $\begin{array}{l}\text { Eldorado } \\
\text { Watt } \\
\text { Early } \\
\quad \text { Harvest } \\
\text { Lucretia } \\
\text { Cuthbert }\end{array}$ & $\begin{array}{l}6 \times 5 \\
6 \times 5 \\
5 \times 5 \\
5 \times 4 \\
4 \times 4\end{array}$ & $\begin{array}{r}12 \\
10 \\
\\
5 \\
8 \\
6\end{array}$ & $\begin{array}{c}\cdots \cdots \\
\ldots \ldots \\
\ldots \\
\ldots\end{array}$ & $\begin{array}{r}100 \\
100 \\
\\
100 \\
75 \\
100\end{array}$ & $\begin{array}{r}100 \\
100 \\
\\
100 \\
75 \\
100\end{array}$ & $\begin{array}{r}100 \\
100 \\
\\
100 \\
75 \\
100\end{array}$ & $\begin{array}{r}20 \\
20 \\
35 \\
\cdots 100\end{array}$ & \begin{tabular}{l}
\multicolumn{2}{|}{} \\
$\cdots \ldots$ \\
$\cdots \cdots$ \\
$\cdots \cdots$
\end{tabular} \\
\hline$-7^{\circ}$ & $\begin{array}{c}\text { March } 23 \\
\text { to } \\
\text { April } 17\end{array}$ & $\begin{array}{l}\text { Eldorado } \\
\text { Watt } \\
\text { Early } \\
\quad \text { Harvest } \\
\text { Lucretia } \\
\text { Austin }\end{array}$ & $\begin{array}{l}6 \times 5 \\
3 \times 2 \\
3 \times 2 \\
3 \times 2 \\
2 \times 1 \\
2 \times 1\end{array}$ & $\begin{array}{r}2 \\
11 \\
7 \\
7 \\
17 \\
11\end{array}$ & $\begin{array}{r}1 \\
11 \\
7 \\
7 \\
15 \\
11\end{array}$ & & & $\begin{array}{l}\cdots \cdots \\
\cdots \cdots \\
\cdots \cdots \\
\cdots \\
{ }_{25}\end{array}$ & $\begin{array}{r}\quad \\
\ldots \ldots \\
\cdots \\
\ldots \\
\ldots \ldots\end{array}$ & $\begin{array}{l}\ldots \ldots \\
\cdots \\
\cdots \\
\cdots\end{array}$ \\
\hline
\end{tabular}


TABLE 7 (concluded)

\begin{tabular}{|c|c|c|c|c|c|c|c|c|c|c|}
\hline \multirow{2}{*}{$\begin{array}{c}\text { Temper- } \\
\text { ature } \\
\text { (centi- } \\
\text { grade) }\end{array}$} & \multirow{2}{*}{$\begin{array}{l}\text { Date of } \\
\text { freezing }\end{array}$} & \multirow{2}{*}{ Variety } & \multirow{2}{*}{$\begin{array}{l}\text { Diam- } \\
\text { eter } \\
\text { of roots } \\
\text { (milli- } \\
\text { meters) }\end{array}$} & \multirow{2}{*}{$\begin{array}{l}\text { Num- } \\
\text { ber of } \\
\text { roots }\end{array}$} & \multirow{2}{*}{$\begin{array}{l}\text { Num - } \\
\text { ber of } \\
\text { roots } \\
\text { unill- } \\
\text { jured }\end{array}$} & \multicolumn{5}{|c|}{$\begin{array}{c}\text { Per cent of cells killed in injured } \\
\text { roots }\end{array}$} \\
\hline & & & & & & $\begin{array}{l}\text { Cam- } \\
\text { bium }\end{array}$ & Phloz̈m & Cortex & Pith & Xylem \\
\hline$($ conc.) & $\begin{array}{c}\text { March } 23 \\
\text { to } \\
\text { April 17 } \\
\text { (concluded) }\end{array}$ & $\begin{array}{l}\text { Cuthbert } \\
\text { Perfection } \\
\text { Loudon }\end{array}$ & $\begin{array}{l}4 \times 3 \\
3 \times 2 \\
4 \times 3 \\
3 \times 2 \\
\end{array}$ & $\begin{array}{r}6 \\
10 \\
5 \\
4 \\
\end{array}$ & $\begin{array}{c}6 \\
4 \\
4 \\
2\end{array}$ & & & $\begin{array}{r}\cdots \cdots \\
10 \\
25 \\
\end{array}$ & & $\begin{array}{l}\ldots \ldots \\
\cdots \cdots \\
\cdots \cdots \\
\cdots \cdots \\
\end{array}$ \\
\hline$-8^{\circ}$ & . & $\begin{array}{l}\text { Eldorado } \\
\text { Watt } \\
\text { Early } \\
\quad \text { Harvest } \\
\text { Lucretia } \\
\text { Cuthbert } \\
\text { Perfection } \\
\text { Loudon }\end{array}$ & $\begin{array}{l}7 \times 2 \\
3 \times 2 \\
3 \times 2 \\
3 \times 2 \\
5 \times 5 \\
3 \times 2 \\
7 \times 5 \\
3 \times 2 \\
5 \times 3 \\
6 \times 4 \\
4 \times 2 \\
\end{array}$ & $\begin{array}{r}4 \\
7 \\
6 \\
6 \\
3 \\
20 \\
3 \\
3 \\
5 \\
4 \\
4 \\
4\end{array}$ & $\begin{array}{r}4 \\
7 \\
6 \\
3 \\
3 \\
14 \\
3 \\
\cdots 3 \\
3 \\
4 \\
\ldots .\end{array}$ & 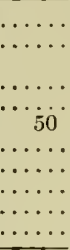 & 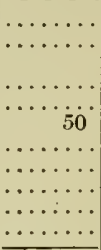 & $\begin{array}{r}\cdots \\
\cdots \\
\cdots 100 \\
100 \\
100 \\
\cdots \\
50 \\
\end{array}$ & & 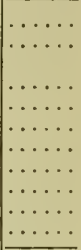 \\
\hline$-9^{\circ}$ & & $\begin{array}{l}\text { Eldorado } \\
\text { Lucretia } \\
\text { Cuthbert } \\
\text { Perfection }\end{array}$ & $\begin{array}{l}8 \times 8 \\
5 \times 5 \\
4 \times 3 \\
3 \times 2 \\
5 \times 5 \\
3 \times 2 \\
3 \times 2 \\
\end{array}$ & $\begin{array}{r}3 \\
8 \\
10 \\
4 \\
4 \\
3 \\
4 \\
\end{array}$ & \begin{tabular}{c}
1 \\
$\dddot{9}$ \\
$\mathbf{2}$ \\
$\mathbf{2}$ \\
\hdashline \\
3
\end{tabular} & $\begin{array}{r}70 \\
60 \\
25 \\
20 \\
100 \\
\cdots 90 \\
\end{array}$ & $\begin{array}{r}20 \\
60 \\
25 \\
20 \\
100 \\
+90 \\
\end{array}$ & $\begin{array}{r}20 \\
60 \\
25 \\
20 \\
100 \\
100 \\
90 \\
\end{array}$ & $\begin{array}{r}50 \\
30 \\
\ldots \ldots \ldots \\
\cdots \cdots \\
\cdots \cdots \\
\cdots \cdots \\
\end{array}$ & $\begin{array}{l}\cdots \cdots \\
35 \\
\cdots \cdots \\
\cdots \cdots \\
\cdots \cdots \cdots \\
\cdots \cdots \\
\end{array}$ \\
\hline$-10^{\circ}$ & & $\begin{array}{l}\text { Eldorado } \\
\text { Lucretia } \\
\text { Cuthbert } \\
\text { Perfection }\end{array}$ & $\begin{array}{l}6 \times 5 \\
3 \times 2 \\
5 \times 4 \\
3 \times 2\end{array}$ & $\begin{array}{r}9 \\
8 \\
6 \\
10\end{array}$ & $\begin{array}{c}\mathbf{1} \\
\mathbf{2} \\
\cdots \\
\cdots\end{array}$ & $\begin{array}{r}95 \\
55 \\
100 \\
100\end{array}$ & $\begin{array}{r}100 \\
55 \\
100 \\
100\end{array}$ & $\begin{array}{r}95 \\
55 \\
100 \\
100\end{array}$ & $\begin{array}{c}100 \\
\ldots \ldots \ldots \\
\cdots \cdots \\
\cdots \cdots\end{array}$ & $\begin{array}{r}\quad 60 \\
\cdots \cdots \cdots \\
\cdots \cdots \\
\end{array}$ \\
\hline$-11^{\circ}$ & & $\begin{array}{l}\text { Eldorado } \\
\text { Watt } \\
\text { Lucretia } \\
\text { Cuthbert } \\
\text { Perfection }\end{array}$ & $\begin{array}{l}6 \times 5 \\
7 \times 2 \\
5 \times 4 \\
5 \times 4 \\
5 \times 3 \\
5 \times 4\end{array}$ & $\begin{array}{r}10 \\
2 \\
3 \\
6 \\
9 \\
7\end{array}$ & $\begin{array}{l}\cdots \cdots \cdots \\
\cdots \cdots \cdots \\
\cdots \cdots \cdots\end{array}$ & $\begin{array}{r}100 \\
75 \\
100 \\
90 \\
100 \\
100\end{array}$ & $\begin{array}{r}100 \\
75 \\
100 \\
90 \\
100 \\
100 \\
\end{array}$ & $\begin{array}{r}100 \\
75 \\
100 \\
90 \\
100 \\
100 \\
\end{array}$ & $\begin{array}{r}50 \\
60 \\
100 \\
75 \\
\ldots .\end{array}$ & 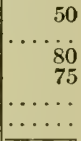 \\
\hline$-12^{\circ}$ & & Eldorado & $5 \times 4$ & 5 & & 100 & 100 & 100 & 100 & 100 \\
\hline
\end{tabular}

At an exposure of $-9^{\circ} \mathrm{C}$., three roots out of five of the Austin dewberry were killed while the Lucretia was unhurt. In practically all comparable freezings, the Lucretia seems a trifle hardier than the Eldorado blackberry, but the margin of difference is small.

A comparison of the red raspberry varieties indicates the advantage of the Cuthbert root over the Perfection. The number of Loudon roots tested was not sufficient to permit comparison. Contrast of the relative resistance of Cuthbert as compared with Lucretia suggests the superior hardiness of the latter, while Cuthbert has the approximate killing point of the Eldorado blackberry. 
It is seen from the results given in table 7 that none of this Material survived a temperature of $-12^{\circ} \mathrm{C}$. However, many of the larger roots tested at $-11^{\circ}$ previous to March 20 were uninjured. Their relative hardiness, therefore, would place these varieties in the group with the Myrobalan plum and the Mazzard cherry.

RESISTANCE OF GOOSEBERRY AND CURRANT ROOTS TO LOW TEMPERATURE

The study of the freezing point of gooseberry and currant roots offered more difficulty than any other determinations undertaken. During the winter of 1915-16 a large amount of currant and gooseberry material was tested; in fact, in nearly every freezing a few roots of these species were included. Upon examination for injury no appreciable change could be observed within the usual time limit. At the end of a still longer period between the testing and the examination, no features were exhibited that the unfrozen roots did not possess. Owing to the pink or reddish pigment found in the cells of the cortex, these cells were examined for injury under the microscope. At $-15^{\circ}$ C. no discoloration suggesting injury was noted.

It was accordingly decided to repeat the experiment with the gooseberry and the currant roots in a somewhat different way. The varieties were restricted to the Downing gooseberry and the Wilder currant. In this test, whole two-year plants were root-pruned to about four inches and the tops were cut back to four or five branches with three buds left on each. The plants thus treated were then placed in the freezing chamber. At the same time four-inch pieces of root for microscopic examination were tested. After each determination the plants were immediately placed in moist sawdust in common storage, where they were allowed to remain until May 10. On that date they were planted out in the field.

Observations on these plants were taken on June 16, and record was made of the growth that had taken place up to that time. On August 4 , the observations were repeated, and it was found that no growth had taken place in any of the specimens recorded as dead in June. These data serve as criteria for the amount of injury that the roots experienced. It is clear that this method is less exact than the previous manner of determining injury by direct observation. It is not possible, for example, to state the size of root affected, or the tissues and the amount of roots 
killed, except as these facts are expressed by the relative top growth. Still this test, supplemented by the microscopic observations, should suggest the approximate and comparative resistance of the two species.

\section{Table 8. Effect of Low Temperature on Gooseberry and Currant Roots} (April 3-11, 1917)

\begin{tabular}{|c|c|c|c|c|c|c|}
\hline $\begin{array}{l}\text { Temper- } \\
\text { ature } \\
\text { (centi- } \\
\text { grade) }\end{array}$ & $\begin{array}{l}\text { Serial } \\
\text { num- } \\
\text { ber }\end{array}$ & Variety & $\begin{array}{l}\text { Num- } \\
\text { ber of } \\
\text { roots }\end{array}$ & $\begin{array}{l}\text { Depth } \\
\text { in soil } \\
\text { (inches) }\end{array}$ & $\begin{array}{l}\text { Diameter } \\
\text { of roots } \\
\text { (milli- } \\
\text { meters) }\end{array}$ & Results \\
\hline \multirow[t]{6}{*}{$-19^{\circ}$} & 1 & Wilder..... & 10 & $6-8$ & $1-6$ & $\begin{array}{l}5 \text { small leaves present; most of stem } \\
\text { seemed alive, but growth seriously if } \\
\text { not fatally delayed }\end{array}$ \\
\hline & 2 & Wilder.... & 9 & $8-10$ & $2-6$ & $\begin{array}{l}1 \text { small yellow leaf appeared; most of } \\
\text { stem tissues brown }\end{array}$ \\
\hline & 3 & Wilder. . & 12 & $6-10$ & $2-6$ & $\begin{array}{l}\text { No leaves present; stem seemed entirely } \\
\text { dead thruout }\end{array}$ \\
\hline & 4 & Downing. . & 13 & $8-10$ & $1-6$ & $\begin{array}{l}10 \text { or more small green leaves present; } \\
\text { stem tissues seemed active }\end{array}$ \\
\hline & 5 & Wilder. & 9 & $4-8$ & $3-6$ & $\begin{array}{l}\text { Sections examined, } 6 \mathrm{~mm} \text {. and } 3 \mathrm{~mm} \text {. } \\
\text { Less than } 5 \text { per cent of cortex cells } \\
\text { appeared brown }\end{array}$ \\
\hline & 6 & Downing... & 8 & $4-8$ & $3-6$ & $\begin{array}{l}\text { Sections examined, } 5 \mathrm{~mm} \text {. and } 3 \mathrm{~mm} \text {. } \\
\text { Small root scemed the less affected, } \\
\text { but } 50 \text { per ent of cortex appeared } \\
\text { injured in each }\end{array}$ \\
\hline \multirow[t]{3}{*}{$-20.5^{\circ}$} & 7 & Downing. . & 6 & $4-8$ & $3-6$ & $\begin{array}{l}\text { Sections examined, } 6 \mathrm{~mm} \text {. and } 3 \mathrm{~mm} \text {. } \\
\text { No cambium injury; at least } 50 \text { per } \\
\text { cent of cortex cells appeared injured, } \\
\text { with a brownish yellow color }\end{array}$ \\
\hline & 8 & Downing. . & 9 & $5-8$ & $1-6$ & $\begin{array}{l}\text { S small leaves had developed; slightly } \\
\text { more injury than in no. } 4\end{array}$ \\
\hline & 9 & Downing. . & 9 & $6-8$ & $1-5$ & $\begin{array}{l}\text { No leaves present; buds and stem } \\
\text { seemed entirely dead }\end{array}$ \\
\hline \multirow[t]{3}{*}{$-18^{\circ}$} & 10 & Wilder.... & 8 & 8 & $1-6$ & $\begin{array}{l}\text { No leaves present; entire top dead as in } \\
\text { no. } 9\end{array}$ \\
\hline & 11 & Wilder.... & 7 & 8 & $1-6$ & Same condition of top as in no. 9 \\
\hline & 12 & Wilder.... & 8 & 8 & $2-6$ & Same condition of top as in no. 9 \\
\hline$-19^{\circ}$ & 13 & Wilder..... & 5 & $4-8$ & $3-6$ & $\begin{array}{l}\text { Sections examined, } 5 \mathrm{~mm} \text {. and } 3 \mathrm{~mm} \text {. } \\
\text { Injury less severe than in no. } 7 \\
\text { Downing, but on one side of cortex } \\
50 \text { per cent of cells killed, on the other } \\
\text { side } 30 \text { per cent injured } \\
\end{array}$ \\
\hline \multirow[t]{3}{*}{$-17^{\circ}$} & 14 & Downing... & 12 & 10 & $1-6$ & $\begin{array}{l}40 \text { or more medium-sized green leaves } \\
\text { had developed; more vigorous top } \\
\text { than any of preceding }\end{array}$ \\
\hline & 15 & Downing. . & 15 & 8 & $1-6$ & $\begin{array}{l}\text { A few less leaves than in no } 14 \text {, but } \\
\text { all stem tissues active }\end{array}$ \\
\hline & 16 & Downing.... & 15 & 8 & $2-6$ & $\begin{array}{l}\text { Practically the same conditions as in } \\
\text { no. } 15\end{array}$ \\
\hline
\end{tabular}


TABLE S (concluded)

\begin{tabular}{|c|c|c|c|c|c|c|}
\hline $\begin{array}{l}\text { Temper- } \\
\text { ature } \\
\text { (centi- } \\
\text { grade) }\end{array}$ & $\begin{array}{l}\text { Serial } \\
\text { num- } \\
\text { ber }\end{array}$ & Variety & $\begin{array}{l}\text { Num- } \\
\text { ber of } \\
\text { roots }\end{array}$ & $\begin{array}{l}\text { Depth } \\
\text { in soil } \\
\text { (inches) }\end{array}$ & $\begin{array}{l}\text { Diameter } \\
\text { of roots } \\
\text { (milli- } \\
\text { meters) }\end{array}$ & Results \\
\hline \multirow[t]{4}{*}{$-17^{\circ}$} & 17 & Downing. & 9 & $4-8$ & $1-5$ & $\begin{array}{l}\text { Sections examined, } 5 \mathrm{~mm} \text {. and } 3 \mathrm{~mm} \text {. } \\
\text { In small root } 25 \text { per cent of cortex } \\
\text { cells were of a characteristie yellow } \\
\text { color; large root appeared with } 35-40 \\
\text { per cent injury }\end{array}$ \\
\hline & 18 & Wilder. & 10 & $8-10$ & $2-6$ & $\begin{array}{l}\text { Not a leaf present; bud and stem dead } \\
\text { thruout }\end{array}$ \\
\hline & 19 & Wilder. & 6 & 10 & $1-6$ & Complete injury to top as in no. 18 \\
\hline & 20 & Wilder. & 9 & $6-8$ & $2-5$ & $\begin{array}{l}\text { Sections examined, } 5 \mathrm{~mm} \text {. and } 3 \mathrm{~mm} \text {. } \\
85 \text { per cent of cambium, phloëm, and } \\
\text { cortex seemed browned in both large } \\
\text { and small root; severest injury thus } \\
\text { far observed }\end{array}$ \\
\hline \multirow[t]{6}{*}{$-18.5^{\circ}$} & 21 & Downing. & 12 & 10 & $1-6$ & $\begin{array}{l}15 \text { or more small green leaves present; } \\
\text { stem tissues scemed active }\end{array}$ \\
\hline & 22 & Downing... & 15 & 8 & $1-6$ & $\begin{array}{l}\text { No leaves developed; buds and stem } \\
\text { entirely brown }\end{array}$ \\
\hline & 23 & Downing... & 9 & $4-8$ & $2-5$ & $\begin{array}{l}\text { Not more than } 10 \text { per cent of injury } \\
\text { in cortex, with no browning in cam- } \\
\text { bium or phloëm cells }\end{array}$ \\
\hline & 24 & Wilder.... & 10 & 10 & $1-5$ & $\begin{array}{l}\text { No leaves present; top still had con- } \\
\text { siderable live tissue }\end{array}$ \\
\hline & 25 & Wilder... & 10 & 8 & $1-6$ & $\begin{array}{l}\text { No leaves developed; buds and stem } \\
\text { entirely dead }\end{array}$ \\
\hline & 26 & Wilder.... & 8 & $4-3$ & $2-5$ & $\begin{array}{l}\text { Only } 5 \text { per cent of eortex cells seemed } \\
\text { injured, witi no browning in other } \\
\text { tissues }\end{array}$ \\
\hline \multirow[t]{5}{*}{$-18^{\circ}$} & 27 & Wilder. . & 18 & $4-8$ & $1-6$ & $\begin{array}{l}12 \text { leaves present, ranging in size froin } \\
1 \text { to } 4 \mathrm{~cm} \text {. wide }\end{array}$ \\
\hline & 28 & Wilder. & 14 & 8 & $2-6$ & $\begin{array}{l}\text { No leaves developed; whole top eom- } \\
\text { pletely dead }\end{array}$ \\
\hline & 29 & Wilder... & 15 & 8 & ${ }^{2-5}$ & $\begin{array}{l}\text { No leaves present; small amount of live } \\
\text { cortex and phloëm appeared in one } \\
\text { stem }\end{array}$ \\
\hline & 30 & Downing. . & 7 & $4-8$ & $2-6$ & $\begin{array}{l}25 \text { or more medium-sized leaves; all } \\
\text { stem tissues active }\end{array}$ \\
\hline & 31 & Downing. . & 11 & $6-9$ & $1-6$ & $\begin{array}{l}\text { A few less leaves present than in no. } 30 \text {; } \\
\text { otherwise the same }\end{array}$ \\
\hline \multirow[t]{4}{*}{$-16.5^{\circ}$} & 32 & Wilder. . & 9 & $4-8$ & $1-5$ & $\begin{array}{l}\text { No leaves developed; top appeared dead } \\
\text { thruout }\end{array}$ \\
\hline & 33 & Wilder.... & 13 & $6-12$ & $1-6$ & $\begin{array}{l}\text { No leaves developed; considerable active } \\
\text { stem tissue }\end{array}$ \\
\hline & 34 & Downing. & 11 & $4-8$ & $1-6$ & $\begin{array}{l}8 \text { leaves present; all stem tissues seemed } \\
\text { alive }\end{array}$ \\
\hline & 35 & Downing. & 15 & $4-8$ & $1-6$ & $\begin{array}{l}12 \text { leaves present; no dead tissue in } \\
\text { the top }\end{array}$ \\
\hline
\end{tabular}


From an examination of numbers $1,2,3$, and 4 in table 8 , the gooseberry seems slightly hardier than the currant. The microscopic examination of numbers 5 and 6 , however, are not in accord with the field test. While the roots sectioned were kept for four days under the bell jar before examination, it is possible that the currant, at least in this case, may offer another instance of delayed death after freezing.

In the next test no currants were included. One Downing survived a temperature of $-20.5^{\circ} \mathrm{C}$. but, since one was killed completely, this minimum would probably be near the limit of the gooseberry's hardiness at this season. However, microscopic observations showed no more cell injury than in material exposed to $-19^{\circ}$.

In numbers 10 to 20 , considerable evidence is presented to show a greater resistance in the gooseberry root than in the currant. The microscopic examination also bears this out. Further examination of the data from numbers 27 to 35 gives additional proof of the gooseberry's superior hardiness. But in the last determination the increase in tenderness of the gooseberry is noticeable.

One point especially to be remembered in regard to this table is the date of freezing. On comparing the killing temperature of all of the roots in the other species considered, the relative resistance of the currant and the gooseberry, particularly the latter, is very obvious. These differences represent a range of from five to ten centigrade degrees below the killing temperature of the other roots.

\section{SAP CONCENTRATION OF AMERICAN AND FRENCH APPLE SEEDLINGS AND WILDER CURRANT AS MEASURED BY THE FREEZING-POINT DEPRESSION}

It was thought possible that the wide variation in hardiness shown by the roots in the preceding experiments might be due in part to differences in the concentration of the cell sap. Consequently an effort was made to ascertain the sap concentration of the various species. Unfortunately, however, in many cases the sap was found to be very difficult to obtain. In the red raspberry, the dewberry, and the grape, respectively, the sap tissue from the roots of twenty-five plants when expressed yielded less than a cubic centimeter of sap. In other cases sufficient material was not available for this determination. 
In the few instances reported in table 9 , the roots used for each determination were first entirely killed by freezing. The concentration was determined by means of a Beckmann freezing-point apparatus, and the results, expressed as freezing-point depression, are given in table 9:

Table 9. Sap Concentration in the Roots of American and French Apple Seedlings and Wilder Currant as Measured by the Freezing-Point Depression

\begin{tabular}{|c|c|c|}
\hline Date & Variety & Depression \\
\hline April 25. & American apple roots, upper half . . . . . . . . . . & 2.487 \\
\hline April $25 \ldots \ldots \ldots$ & American apple roots, lower half. & 2.214 \\
\hline May $12 \ldots \ldots \ldots$. & Wilder currant roots. . . . . . . . . . . . . . & 2.685 \\
\hline May 12 . & One-year French apple roots stored one year....... & 2.461 \\
\hline May 12. & Two-year French apple roots... & 1.988 \\
\hline
\end{tabular}

The data in table 9 show a considerable difference in depression between the sap of the one- and the two-year-old French apple roots. Indeed, these differences indicate a wider variation than actually existed. The sap concentration of the two parts of the American apple root may partly explain the fact that the upper half of this root usually suffered less injury than did the lower half at the same temperature. . A difference in depression of 0.273 should certainly be of some significance. The root of the Wilder currant proved to have the highest concentration of sap of any of the roots tested. It is indeed, the hardiest of these roots. While this superior sap concentration is not without meaning, it probably does not wholly explain the exceptional resistance of this variety to low temperature.

\section{EFFECT OF RAPID TEMPERATURE FALL ON THE FREEZING OF APPLE ROOTS}

Pfeffer (1903:235) stated that " resistant plants withstand rapid and slow cooling equally well, and it is doubtful whether a rapid fall of temperature is more injurious to plants killed by freezing than is gradual cooling." Winkler (1913), however, working with Pfeffer, found that various buds endure a much lower temperature when the fall is very slow.

Chandler (1913), testing many kinds of fruit buds and twigs, found the rate of freezing to be an important factor in the killing temperature. 
He observed further that the injury by quick cooling seemed more serious when the rapid fall took place in the early part of the freezing period. The latter observation is in accord with Müller-Thurgau's (1880 and 1886) determinations from which he calculated the size and the time of formation of ice masses in the apple and the potato.

Mix (1916) found that tissue from the trunks of apples killed at a temperature several degrees higher when rapidly frozen than when frozen more slowly.

Some data were procured in this study with a view of determining just how great a difference in injury there would be between roots cooled rapidly and those cooled slowly. An attempt was made also to find out whether the severer injury came during the early or the late period of freezing.

In one freezing the temperature of the air surrounding a large number of roots, all but a few of which were American-grown apple seedlings, was lowered from $1.5^{\circ}$ to $-4^{\circ} \mathrm{C}$. in one hour and forty minutes, and from $-4^{\circ}$ to $-8^{\circ}$ in twenty minutes, when the roots were removed. In another freezing the temperature with the same kind of roots was lowered from $1.5^{\circ}$ to $-4^{\circ}$ in twenty minutes, and from $-4^{\circ}$ to $-8^{\circ}$ in one hour and twenty-five minutes, when the roots were removed. It is difficult to draw conclusions from but one freezing of each kind, and therefore the data are not included. In the second freezing in which the rapid temperature fall was at the beginning - that is, from $1.5^{\circ}$ to $-4^{\circ} \mathrm{C}$. - the killing was slightly the worse, tho a few French seedlings included were not killed as badly as in the first freezing.

Of course it should be borne in mind that the roots in the second freezing probably reached a lower temperature than did those in the first. It is doubtful whether the roots themselves actually reached the temperature of $-8^{\circ} \mathrm{C}$. in twenty minutes. The results suggest that there is little difference in the effect on the killing temperature, whether the rapid temperature fall is near the point where freezing begins or nearer the point of the killing temperature. Many more freezings would be necessary, however, before conclusive results could be reached.

Another set of three freezings was made in order to learn the effect of rapid temperature fall on the amount of injury done. In one freezing an attempt was made to approach what would be a normal temperature fall, the temperature falling from $1.5^{\circ}$ to $-8^{\circ} \mathrm{C}$. in three hours and ten minutes. 
In the second freezing the temperature fell from $1.5^{\circ}$ to $-8^{\circ}$ in fortyfive minutes, when the roots were removed. In the third freezing the temperature fell from $1.5^{\circ}$ to $-8^{\circ}$ in fifteen minutes, and the roots were held at that temperature for one hour. It is of course probable that in the second freezing, in which the roots were removed at once when the temperature of the surrounding air had reached $-8^{\circ} \mathrm{C}$., the tissue of the roots never reached that temperature. The injury was certainly the least with the slow temperature fall; it was somewhat greater in the second freezing, in which the roots were removed at once; and it was markedly greater in the third freezing, in which, after the temperature had fallen to $-8^{\circ}$ in fifteen minutes, the roots were held at that temperature for one hour. Thus, with the slow temperature fall, of twelve pieces of American roots seven had no injury, one had 15 per cent of the cambium browned, three had from 30 to 35 per cent of the cambium browned, and one had from 50 to 80 per cent of the cambium browned; in the second freezing, in which the roots were removed immediately after the temperature had reached $-8^{\circ} \mathrm{C}$. in forty-five minutes, of fourteen pieces of Americangrown apple roots five were uninjured, one was very slightly injured, three had from 10 to 20 per cent of the cambium browned, with slight injury to the phloëm and the cortex, one had 25 per cent of injury in these tissues, three had from 50 to 75 per cent of injury, and one was apparently killed thruout; in the case of the third freezing, in which the roots were held at $-8^{\circ}$ C. for one hour after the surrounding air had dropped to that temperature in fifteen minutes, of nineteen pieces of American-grown apple roots seven showed from 25 to 60 per cent of cambium injury and the remainder showed more injury than that, three being killed practically thruout. Comparing these last two freezings with the slow freezing, it is plain that the rapid temperature fall was the most injurious. In all of these freezings careful records were kept as to the resistance of roots near the surface and of those that had grown deeper in the soil, and roots of the same size showed approximately equal resistance regardless of the soil depth from which they came.

\section{EFFECT OF RATE OF THAWING ON THE FREEZING OF ROOTS}

Göppert (1830) concluded, after many experiments, that the rate of thawing had nothing to do with the subsequent injury caused by cold. This view was contrary to the popular belief of his time. Sachs (1860) 
stated that "the same tissue which, after exposure to freezing temperature, with slower thawing remained alive unhurt, becomes disorganized when with similar freezing it is thawed rapidly." 3 Müller-Thurgau (1886) pointed out that Sachs' method of placing his tissues in cold water to thaw them was really a case of rapid thawing, since a layer of ice formed about the tissues, thus releasing considerable heat. Müller-Thurgau, using many plants and plant parts, found that the ripe fruits of the pear and the apple, and the leaves of Agave americana L., were injured somewhat less when slow thawing was practiced. Molisch (1897) confirmed these results of Müller-Thurgau. Chandler (1913), in his experiments, also found that when the temperature did not go too low, slow thawing reduced the injury to ripe apple and pear fruits and to lettuce leaves; the rate of thawing did not influence the amount of injury to the many other tissues studied.

In this work several experiments were conducted to determine the influence of slow and of rapid thawing on most of the root species used. After being lowered to the killing temperature the material was divided into four comparable lots. It was then thawed at the following temperatures: slightly below freezing but gradually rising; at $0^{\circ} \mathrm{C}$.; at $8^{\circ} \mathrm{C}$. in the basement storage; and at $22^{\circ} \mathrm{C}$. in the laboratory. After a number of hours all the lots were placed under a bell jar at room temperature. Slight differences were noted, but these were confined to very narrow limits and seemed to result from an inherent tendency to vary rather than to be due io any particular set of thawing conditions. When summarized the variations practically canceled themselves and no specific effect could be attributed to the rate of thawing.

\section{INJURY TO APPLE ROOTS WHEN FROZEN IN SOIL, IN WATER, AND IN PARAFFIN}

Some determinations were made in which American-grown apple roots were placed in the freezing chamber and completely surrounded by a garden loam soil. In one case the soil was well dried by exposure to warm air. In another case enough water was added to the loam to make it rather muddy. A third soil contained a normal amount of moisture. Twenty-five roots were used in each treatment, and, except in the case of the muddy soil, an effort was made to pack the earth about the roots. In a fourth determination water was substituted for the soil. The water

3 Translation from the original German. 
came well above the top of the material. When the thermometer and the roots were removed after the freezing period, the water was frozen into a solid block of ice about them.

The conditions of these determinations seem too artificial to justify the presentation of tables, but the results may be briefly stated. On comparing the influence of the different soils with a normal air determination, it was found that the roots frozen in air-dried loam were very nearly as resistant to cold as were those frozen in the air. The roots treated in muddy and normal soil seemed slightly easier to injure than those tested in the air or in the air-dried loam. However, these differences were hardly large enough to be dependable, especially when the natural tendency of the species to vary is considered. The material surrounded by water manifested no constant behavior different from that of the other roots.

Since it was believed that the freezing might not be uniform in such a large volume of water, and that severer injury might occur in certain areas of the tissue than in other areas due to the presence of air pockets, another test was made some weeks later. One resistance thermometer was placed in a graduated cylinder of 100 cubic centimeters capacity; a second was placed in water in a large test tube $1 \frac{1}{2}$ by 5 inches in size; and a third was exposed to the air in the chamber. Pieces of apple root were placed in large test tubes with and without water. While a large quantity of salt and ice was being used, the readings given in table 10 were recorded. It is evident from this table that low temperature can be temporarily excluded by appropriate quantities of water. After a certain period of time, however, such protection becomes ineffective. The length of time of such insulation seems to vary with the volume of water used.

On examining another large test tube taken from the freezing chamber, in which were placed three medium-sized apple roots, it was noticed that some of the water in the tube was unfrozen. It seems significant also that when the roots were examined two days later, not a cell appeared to be injured, while the cambium, the phloëm, and the cortex tissues of three similar roots placed in the air were entirely dead. The water in the graduated cylinder in which a thermometer was placed was completely frozen.

From these facts the effect of the water seems to be due to the unfrozen water. When the entire mass becomes ice, it readily conducts the heat out of the interior. 
TABle 10. Influence of Air and Water in Lowering the Temperature Around Resistance Thermometers

(August 4, 1917)

\begin{tabular}{|c|c|c|c|}
\hline \multirow{2}{*}{ Hour } & \multicolumn{3}{|c|}{ Temperature (centigrade) } \\
\hline & $\begin{array}{l}\text { Thermom- } \\
\text { eter in } \\
\text { graduated } \\
\text { cylinder }\end{array}$ & $\begin{array}{l}\text { Thermom- } \\
\text { eter in } \\
\text { large } \\
\text { test tube }\end{array}$ & $\begin{array}{l}\text { Thermom- } \\
\text { eter in } \\
\text { air }\end{array}$ \\
\hline 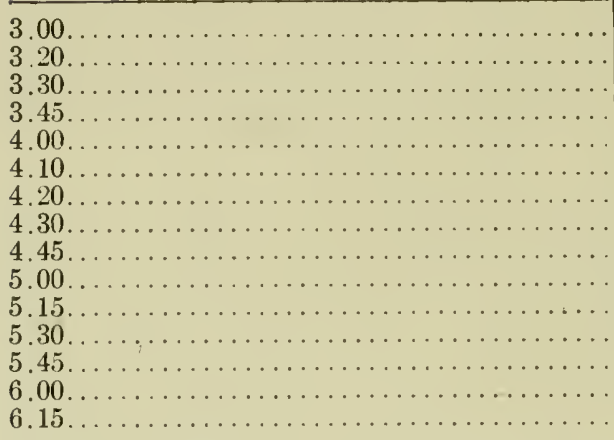 & $\begin{array}{l}11^{\circ} \\
4.5^{\circ} \\
0^{\circ} \\
0^{\circ} \\
0^{\circ} \\
-0.5^{\circ} \\
-0.5^{\circ} \\
-0.5^{\circ} \\
-0.5^{\circ} \\
-0.5^{\circ} \\
-1^{\circ} \\
-2^{\circ} \\
-7^{\circ} \\
-11.5^{\circ} \\
-12^{\circ}\end{array}$ & $\begin{array}{l}13^{\circ} \\
6^{\circ} \\
4.5^{\circ} \\
1^{\circ} \\
0^{\circ} \\
-0.5^{\circ} \\
-0.5^{\circ} \\
-0.5^{\circ} \\
-0.5^{\circ} \\
-0.5^{\circ} \\
-0.5^{\circ} \\
-0.5^{\circ} \\
-1^{\circ} \\
-3^{\circ} \\
-8^{\circ}\end{array}$ & $\begin{aligned} & 15^{\circ} \\
& 8^{\circ} \\
& 6.5^{\circ} \\
& 3^{\circ} \\
&-0.5^{\circ} \\
&-5.5^{\circ} \\
&-9.5^{\circ} \\
&-10.5^{\circ} \\
&-11^{\circ} \\
&-11.5^{\circ} \\
&-11.5^{\circ} \\
&-12^{\circ} \\
&-12^{\circ} \\
&-12^{\circ} \\
&-12^{\circ}\end{aligned}$ \\
\hline
\end{tabular}

A rather extensive series of seventy-one tests was conducted, to determine whether water or paraffin might be possible factors in influencing the amount of injury. The method and results of these tests were as follows:

Apple roots were placed in ordinary test tubes, which were sealed and in their turn put into larger test tubes, and the surrounding space was filled with water, paraffin, or air. Other apple roots were completely coated with melted paraffin and frozen in the usual way, while still others were immersed and frozen in test tubes containing water. All the lots were given an exposure of from $-9^{\circ}$ to $-12^{\circ} \mathrm{C}$.

In most cases in which water surrounded the tissue but was not in direct contact with it, some protection from freezing was afforded as compared with material lacking such treatment. As previously noted, the amount of protection seemed directly proportional to the volume of water used. In the case in which the roots were immediately surrounded by water, the protective influence was less pronounced. This may have been due 
in part to an increased moisture content of the tissue brought about by several hours of exposure in the water.

Among the roots used in these tests, thirty-six were covered with paraffin and were tested at different temperatures. Of these roots, twenty-five suffered considerably more injury in the three outer tissues than did the corresponding checks, eight seemed to be injured somewhat less than the normal, and three showed injury similar to that in the untreated roots. The removal of the paraffin immediately after the exposure seemed inconsequential.

The cause for this behavior is not readily apparent, unless, perhaps, it may be associated with the phenomenon of supercooling. According to this hypothesis, the coating of paraffin might have functioned to delay ice formation in the tissue by preventing normal inoculation from the surface crystals, thus prolonging the supercooling period. The surrounding air temperature constantly being lowered, more serious damage might have resulted from rapid freezing once ice crystallization began.

\section{INFLUENCE OF THE SCION ON THE HARDINESS OF ONE-YEAR ROOTS OF THE STOCK}

In February, 1916, 640 piece-root apple grafts were made, the varieties Tompkins King, Baldwin, Oldenburg, and McIntosh being used as scion wood. These varieties were selected for the scions because of the wellknown difference in the hardiness of their twigs. The stocks were taken from long-rooted American seedlings. Each stock was cut into four equal parts, from three to four inches in length. Since the lower pieces of a seedling are smaller than the crown cut, each variety was grafted on each of the four cuts, in order to exclude any variation from this source. This gave sixteen possibilities, each represented by forty plants. The column in table 11 headed "Section of stock" indicates the cut of the stock used; for example, section 1 is the crown cut, section 2 is the first cut below the crown, and so on.

This material was planted out rather early and was given average care thru the summer. The roots were dug after the leaves had fallen, and were placed in common storage until tested. Only the roots that had developed in 1916 from the parent stock were used. They were rather abundant at the lower callus, and were generally from two to three millimeters in diameter. Other roots of the American and French apples were tested from time to time for comparison. 
TABLE 11. Influence of the Scion on the Hardiness of One-Year Roots of the Stock

\begin{tabular}{|c|c|c|c|c|c|c|c|c|c|}
\hline \multirow{2}{*}{$\begin{array}{c}\text { Temper- } \\
\text { ature } \\
\text { (centi- } \\
\text { grade) }\end{array}$} & \multirow{2}{*}{$\begin{array}{l}\text { Date of } \\
\text { freezing }\end{array}$} & \multirow{2}{*}{ Variety } & \multirow{2}{*}{$\begin{array}{c}\text { Section } \\
\text { of } \\
\text { stock }\end{array}$} & \multirow{2}{*}{$\begin{array}{l}\text { Diam- } \\
\text { eter } \\
\text { of roots } \\
\text { (milli- } \\
\text { meters) }\end{array}$} & \multirow{2}{*}{$\begin{array}{l}\text { Num- } \\
\text { ber of } \\
\text { roots }\end{array}$} & \multirow{2}{*}{$\begin{array}{l}\text { Num= } \\
\text { ber of } \\
\text { roots } \\
\text { unin= } \\
\text { jured }\end{array}$} & \multicolumn{3}{|c|}{$\begin{array}{l}\text { Per cent of cells killed } \\
\text { in injured roots }\end{array}$} \\
\hline & & & & & & & $\begin{array}{l}\text { Cam- } \\
\text { bium }\end{array}$ & Phloëm & Cortex \\
\hline \multirow[t]{6}{*}{$-10^{\circ}$} & \multirow[t]{6}{*}{$\begin{array}{l}\text { February } \\
21 \text { to } 24\end{array}$} & McIntosh & $\begin{array}{l}1 \\
4\end{array}$ & $\begin{array}{l}3 \times 3 \\
3 \times 2\end{array}$ & $\begin{array}{l}5 \\
5\end{array}$ & $\begin{array}{l}\mathbf{5} \\
\mathbf{5}\end{array}$ & 15 & & $\cdots \cdots$ \\
\hline & & Oldenburg & $\begin{array}{l}3 \\
4 \\
4\end{array}$ & $\begin{array}{l}3 \times 2 \\
4 \times 3 \\
3 \times 2\end{array}$ & $\begin{array}{l}5 \\
5 \\
8\end{array}$ & $\begin{array}{l}4 \\
5 \\
8\end{array}$ & & & \\
\hline & & Baldwin & $\begin{array}{l}1 \\
4\end{array}$ & $\begin{array}{l}3 \times 3 \\
3 \times 3\end{array}$ & $\begin{array}{l}5 \\
5\end{array}$ & $\begin{array}{l}5 \\
5\end{array}$ & & & \\
\hline & & $\begin{array}{c}\text { Tompkins } \\
\text { King }\end{array}$ & $\begin{array}{l}4 \\
1\end{array}$ & $\begin{array}{l}3 \times 3 \\
3 \times 2\end{array}$ & $\begin{array}{l}8 \\
5\end{array}$ & $\begin{array}{l}7 \\
5\end{array}$ & $\begin{array}{r}50 \\
\ldots \ldots\end{array}$ & $\begin{array}{r}50 \\
\ldots \ldots\end{array}$ & \\
\hline & & American & . & $\begin{array}{l}3 \times 3 \\
3 \times 2\end{array}$ & $\begin{array}{l}4 \\
3\end{array}$ & $\begin{array}{l}4 \\
2\end{array}$ & & 15 & 15 \\
\hline & & French & .. & $3 \times 2$ & 4 & 4 & & $\ldots \ldots$ & $\ldots \ldots$ \\
\hline \multirow[t]{9}{*}{$-11^{\circ}$} & \multirow[t]{3}{*}{$\begin{array}{c}\text { February } \\
17\end{array}$} & McIntosh & $\begin{array}{l}2 \\
3 \\
3\end{array}$ & $\begin{array}{l}4 \times 3 \\
4 \times 3 \\
3 \times 2\end{array}$ & $\begin{array}{l}5 \\
5 \\
4\end{array}$ & $\begin{array}{l}5 \\
5 \\
4\end{array}$ & & & \\
\hline & & Oldenburg & $\begin{array}{l}2 \\
3\end{array}$ & $\begin{array}{l}4 \times 3 \\
3 \times 2\end{array}$ & $\begin{array}{r}5 \\
10\end{array}$ & $\begin{array}{r}5 \\
10\end{array}$ & & & \\
\hline & & Baldwin & $\begin{array}{l}2 \\
3 \\
3\end{array}$ & $\begin{array}{l}4 \times 3 \\
4 \times 3 \\
3 \times 2\end{array}$ & $\begin{array}{r}6 \\
3 \\
12\end{array}$ & $\begin{array}{r}4 \\
3 \\
11\end{array}$ & $\begin{array}{l}15 \\
15\end{array}$ & $\begin{array}{r}\quad \\
\ldots \ldots \\
\cdots\end{array}$ & $\begin{array}{r}15 \\
\cdots \\
15\end{array}$ \\
\hline & \multirow{6}{*}{$\begin{array}{l}\text { February } \\
\quad 21\end{array}$} & McIntosh & 2 & $3 \times 2$ & 13 & 10 & 25 & & \\
\hline & & Oldenburg & $\begin{array}{l}1 \\
2\end{array}$ & $\begin{array}{l}3 \times 2 \\
3 \times 2\end{array}$ & $\begin{array}{l}7 \\
8\end{array}$ & $\begin{array}{l}5 \\
4\end{array}$ & $\begin{array}{l}25 \\
30\end{array}$ & & \\
\hline & & Baldwin & $\begin{array}{l}1 \\
2\end{array}$ & $\begin{array}{l}3 \times 2 \\
3 \times 2\end{array}$ & $\begin{array}{r}13 \\
8\end{array}$ & $\begin{array}{r}13 \\
5\end{array}$ & $\ddot{2} \dot{5}$ & & \\
\hline & & $\begin{array}{c}\text { Tompkins } \\
\text { King }\end{array}$ & $\begin{array}{l}1 \\
2\end{array}$ & $\begin{array}{l}3 \times 2 \\
3 \times 2\end{array}$ & $\begin{array}{r}8 \\
10\end{array}$ & $\begin{array}{r}6 \\
\cdots\end{array}$ & $\begin{array}{l}50 \\
15\end{array}$ & $\begin{array}{l}25 \\
15\end{array}$ & $\begin{array}{l}25 \\
15\end{array}$ \\
\hline & & American & $\ldots$ & $4 \times 3$ & 6 & 6 & & & \\
\hline & & French & & $3 \times 2$ & 4 & 4 & & & \\
\hline
\end{tabular}


TABLE 11 (continued)

\begin{tabular}{|c|c|c|c|c|c|c|c|c|c|}
\hline \multirow{2}{*}{$\begin{array}{l}\text { Temper- } \\
\text { ature } \\
\text { (centi- } \\
\text { grade) }\end{array}$} & \multirow{2}{*}{$\begin{array}{l}\text { Date of } \\
\text { freezing }\end{array}$} & \multirow{2}{*}{ Variety } & \multirow{2}{*}{$\begin{array}{l}\text { Section } \\
\text { of } \\
\text { stock }\end{array}$} & \multirow{2}{*}{$\begin{array}{l}\text { Diam- } \\
\text { eter } \\
\text { of reots } \\
\text { (milli- } \\
\text { meters) }\end{array}$} & \multirow{2}{*}{$\begin{array}{l}\text { Num- } \\
\text { ber of } \\
\text { roots }\end{array}$} & \multirow{2}{*}{$\begin{array}{l}\text { Num= } \\
\text { ber of } \\
\text { roots } \\
\text { unin= } \\
\text { jured }\end{array}$} & \multicolumn{3}{|c|}{$\begin{array}{l}\text { Per cent of cells killed } \\
\text { in injured roots }\end{array}$} \\
\hline & & & & & & & $\begin{array}{l}\text { Cam- } \\
\text { bium }\end{array}$ & Phloëm & Cortex \\
\hline \multirow{2}{*}{${ }_{(\text {conc. })}^{-11^{\circ}}$} & \multirow[t]{2}{*}{ March 3} & American & . & $3 \times 2$ & 6 & 4 & 20 & 20 & 20 \\
\hline & & French & & $3 \times 2$ & 6 & 4 & $=0$ & 20 & 20 \\
\hline \multirow[t]{6}{*}{$-11.5^{\circ}$} & \multirow[t]{6}{*}{$\begin{array}{c}\text { February } \\
28\end{array}$} & McIntosh & $\begin{array}{l}1 \\
4 \\
\end{array}$ & $\begin{array}{l}3 \times 2 \\
3 \times 2 \\
\end{array}$ & $\begin{array}{l}5 \\
6\end{array}$ & $\begin{array}{l}5 \\
6\end{array}$ & & & \\
\hline & & Oldenburg & 3 & $3 \times 2$ & 5 & $\ldots \ldots$ & 50 & 50 & 50 \\
\hline & & Baldwin & $\begin{array}{l}3 \\
1\end{array}$ & $\begin{array}{l}3 \times 2 \\
3 \times 2\end{array}$ & $\begin{array}{l}5 \\
3\end{array}$ & $\begin{array}{l}1 \\
3\end{array}$ & $\begin{array}{r}50 \\
\ldots \\
\end{array}$ & $\begin{array}{l}50 \\
\cdots \\
\end{array}$ & $\begin{array}{r}50 \\
\cdots \\
\end{array}$ \\
\hline & & $\begin{array}{c}\text { Tompkins } \\
\text { King }\end{array}$ & 2 & $3 \times 3$ & 5 & 2 & 40 & 40 & 40 \\
\hline & & American & 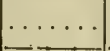 & $3 \times 2$ & 5 & 1 & 50 & 50 & 50 \\
\hline & & French & . & $3 \times 2$ & 5 & $\ldots \ldots$ & 70 & 70 & 70 \\
\hline \multirow[t]{9}{*}{$-12^{\circ}$} & \multirow[t]{6}{*}{$\begin{array}{c}\text { February } \\
17\end{array}$} & McIntosh & $\begin{array}{l}1 \\
4\end{array}$ & $\begin{array}{l}3 \times 2 \\
3 \times 2\end{array}$ & $\begin{array}{l}5 \\
6\end{array}$ & & $\begin{array}{l}100 \\
100\end{array}$ & $\begin{array}{l}100 \\
100\end{array}$ & $\begin{array}{r}100 \\
90\end{array}$ \\
\hline & & Oldenburg & $\begin{array}{l}3 \\
4\end{array}$ & $\begin{array}{l}3 \times 2 \\
3 \times 2\end{array}$ & $\begin{array}{l}6 \\
7\end{array}$ & & $\begin{array}{l}60 \\
70\end{array}$ & $\begin{array}{l}60 \\
70\end{array}$ & $\begin{array}{l}60 \\
70\end{array}$ \\
\hline & & Baldwin & $\begin{array}{l}1 \\
4\end{array}$ & $\begin{array}{l}3 \times 2 \\
3 \times 2\end{array}$ & $\begin{array}{l}6 \\
6\end{array}$ & & $\begin{array}{l}70 \\
90\end{array}$ & $\begin{array}{l}70 \\
90\end{array}$ & $\begin{array}{l}70 \\
90\end{array}$ \\
\hline & & $\begin{array}{c}\text { Tompkins } \\
\text { King }\end{array}$ & $\begin{array}{l}1 \\
3\end{array}$ & $\begin{array}{l}3 \times 2 \\
3 \times 2\end{array}$ & $\begin{array}{l}5 \\
6\end{array}$ & & $\begin{array}{l}75 \\
60\end{array}$ & $\begin{array}{l}75 \\
60\end{array}$ & $\begin{array}{l}75 \\
60\end{array}$ \\
\hline & & American & & $\begin{array}{l}4 \times 3 \\
3 \times 2\end{array}$ & $\begin{array}{l}2 \\
5\end{array}$ & & $\begin{array}{l}75 \\
80\end{array}$ & $\begin{array}{l}75 \\
80\end{array}$ & $\begin{array}{l}75 \\
80\end{array}$ \\
\hline & & French & & $\begin{array}{l}4 \times 3 \\
3 \times 2\end{array}$ & $\frac{2}{5}$ & & $\begin{array}{r}90 \\
100\end{array}$ & $\begin{array}{r}90 \\
100\end{array}$ & $\begin{array}{r}90 \\
100 \\
\end{array}$ \\
\hline & \multirow{3}{*}{$\begin{array}{l}\text { February } \\
26\end{array}$} & McIntosh & $\begin{array}{l}2 \\
3\end{array}$ & $\begin{array}{l}4 \times 3 \\
4 \times 3\end{array}$ & $\begin{array}{l}5 \\
5\end{array}$ & & $\begin{array}{l}60 \\
80\end{array}$ & $\begin{array}{l}60 \\
80\end{array}$ & $\begin{array}{l}60 \\
80\end{array}$ \\
\hline & & Oldenburg & 2 & $4 \times 3$ & 6 & 3 & 20 & 20 & 20 \\
\hline & & Baldwin & $\begin{array}{l}2 \\
3\end{array}$ & $\begin{array}{l}4 \times 3 \\
4 \times 3\end{array}$ & $\begin{array}{l}5 \\
5\end{array}$ & $\cdots$ & $\begin{array}{r}100 \\
85\end{array}$ & $\begin{array}{r}100 \\
85\end{array}$ & $\begin{array}{r}100 \\
85 \\
\end{array}$ \\
\hline
\end{tabular}


TABLE 11 (concluded)

\begin{tabular}{|c|c|c|c|c|c|c|c|c|c|}
\hline \multirow{2}{*}{$\begin{array}{c}\text { Temper- } \\
\text { ature } \\
\text { (centi- } \\
\text { grade) }\end{array}$} & \multirow{2}{*}{$\begin{array}{l}\text { Date of } \\
\text { freezing }\end{array}$} & \multirow{2}{*}{ Variety } & \multirow{2}{*}{$\begin{array}{l}\text { Section } \\
\text { of } \\
\text { stock }\end{array}$} & \multirow{2}{*}{$\begin{array}{l}\text { Diam- } \\
\text { eter } \\
\text { of roots } \\
\text { (milli- } \\
\text { meters) }\end{array}$} & \multirow{2}{*}{$\begin{array}{l}\text { Num- } \\
\text { ber of } \\
\text { roots }\end{array}$} & \multirow{2}{*}{$\begin{array}{l}\text { Num= } \\
\text { ber of } \\
\text { roots } \\
\text { unin= } \\
\text { jured }\end{array}$} & \multicolumn{3}{|c|}{$\begin{array}{l}\text { Per cent of cells killed } \\
\text { in injured roots }\end{array}$} \\
\hline & & & & & & & $\begin{array}{l}\text { Cam- } \\
\text { bium }\end{array}$ & Phloëm & Cortex \\
\hline \multirow[t]{9}{*}{$\begin{array}{l}-12^{\circ} \\
(\text { conc. })\end{array}$} & \multirow{3}{*}{$\begin{array}{c}\text { February } \\
26 \\
\text { (concluded) }\end{array}$} & $\begin{array}{c}\text { Tompkins } \\
\text { King }\end{array}$ & $\begin{array}{l}2 \\
3\end{array}$ & $\begin{array}{l}4 \times 3 \\
4 \times 3\end{array}$ & $\begin{array}{l}5 \\
5\end{array}$ & & $\begin{array}{l}80 \\
45\end{array}$ & $\begin{array}{l}80 \\
45\end{array}$ & $\begin{array}{l}80 \\
45\end{array}$ \\
\hline & & American & . & $4 \times 3$ & 5 & $\ldots \ldots$ & 70 & 70 & 70 \\
\hline & & French & . . & $4 \times 3$ & 4 & & 100 & 100 & 100 \\
\hline & \multirow[t]{6}{*}{$\begin{array}{l}\text { March } \\
1 \text { to } 3\end{array}$} & MeIntosh & $\begin{array}{l}1 \\
2 \\
3\end{array}$ & $\begin{array}{l}3 \times 2 \\
3 \times 2 \\
3 \times 2\end{array}$ & $\begin{array}{r}5 \\
10 \\
5\end{array}$ & & $\begin{array}{r}100 \\
60 \\
100\end{array}$ & $\begin{array}{r}100 \\
60 \\
100\end{array}$ & $\begin{array}{r}100 \\
60 \\
100\end{array}$ \\
\hline & & Oldenburg & $\begin{array}{r}1-4 \\
2 \\
3\end{array}$ & $\begin{array}{l}3 \times 2 \\
3 \times 2 \\
3 \times 2\end{array}$ & $\begin{array}{r}12 \\
5 \\
7\end{array}$ & $\begin{array}{l}2 \\
\ldots . \cdots \\
1\end{array}$ & $\begin{array}{l}55 \\
80 \\
70\end{array}$ & $\begin{array}{l}55 \\
80 \\
70\end{array}$ & $\begin{array}{l}55 \\
80 \\
70\end{array}$ \\
\hline & & Baldwin & $\begin{array}{r}1 \\
3 \\
3-4\end{array}$ & $\begin{array}{l}3 \times 2 \\
3 \times 2 \\
3 \times 2\end{array}$ & $\begin{array}{r}5 \\
3 \\
11\end{array}$ & $\cdots \cdots$ & $\begin{array}{l}70 \\
85 \\
70\end{array}$ & $\begin{array}{l}70 \\
85 \\
70\end{array}$ & $\begin{array}{l}70 \\
85 \\
70\end{array}$ \\
\hline & & $\begin{array}{c}\text { Tompkins } \\
\text { King }\end{array}$ & $\begin{array}{r}1-3 \\
2 \\
3\end{array}$ & $\begin{array}{l}3 \times 2 \\
3 \times 2 \\
3 \times 2\end{array}$ & $\begin{array}{r}11 \\
6 \\
6\end{array}$ & & $\begin{array}{l}90 \\
90 \\
70\end{array}$ & $\begin{array}{l}90 \\
90 \\
70\end{array}$ & $\begin{array}{r}90 \\
90 \\
.70\end{array}$ \\
\hline & & American & $\ldots$ & $3 \times 2$ & 18 & & 70 & 70 & 70 \\
\hline & & French & . & $3 \times 2$ & 14 & $\ldots \ldots$ & 70 & 70 & 70 \\
\hline
\end{tabular}

The results shown in table 11 require but little comment. At a temperature of $-10^{\circ} \mathrm{C}$, as was expected, only a negligible amount of injury occurred in any roots. Likewise at $-11^{\circ}$ most of the root tissues escaped severe browning. An exposure to $-12^{\circ}$, however, resulted in serious injury in practically all the roots tested. The temperature of $-11.5^{\circ}$ suggests a point below which most of the roots are killed, and above which little or no injury takes place in any variety.

The above observations are limited in extent and might not apply to other conditions. However, an analysis of these particular data seems to indicate strongly, not only that the size of the section of root used for the stock has no influence on the freezing point of the new roots, but also 
that there are no constant nor considerable differences in hardiness of the roots developed from any of the four different varieties. It is shown further that there is no significant variation in the hardiness of the grafted and the seedling stock.

\section{EFFECT OF SUGAR SOLUTIONS, WATER, AND DRYING OUT, ON THE RESISTANCE OF APPLE ROOTS TO FREEZING}

Since a number of investigators have found that certain solutions have various influences on plant tissue with reference to freezing resistance, data were procured to ascertain whether or not similar effects could be observed in the roots. Before consideration of table 12, containing these data, it seems well to briefly mention some of the results reported regarding the influence of moisture content and the concentration of cell sap on the freezing to death of plant tissue.

It is well known that air-dried seeds can resist a very low temperature, but if allowed to absorb water they are frozen rather easily. MüllerThurgau (1880) found that succulent tissue has a higher freezing point than material with a lower moisture content. Shutt (1903), Selby (1908), Shaw (1911), and Beach and Allen (1915) seemed to find that apple twigs are tender in proportion to the higher moisture content. Mix (1916), on the contrary, reported that tissue from the trunk of apple trees soaked in distilled water for an hour and then frozen was not injured more than normal untreated material.

Bartetzko (1910) found that Aspergillus, Penicillium, and other fungi grown in nutrient solutions of varying concentration, increased their resistance to freezing in proportion to the increase in the osmotic strength of the solution. Ohlweiler (1912) observed that in species of Magnolia in which the cell structure of the leaves was essentially the same, the concentration of sap was an indication of the relative hardiness of the species. Chandler (1913:181) stated, in summarizing his experience in connection with the relation of sap concentration to hardiness, "In case of plants not in a resting condition, a large amount of dissolved material either' in the sap within the cell or in a solution surrounding the cell, will protect the cell from injury due to low temperature, to some extent at least." Chandler noted also that apple roots kept in water for eighteen hours were more severely injured than similar material dried in the air for the same period. 
Maximow (1914) studied at length the influence of several organic and mineral solutions on the protection of red cabbage and tradescantia cells from cold. He found marked protection from these compounds, except when the solution was of a toxic nature or when it precipitated its solutes at a temperature near the freezing point of the cell sap. Not all of the increased cold resistance, however, was explained by the differences in the depression of the freezing point of the sap.

In these observations (table 12) the concentration of the cane sugar solutions to which the apple roots were exposed varied from 0.1 gram to 3 grams molecular. The length of exposure ranged from twenty minutes to ninety-six hours. Similar treatment was given using tap water instead of a sugar solution. In no cases were the roots frozen in the solutions, as in Maximow's (1914) experiments, and the free surface moisture was always removed. The roots were allowed to dry out at storage or laboratory temperature for from fourteen to sixty-eight hours. In a few instances both the drying-out and the solution treatment were given the same root.

table 12. Effect of Various Previous Treatments on the Freezing to Death of American Apple Roots

\begin{tabular}{|c|c|c|c|c|c|c|c|c|}
\hline \multirow{2}{*}{$\begin{array}{c}\text { Temper- } \\
\text { ature } \\
\text { (centi- } \\
\text { grade) }\end{array}$} & \multirow{2}{*}{$\begin{array}{c}\text { Date } \\
\text { of } \\
\text { freezing }\end{array}$} & \multirow{2}{*}{ Previous treatment } & \multirow{2}{*}{$\begin{array}{c}\text { Average } \\
\text { diameter } \\
\text { of roots } \\
\text { (milli- } \\
\text { meters) }\end{array}$} & \multirow{2}{*}{$\begin{array}{l}\text { Num- } \\
\text { ber of } \\
\text { roots }\end{array}$} & \multirow{2}{*}{$\begin{array}{l}\text { Num- } \\
\text { ber of } \\
\text { roots } \\
\text { unin- } \\
\text { jured }\end{array}$} & \multicolumn{3}{|c|}{$\begin{array}{l}\text { Per cent of cells killed } \\
\text { in injured roots }\end{array}$} \\
\hline & & & & & & $\begin{array}{l}\text { Cam- } \\
\text { bium }\end{array}$ & Phloëm & Cortex \\
\hline \multirow[t]{4}{*}{$-8^{\circ}$} & \multirow[t]{4}{*}{ April 28} & \multirow{4}{*}{ 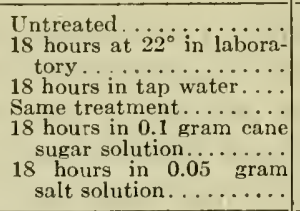 } & $7 \times 6$ & 4 & & 25 & 10 & 10 \\
\hline & & & $\begin{array}{l}7 \times 7 \\
8 \times 7 \\
6 \times 6\end{array}$ & $\begin{array}{l}7 \\
3 \\
2 \\
2\end{array}$ & $\begin{array}{c}{ }^{7} \\
\ldots \ldots \ldots \\
\ldots \ldots \ldots\end{array}$ & $\cdots \cdots \begin{array}{r}50 \\
70\end{array}$ & $\begin{array}{l}30 \\
4 \cdots\end{array}$ & \\
\hline & & & $7 \times 6$ & 7 & & 55 & 20 & \\
\hline & & & $8 \times 6$ & 3 & 1 & 15 & 10 & \\
\hline \multirow[t]{6}{*}{$-9^{\circ}$} & \multirow{6}{*}{$\underset{1 \text { to } 2}{\operatorname{May}}$} & \multirow{6}{*}{ 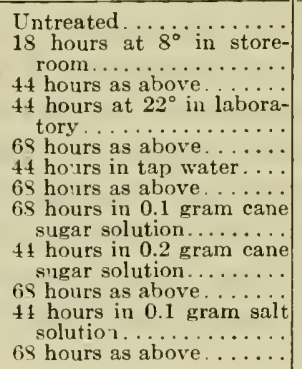 } & $7 \times 6$ & 16 & 5 & 60 & 20 & 15 \\
\hline & & & $\begin{array}{l}7 \times 7 \\
7 \times 6\end{array}$ & $\begin{array}{l}2 \\
4\end{array}$ & $\begin{array}{l}1 \\
3\end{array}$ & $\begin{array}{l}40 \\
10\end{array}$ & 10 & \\
\hline & & & $\begin{array}{l}8 \times 6 \\
6 \times 5 \\
7 \times 7 \\
7 \times 6\end{array}$ & $\begin{array}{r}\cdot 7 \\
6 \\
4 \\
4\end{array}$ & $\begin{array}{l}6 \\
5\end{array}$ & $\begin{array}{r}10 \\
65 \\
100 \\
100\end{array}$ & $\begin{array}{r}10 \\
65 \\
100 \\
100\end{array}$ & $\begin{array}{r}\cdots \\
65 \\
100 \\
100\end{array}$ \\
\hline & & & $7 \times 6$ & 4 & & 100 & 100 & 100 \\
\hline & & & $\begin{array}{l}8 \times 7 \\
7 \times 7\end{array}$ & $\begin{array}{l}4 \\
6\end{array}$ & & $\begin{array}{r}100 \\
80\end{array}$ & $\begin{array}{r}100 \\
70\end{array}$ & $\begin{array}{r}100 \\
60\end{array}$ \\
\hline & & & $\begin{array}{l}8 \times 7 \\
8 \times 7\end{array}$ & $\begin{array}{l}4 \\
4\end{array}$ & $\begin{array}{r}1 \\
\cdots \cdots \cdots\end{array}$ & $\begin{array}{r}70 \\
100\end{array}$ & $\begin{array}{l}35 \\
90\end{array}$ & $\begin{array}{r}5 \\
80\end{array}$ \\
\hline
\end{tabular}


TABLE 12 (concluded)

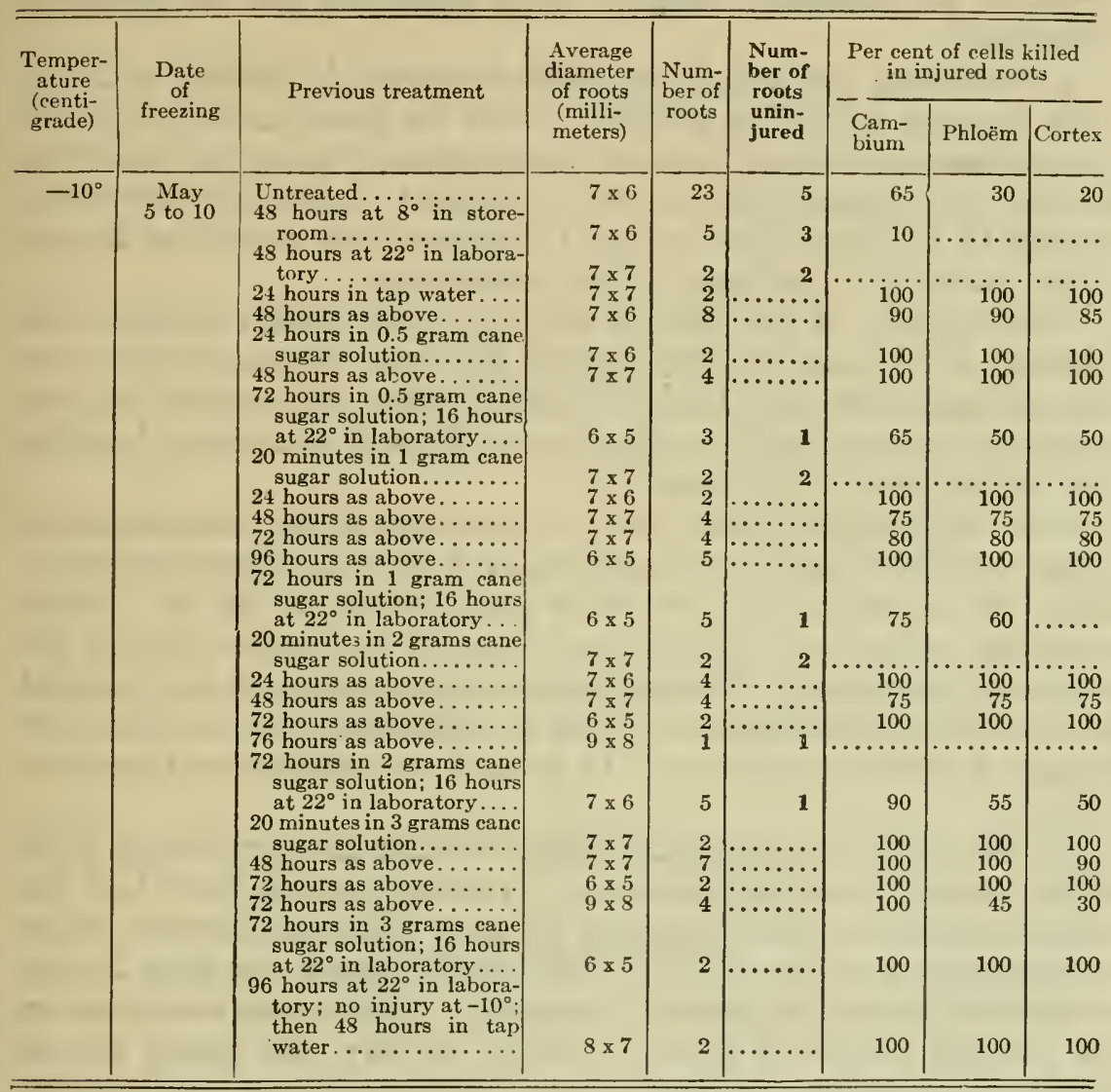

It is readily seen, in essentially all cases in table 12 , that the roots kept in cane sugar and salt solutions longer than twenty minutes were injured more than the untreated tissue and about the same as the roots placed in water. On the other hand, roots dried in the air at $8^{\circ}$ and $22^{\circ} \mathrm{C}$. exhibited less killing than the normal tissue. These conclusions seem true regardless of the freezing temperature used, the time exposure above eighteen hours, or the concentration of the solution employed. The few roots exposed for twenty minutes in sugar solution did not decrease in resistance. More 
examples are necessary, however, before these data can be considered dependable.

An interesting fact brought out in this connection is the effect of drying after exposure to a sugar solution. While the roots scarcely recovered normal hardiness in most instances, the percentage of injury was somewhat lessened except when small roots were employed. In the last case shown in table 12 , two roots exposed to $-10^{\circ} \mathrm{C}$. without injury were killed thruout after remaining in tap water for forty-eight hours.

Unfortunately, at the time of this study not enough material was available to determine the freezing-point depression of the sap of the roots kept in sugar solutions. If the sap concentration was increased by such treatment, another factor, or other factors, inhibited its action in lowering the freezing point of the tissue.

According to table 9 (page 643) the depression of the American-grown apple root would indicate a concentration of about 1.33 gram molecular. Since the concentration of the sugar solutions ran as high as 3 grams molecular, either plasmolysis or an increase in the concentration of cell sap would be expected. To determine this point, sections of roots exposed to the various concentrations used in the experiment just described were examined under the microsope. In all cases the cells appeared normally turgid.

The cause of the severer injury to cells of higher moisture content, while often observed, is also rather obscure. It seems, however, that if both the moist and the dry tissues possessed the same initial concentration, at an air temperature of $-9^{\circ}$ or $-10^{\circ} \mathrm{C}$. both should possess the same amount of water in the cells, regardless of the injury. Indeed, both have given up the identical amount of water at $-10^{\circ} \mathrm{C}$., the dry root having lost its water thru evaporation and ice formation, the moist root thru ice formation only. This reasoning suggests that the greater injury in the moist cells may be due to a larger ice mass formed in them. It suggests further that causes other than dehydration must account for the phenomenon of freezing to death of plant tissue.

\section{SUMMARY}

There is little difference in hardiness of the roots between American and French apple seedlings. Normal one-year roots are hardier than one-year stocks held one year in cold storage or grown in the field a second year. 


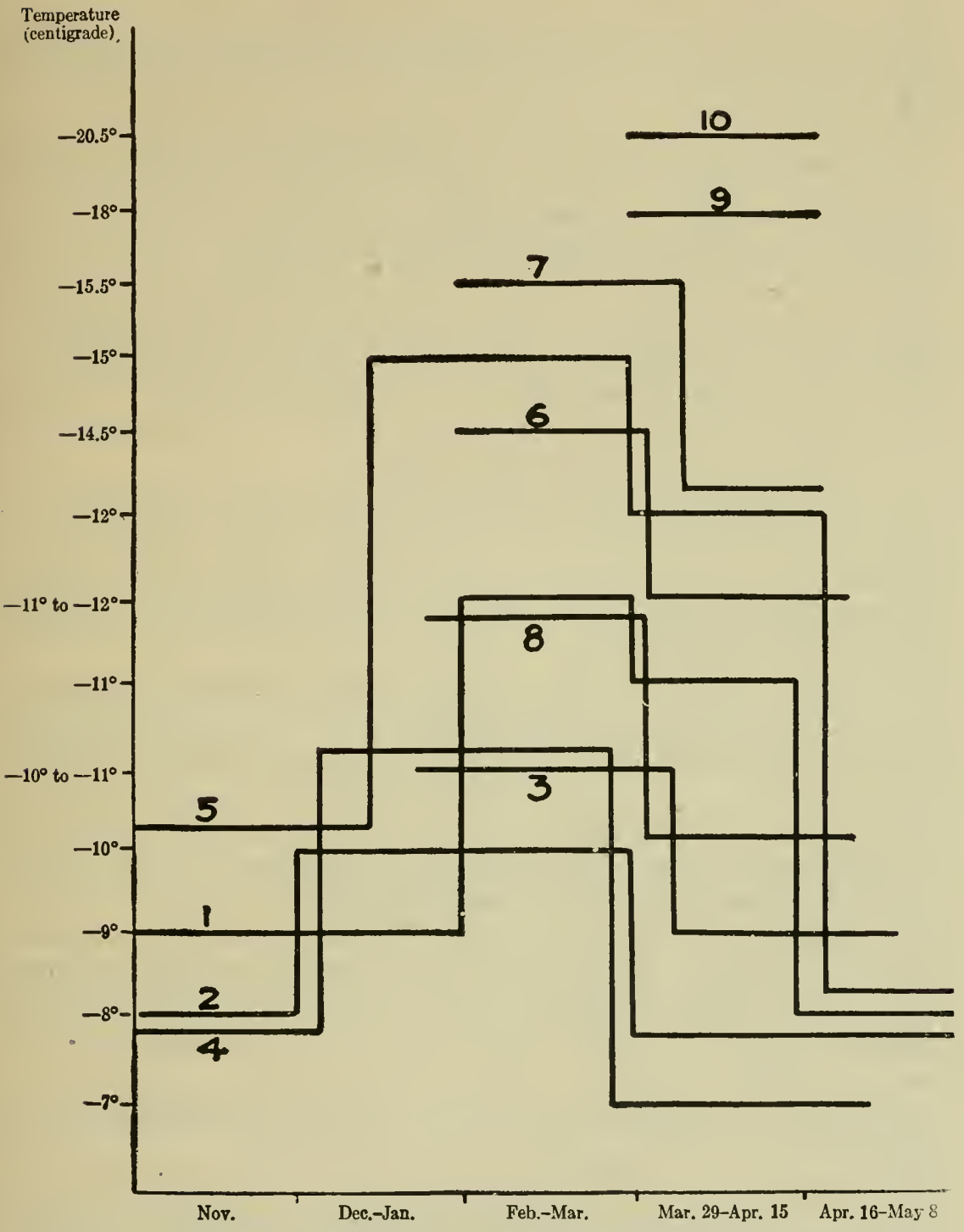

Fig. 164. SEASONAL hardiness of Fruit roots

1, Apple (French "crab"), and grape (Lindley, Norton, and Cynthiana). 2, Pear (French) and plum (Myrobalan). 3, Peach. 4, Cherry (Mazzard). 5, Cherry (Mahaleb). 6, Grape (Diamond). 7, Grape Clinton and Concord). 8, Raspberry, blackberry, and dewberry. 9, Currant. 10 Gooseberry 
The state of maturity and the diameter of the roots were the important factors in determining the resistance to freezing of all species tested in these experiments.

The French pear stock seems more tender than the Kieffer stock. Both roots are less resistant to freezing than is the apple.

Peach roots on which the variety Elberta had been budded proved less hardy than the apple and about equal to the Kieffer pear.

The order of hardiness of the four cherry stocks tested is as follows: Mahaleb, Prunus Besseyi, Prunus pennsylvanicum, Mazzard. The Mahaleb stock is considerably superior to the apple, while the Mazzard is about equal to the French pear.

Myrobalan plum roots are quite as easily killed by low temperature as are the French pear and the Mazzard cherry.

In the six varieties of grapes studied, the roots of the Clinton and the Concord are as hardy as the root of the Mahaleb cherry. The Diamond is slightly less hardy. The roots of the varieties Lindley, Norton, and Cynthiana are more resistant than the root of the Mazzard cherry but less resistant than the apple root.

No significant differences are seen between the hardiness of the blackberry root and that of the red raspberry root. The Lucretia dewberry, however, is slightly less tender than either, and is about equal to the apple stock.

Roots of the Downing gooseberry are more resistant to freezing than are Wilder currant roots. The roots of the gooseberry and the currant seem much hardier than any other roots examined.

The freezing-point depression of the Wilder currant sap is greater than that of the apple sap. Sap from the upper half of American-grown apple roots is of a higher concentration than that from the lower half of the same roots. The upper half of the root is also somewhat more resistant to cold.

A rapid fall in temperature is shown to increase the freezing injury in apple roots.

The placing of soils of different moisture content in the freezing chamber around the roots causes no appreciable difference in the amount of injury.

A majority of roots entirely covered with melted paraffin killed more severely than did similar untreated roots. 
Resistance of Roots of Fruit Species to Low Temperature 659

Water, when placed in the same test tube with the root tissue or when placed around it in another container, often provides protection against a low temperature, until all the water is frozen.

The hardiness of the scion does not seem to affect the resistance of the one-year roots of the apple stock.

Roots placed in sugar solutions varying in concentration from 0.1 gram to 3 grams molecular, are injured more easily than are normal roots. Roots allowed to absorb moisture for several hours are similarly injured.

In nearly all cases in which the material was allowed to dry, its resistance was increased.

The difference in the response to cold of the moist tissue and the dry tissue may be due to the smaller ice mass formed in the dry root. 


\section{LITERATURE CITED}

Bartetzko, Hugo. Untersuchungen über das Erfrieren von Schimmelpilzen. Jahrb. wiss. Bot. 47:57-98. 1910.

Beach, S. A., ANd Allen, F. W., Jr. Correlation of maturity and water content with hardiness. In Hardiness in the apple as correlated with structure and composition. Iowa Agr. Exp. Sta. Research bul. 21:181-189. 1915.

Chandler, W. H. The killing of plant tissue by low temperature. Univ. Missouri Agr. Exp. Sta. Research bul. 8:141-309. 1913.

CraIg, John. Observations and suggestions on the root-killing of fruit trees. Iowa Agr. Coll. Exp. Sta. Bul. 44:179-213. 1900.

Emerson, R. A. Experiments in orchard culture. Nebraska Agr. Exp. Sta. Bul. 79:1-33. 1903.

Cover-crops for young orchards. Nebraska Agr. Exp. Sta. Bul. 92:1-23. 1906.

Göppert, H. R. Über die Wärmeentwickelung in den Pflanzen; deren Gefrieren und die Schutzmittel gegen dasselbe, p. 1-273. 1830.

Hedrick, U. P. The grapes of New York, p. 1-564. 1908.

Macoun, W. T. Winter injury to fruit trees - ten different ways in which trees are affected. Canadian Exp. Farms. Rept. 1908:110116. 1908.

Maximow, N. A. Experimentelle und kritische Untersuchungen über das Gefrieren und Erfrieren der Pflanzen. Jahrb. wiss. Bot. $53: 327-420$. 1914 .

Mrx, A. J. Sun-scald of fruit trees: a type of winter injury. Cornell Univ. Agr. Exp. Sta. Bul. 382:233-284. 1916.

Molisch, Hans. Untersuchungen über das Erfrieren der Pflanzen, 1-73. 1897.

Müller-Thurgau, Hermann. Ueber das Gefrieren und Erfrieren der Pflanzen. I Theil. Landw. Jahrb. 9:133-189. 1880.

II Theil. Landw. Jahrb. 15:453-610. 1886.

Ohlweiler, William Woodward. The relation between the density of cell saps and the freezing points of leaves. Missouri Bot._Gard. Ann. rept. 23:101-131. 1912. 
PfEFfer, W. Freezing and cold-rigor. In The physiology of plants, vol. 2, p. 232-247. (English translation by Alfred J. Ewart.) 1903.

Russell, W. De la survie des tissues végétaux après le gel. Acad. Sci. [Paris]. Compt. rend. 158:508-510. 1914.

SAchs, Julıus. Krystallbildungen bei dem Gefrieren und Veränderung der Zellhäute bei dem Aufthauen saftiger Pflanzentheile. Kön. Sächs. Gesell. Wiss. Leipzig, Math-Phys. Cl. Ber. Verh. 12:1-50. 1860. .

SeLby, A. D. Fall and early winter injuries to orchard trees and shrubbery by freezing. Ohio Agr. Exp. Sta. Bul. 192:129-148. 1908.

SHAw, J. K. Climatic adaptations of apple varieties. Massachusetts (Amherst) Agr. Exp. Sta. Ann. rept. 23:177-245. (Reference on p. 181.) 1911.

Shutt, Frank T. On the relation of moisture-content to hardiness, in apple twigs. Roy. Soc. Canada. Proc. and Trans. 2d ser:9: sec 4:149-153. 1903.

WinkLer, Albert. Uber den Einfluss der Aussenbedingungen auf die Kälteresistenz ausdauernder Gewächse. Jährb. wiss. Bot. 52: 467-506. 1913.

\footnotetext{
Memoir 33, The Ribbed Pine-Borer, the third preceding number in this series of publications, was mailed on August 25, 1920.
} 

MeMolr 36

Plate IX
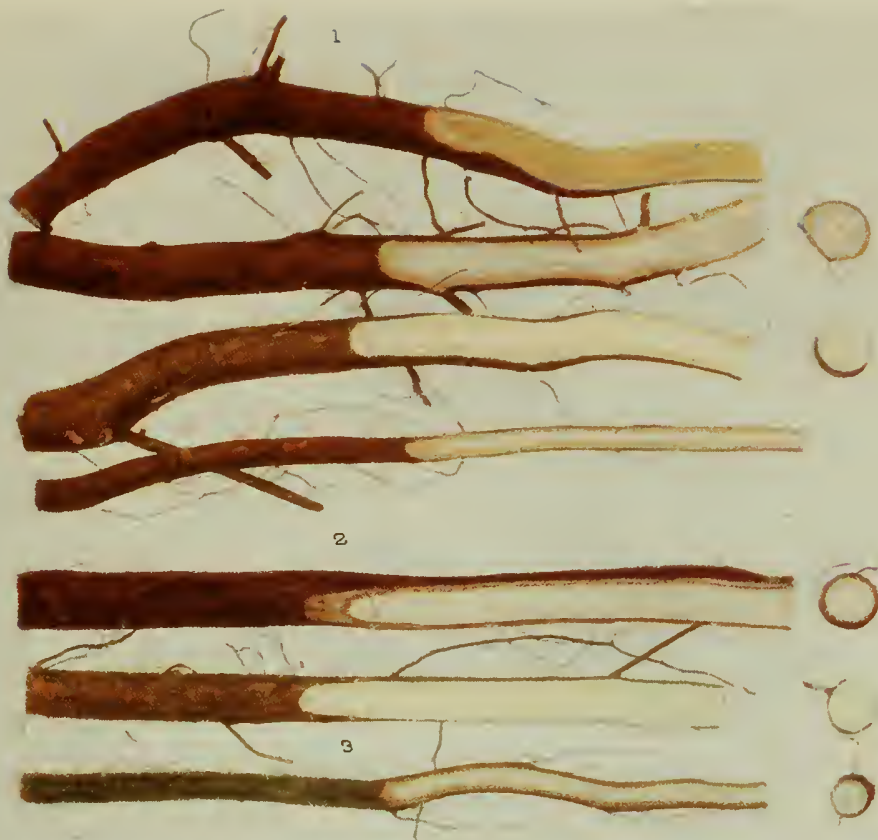

4
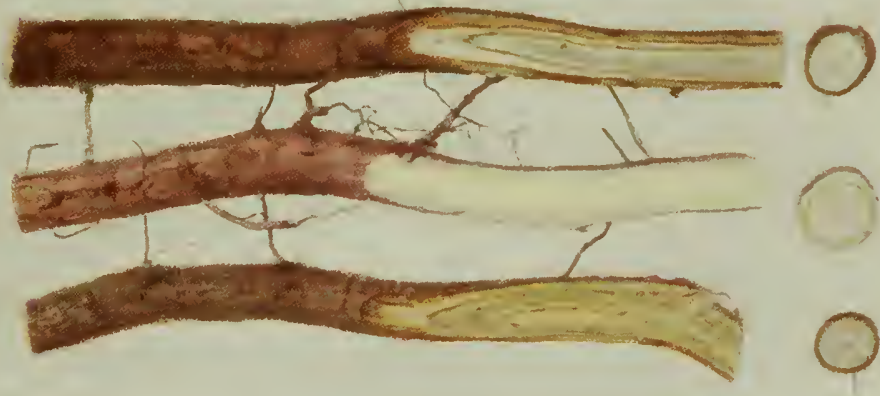

$\longrightarrow$

FREEZING INJURY IN ROOTS OF SOME FRUIT SPECIES

1, Apple. 2, European pear; 3, Kieffer pear. 4, Elberta peach 


$$
\begin{aligned}
& 3477-110 \\
& \text { Lot } 99
\end{aligned}
$$




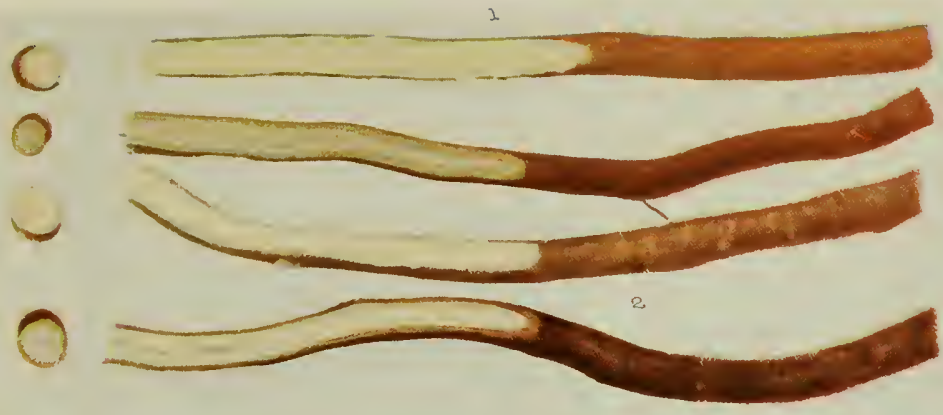

3
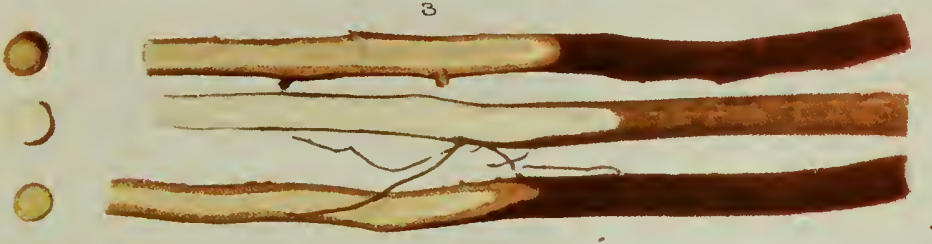

4
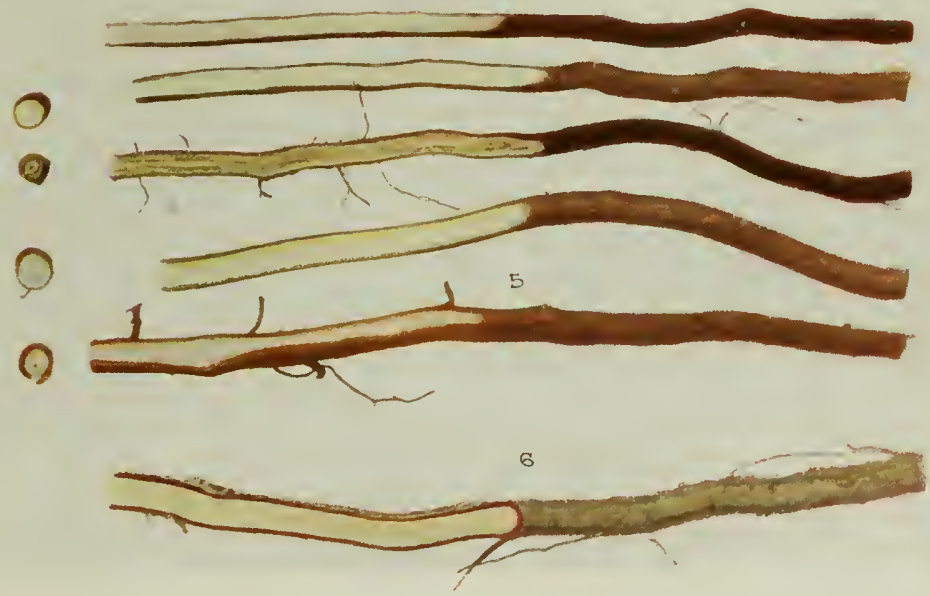

FREEZING INJURY IN ROOTS OF SOME FRUIT SPECIES

1, Morello cherry; 2, Mahaleb cherry. 3, Myrobalan plum. 4, Coneord grape. 5, Red raspberry. 6, Gooseberry, uninjured after fifteen hours exposure at $-22^{\circ} \mathrm{C}$.

$$
\text { 2z-ifis }
$$









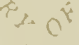

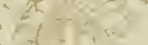 \\ $\therefore x^{2}=x^{\prime}=0^{r}$

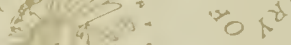

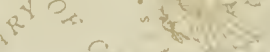 \\ 201 \\ $\mathrm{n}^{0} \bar{\gamma}_{\alpha}$ \\ $0^{\circ}$}

(1)

(Nin

(n)

$a^{2}$

4 -

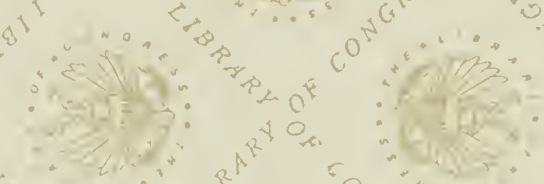

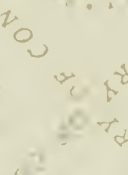

sis

(

$0_{0}$ 


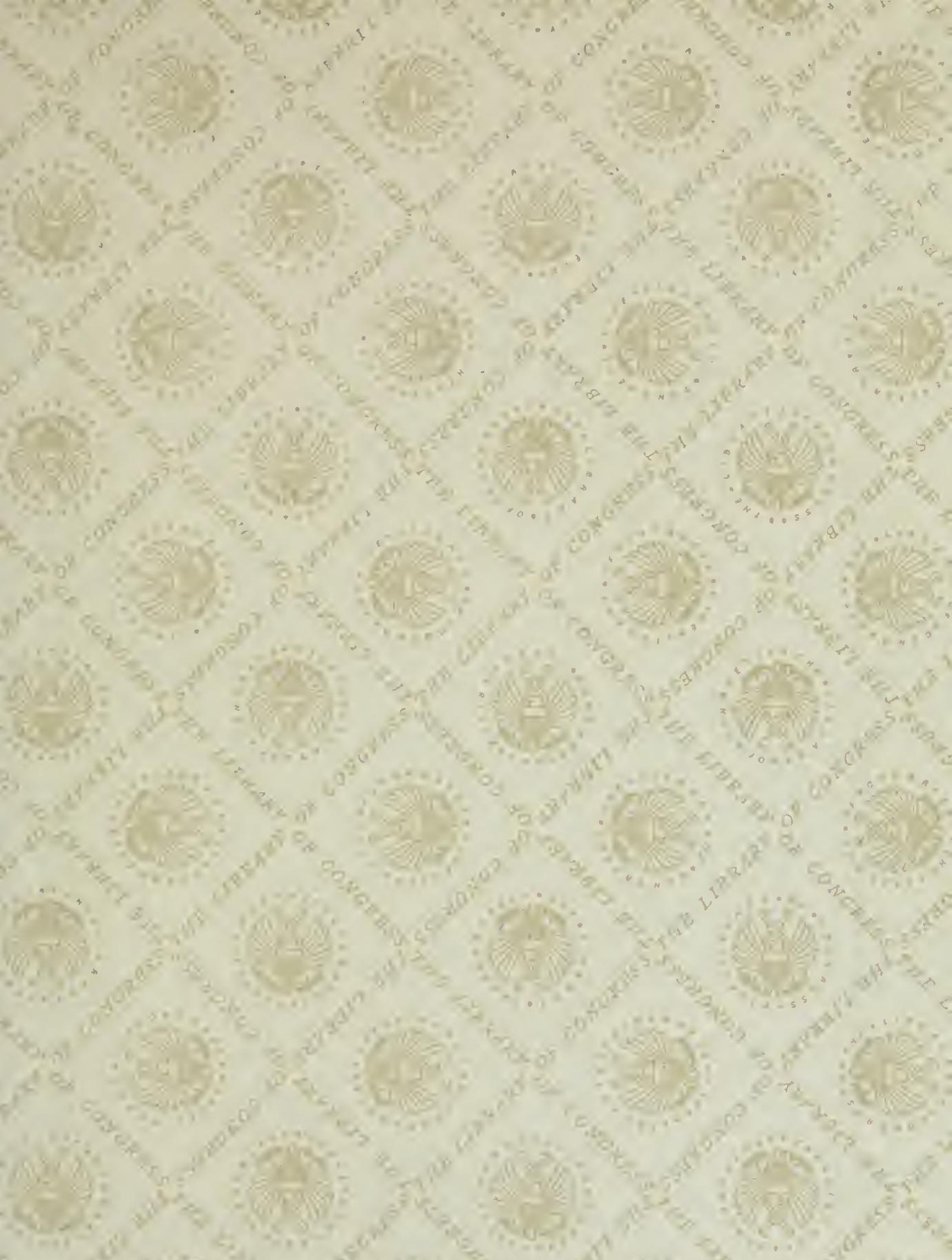

MAR 78

OUNO $\theta_{2}$

$M A$ 
